ROSÉLIA DOS SANTOS DAMASCENO

\title{
Envolvimento do núcleo Kölliker-Fuse e do núcleo parabraquial lateral no controle cardiorrespiratório promovido pela ativação dos quimiorreceptores centrais e periféricos
}

Tese apresentada ao Programa de Pós-Graduação em Fisiologia Humana do Instituto de Ciências Biomédicas da Universidade de São Paulo, para obtenção do Título de Doutor em Ciências. 


\section{Envolvimento do núcleo Kölliker-Fuse e do núcleo parabraquial lateral no controle cardiorrespiratório promovido pela ativação dos quimiorreceptores centrais e periféricos}

Tese apresentada ao Programa de Pós-Graduação em Fisiologia Humana do Instituto de Ciências Biomédicas da Universidade de São Paulo, para obtenção do Título de Doutor em Ciências.

Área de concentração: Fisiologia Humana

Orientador: Prof. Dr. Thiago dos Santos Moreira

Versão corrigida. A versão original eletrônica encontra-se disponível tanto na Biblioteca do ICB quanto na Biblioteca Digital de Teses e Dissertações da USP (BDTD). 


\section{DADOS DE CATALOGAÇÃO NA PUBLICAÇÃO (CIP) \\ Serviço de Biblioteca e Informação Biomédica do \\ Instituto de Ciências Biomédicas da Universidade de São Paulo \\ reprodução não autorizada pelo autor}

Damasceno, Rosélia dos Santos.

Envolvimento do núcleo parabraquial lateral no controle cardiorrespiratório promovido pela ativação dos quimiorreceptores centrais e periféricos / Rosélia dos Santos Damasceno. -- São Paulo, 2014.

Orientador: Prof. Dr. Thiago dos Santos Moreira.

Tese (Doutorado) - Universidade de São Paulo. Instituto de Ciências Biomédicas. Departamento de Fisiologia e Biofísica. Área de concentração: Fisiologia Humana. Linha de pesquisa: Controle neural cardiorrespiratório.

Versão do título para o inglês: Involvement of the Kölliker-Fuse nucleus and lateral parabrachial nucleus in cardiorespiratory control elicited by central and peripheral chemoreceptors activation.

1. Quimioreceptores 2. Cardiorrespiratório 3. Kölliker-Fuse 4. Núcleo parabraquial lateral I. Moreira, Prof. Dr. Thiago dos Santos II. Universidade de São Paulo. Instituto de Ciências Biomédicas. Programa de Pós-Graduação em Fisiologia Humana III. Título. 


\title{
UNIVERSIDADE DE SÃO PAULO \\ INSTITUTO DE CIÊNCIAS BIOMÉDICAS
}

\begin{abstract}
Candidato(a): $\quad$ Rosélia dos Santos Damasceno.
Título da Tese: $\quad$ Envolvimento do núcleo Kölliker-Fuse e do Núcleo Parabraquial Lateral no controle cardiorrespiratório promovido pela ativação dos quimiorreceptores centrais e periféricos.
\end{abstract}

Orientador(a): $\quad$ Prof. Dr. Thiago dos Santos Moreira.

A Comissão Julgadora dos trabalhos de Defesa da Tese de Doutorado, em sessão pública realizada a

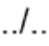
, considerou

( ) Aprovado(a) ( ) Reprovado(a)

\begin{tabular}{|c|c|}
\hline Examinador(a): & Assinatura: .............................. \\
\hline & Nome: ........................ \\
\hline & Instituição: ........ \\
\hline Examinador(a): & Assinatura: ........ \\
\hline & Nome: ................. \\
\hline & Instituição: ......... \\
\hline Examinador(a): & Assinatura: ......... \\
\hline & Nome: ........................ \\
\hline & Instituição: ............ \\
\hline Examinador(a): & Assinatura: ................ \\
\hline & 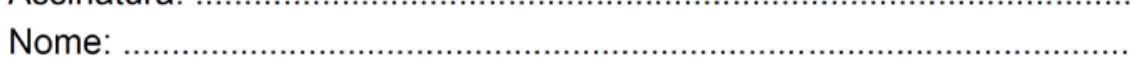 \\
\hline & 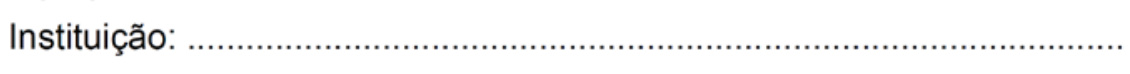 \\
\hline Presidente: & Assinatura: ........ \\
\hline & Nome: ................. \\
\hline & 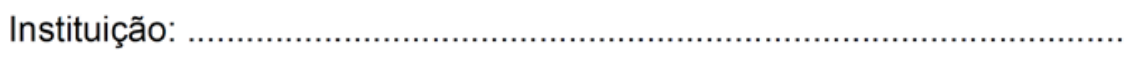 \\
\hline
\end{tabular}




\section{Certificado}

Certificamos que o protocolo registrado sob $\mathrm{n}^{\circ} \mathbf{1 0 0}$ nas fls. $\mathbf{9 1}$ do livro $\mathbf{0 2}$ para uso de animais em experimentação, sob a responsabilidade do Prof(a) $\operatorname{Dr}(a)$ Thiago dos Santos Moreira, Coordenador(a) da Linha de pesquisa Envolvimento do núcleo Kolliker-Fuse no controle cardiorrespiratório durante a ativação dos quimiorreceptores centrais e periféricos em animais não anestesiados do qual participam o(s) alunos Rosélia dos Santos Damasceno, está de acordo com os Princípios Éticos de Experimentação Animal adotado pela Sociedade Brasileira de Ciência de Animais de Laboratório (SBCAL) e foi aprovado pela COMISSÃO DE ÉTICA NO USO DE ANIMAIS (CEUA) em 01.10.2010, com validade de 3 anos.
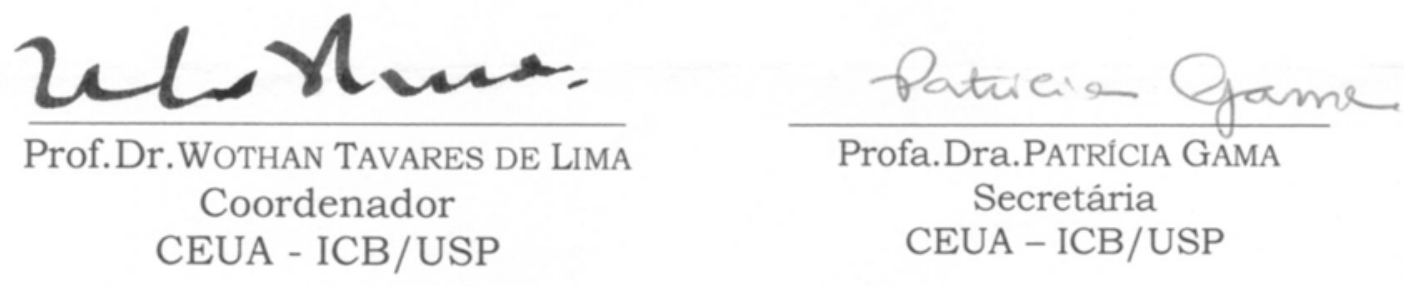
Of.CEUA. 079.13

São Paulo, 09 de outubro de 2013.

REF.: Protocolo n 100/10.

"Envolvimento do núcleo Kolliker-Fuse no controle cardiorrespiratório durante a aîvação dos quimiorreceptores centrais e periféricos em animais não anestesiados"

Prezado Professor,

Sua licença para uso de animais em experimentação, constante no protocolo em epígrafe, foi prorrogada até 01.10.2016.

Reitero que havendo alteração de metodologia e inserção de novos alunos ao projeto de pesquisa vinculado à referida licença a CEUA/ICB deverá ser informada.

Cordialmente,

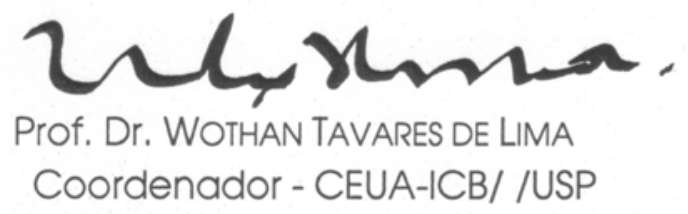

IImo. Sr.

Prof. Dr. Thiago dos Santos Moreira

Departamento de Fisiologia e Biofisica

instituto de Ciências Biomédicas - USP 
Este trabalho é dedicado aos meus amados pais, pela compreensão, apoio e incentivo constante. Eles são minha segurança, meu refúgio, minha paz.

Meu eterno obrigada! 


\section{AGRADECIMENTOS}

Uso este espaço para breves agradecimentos ao final deste doutorado. Primeiramente ao meu orientador Prof. Dr. Thiago Moreira, por ter me aceitado como aluna em seu laboratório, ter acreditado em minha vontade de aprender e encarar um novo desafio. Obrigada pelo apoio e incentivo nos momentos difíceis e compreensão das minhas fraquezas e erros. Deixo aqui todo meu respeito e minha admiração pela pessoa justa e profissional brilhante que é.

Agradeço a Profa. Dra. Ana Carolina Takakura, sempre disposta a dividir comigo seus conhecimentos. Obrigada pelo respeito e incentivo.

Agradeço a minha amada mãe, Terezinha e meu abençoado pai, Alan; que desde a minha infância recebi deles amor, carinho, compreensão, possibilidades de estudo e apoio incondicional me dando a liberdade de fazer escolhas e de ser responsável por minhas atitudes.

Agradeço aos colegas de laboratório que puderam sempre que possível dar apoio aos experimentos e estudos. Um agradecimento especial ao Leonardo, pela paciência em permanecer ao meu lado, enquanto aprendia estereotaxia. À Josiane e à Talita, por me ajudarem nos experimentos.

Agradeço a minha amiga Elida, pelas palavras de carinho e incentivo, e por dividir comigo sua casa durante muitos meses neste doutorado.

Agradeço aos professores por ajudarem na minha formação acadêmica. Agradeço ao Prof. Dr. Eugene Nattie e Profa. Dra. Aihua Li, por me aceitarem no laboratório e por dividir comigo sua experiência científica.

Gostaria também de agradecer a esta banca por sua apreciação e análise deste estudo.

Agradeço a FAPESP e a CAPES pelo apoio financeiro.

Agradeço ao privilégio de realizar experimentos com animais. Eles foram essenciais a este trabalho. A eles meu sincero obrigada e respeito.

Aprendi muito durante este doutorado. Sou grata a todos os amigos e pessoas que colaboraram para este projeto e meu crescimento profissional e pessoal. Agradeço também aquelas pessoas às quais foram difícil a convivência durante estes anos, porque de alguma forma me ensinaram a ter paciência e a me conhecer melhor.

Finalizo agradecendo a Deus, que me proporcionou força, esperança e paciência. Necessitei desta força Divina para encarar os meus erros, os meus acertos, as minhas verdades e as minhas ilusões, o meu poder e a minha impotência, a minha liberdade e os meus limites.

Meu sincero OBRIGADA! 
"Ao me levantar, gosto de saber que conquistei o direito de viver experiências que me enriqueceram espiritualmente e culturalmente com novos caminhos que se abrem e me induzem a seguir adiante, em busca do que ainda não conquistei nesse breve espaço de tempo." 


\section{RESUMO}

DAMASCENO, R. S. Envolvimento do núcleo Kölliker-Fuse e do núcleo parabraquial lateral no controle cardiorrespiratório promovido pela ativação dos quimiorreceptores centrais e periféricos. 2014. 88 f. Tese (Doutorado em Fisiologia Humana) - Instituto de Ciências Biomédicas, Universidade de São Paulo, São Paulo, 2014.

Os núcleos pontinos, particularmente a região Kölliker Fuse (KF) e o núcleo parabraquial lateral (NPBL) parecem possuir uma importante participação no controle cardiorrespiratório. No presente trabalho, avaliamos o envolvimento da região KF e NPBL nas respostas cardiorrespiratórias induzidas pela ativação dos quimiorreceptores centrais e periféricos. Ratos Wistar (280-300g, n=5-9) foram implantados com cânulas-guia de aço inoxidável bilateralmente na região do KF ou NPBL. A injeção bilateral de muscimol (100 e 200 pmol/100 nl) no KF reduziu a ventilação basal (1140 \pm 68 e $978 \pm 100$, vs. salina: $1436 \pm 155 \mathrm{ml} / \mathrm{kg} / \mathrm{min})$, sem alterar a PAM e a FC basal. A injeção bilateral de bicuculina (1 nmol/100 nl) no KF foi capaz de reverter a redução na ventilação (1418 \pm 138 , vs. muscimol: $978 \pm 100$ $\mathrm{ml} / \mathrm{kg} / \mathrm{min}$ ) promovidos pela injeção bilateral de muscimol (200 pmol/100 nl) no KF. A injeção bilateral de muscimol no KF foi capaz de reduzir hiperventilação $(1827 \pm 61$, vs. salina: $3179 \pm 325 \mathrm{ml} / \mathrm{kg} / \mathrm{min}$ ) e a taquicardia (380 \pm 9 , vs. salina: $423 \pm 12 \mathrm{bpm}$ ), sem alterar a hipotensão produzidos pela hipóxia $\left(8 \% \mathrm{O}_{2}-10 \mathrm{~min}\right)$ em ratos não anestesiados. Da mesma maneira, o bloqueio de receptores GABA-A foi capaz de reverter o efeito do muscimol na ventilação produzida por hipóxia em ratos não anestesiados. A mesma injeção de muscimol no KF foi capaz também de reduzir a hiperventilação (1488 \pm 277 , vs. salina: $3539 \pm 374 \mathrm{ml} / \mathrm{kg} / \mathrm{min})$ produzidos pela hipercapnia (7\% $\mathrm{CO}_{2}$ - $\left.10 \mathrm{~min}\right)$ em ratos não anestesiados. Da mesma maneira descrita acima, a injeção bilateral de bicuculina foi capaz de reverter o efeito do muscimol na ventilação produzida por hipercapnia em ratos não anestesiados. Quando a injeção de muscimol atingiu o NPBL não houve alteração na ventilação basal. Por outro lado, a injeção bilateral de muscimol no NPBL promoveu um aumento de PAM ( $\Delta=119 \pm 2$, vs. salina: $104 \pm 2 \mathrm{mmHg}$ ), mas sem alteração na FC basal. A injeção bilateral de muscimol no NPBL não foi capaz de alterar o aumento da atividade respiratória produzida por hipóxia e hipercapnia em ratos não anestesiados. A lesão seletiva dos neurônios KF/A7, promovida pela injeção bilateral de saporina anti-D $\beta H$ no grupamento $A 7$ promoveu uma redução da hiperventilação (1667 \pm 180 , vs. salina: $2209 \pm 358 \mathrm{ml} / \mathrm{kg} / \mathrm{min})$, sem alterar a taquicardia (471 \pm 18 , vs. salina: $509 \pm 12 \mathrm{bpm})$ produzida pela hipóxia $\left(8 \% \mathrm{O}_{2}-10 \mathrm{~min}\right)$ em ratos não anestesiados. A injeção bilateral de anti-D $\beta H$ na área $A 7$ foi capaz de atenuar a hipotensão produzida pela hipóxia (112 \pm 3 , vs. salina: $99 \pm 5 \mathrm{mmHg})$. A mesma injeção de anti-DßH na área $A 7$ foi também capaz de reduzir a hiperventilação (1513 \pm 167 , vs. salina: $2333 \pm 144 \mathrm{ml} / \mathrm{kg} / \mathrm{min})$ produzidos pela hipercapnia $\left(7 \% \mathrm{CO}_{2}-10\right.$ min) em ratos não anestesiados. Diante disso, nossos experimentos mostram a participação da região KF, e não do NPBL, no controle do padrão respiratório eupneico e durante a ativação do quimiorreflexo central e periférico.

Palavras-chave: Kölliker-Fuse. Núcleo parabraquial lateral. Quimiorreceptores. Cardiorrespiratório. 


\begin{abstract}
DAMASCENO, R. S. Involvement of the Kölliker-Fuse nucleus and lateral parabrachial nucleus in cardiorespiratory control elicited by central and peripheral chemoreceptors activation. 2014. 88 p. Ph. D thesis (Human Physiology) - Instituto de Ciências Biomédicas, Universidade de São Paulo, São Paulo, 2014.
\end{abstract}

The pontine nuclei, particularly the Kölliker-Fuse (KF) and the lateral parabrachial nucleus (LPBN) have been implicated in the maintenance of cardiorespiratory control. However, most of the experiments showing the role of pontine KF region were done in anesthetized animals. Here we investigated the involvement of KF region and $\mathrm{LPBN}$ in the cardiorespiratory responses elicited by chemoreceptor activation in conscious rats. Male Wistar rats $(280-300 \mathrm{~g}, \mathrm{n}=5-9)$ with bilateral stainless steel guide-cannulas implanted into the KF region or LPBN were used. In conscious rats, injections of muscimol (100 and $200 \mathrm{pmol} / 100 \mathrm{nl}$ ) into the KF decreased resting ventilation (1140 \pm 68 and $978 \pm 100$, vs. saline: $1436 \pm 155$ $\mathrm{ml} / \mathrm{kg} / \mathrm{min}$ ) without change mean arterial pressure (MAP) and heart rate (HR). Bilateral injection of the GABA-A antagonist bicuculline $(1 \mathrm{nmol} / 100 \mathrm{nl})$ into the KF blocked the inhibitory effect on ventilation (1418 \pm 138 , vs. muscimol: $978 \pm 100$ $\mathrm{ml} / \mathrm{kg} / \mathrm{min}$ ) elicited by muscimol within the KF. Muscimol injection into the KF reduced the increase in ventilation produced by hypoxia $\left(8 \% \mathrm{O}_{2}-10 \mathrm{~min}\right)(1827 \pm 61$, vs. saline: $3179 \pm 325 \mathrm{ml} / \mathrm{kg} / \mathrm{min})$ or hypercapnia $\left(7 \% \mathrm{CO}_{2}-10 \mathrm{~min}\right)(1488 \pm 277$, vs. saline: $3539 \pm 374 \mathrm{ml} / \mathrm{kg} / \mathrm{min}$ ) in unanesthetized rats. Bilateral injection of bicuculline into the KF was able to block the decrease in ventilation produced by muscimol into the KF during peripheral or central chemoreflex activation. Bilateral injection of muscimol into the LPBN did not change resting ventilation, or the increase in ventilation elicited by hypoxia or hypercapnia. The injection of muscimol into the LPBN increased resting MAP (119 \pm 2 , vs. saline: $104 \pm 2 \mathrm{mmHg})$, without change resting HR. Muscimol into the LPBN did not change the increase in ventilation elicited by hypoxia or hypercapnia in unanesthetized rats. Selective bilateral lesion with antidopamine- $\beta$-hydroxylase-saporin (anti-D $\beta H$-SAP) into the $A 7$ region promoted a reduction of hyperventilation (1667 \pm 180 , vs. saline: $2209 \pm 358 \mathrm{ml} / \mathrm{kg} / \mathrm{min}$ ), without changing the tachycardia ( $471 \pm 18$, vs. saline: $509 \pm 12 \mathrm{bpm}$ ) elicited by hypoxia $\left(8 \% \mathrm{O}_{2}-10 \mathrm{~min}\right)$ in unanesthetized rats. Bilateral injection of anti-D $\beta H$-SAP into the A7 region was able to attenuate the hypotension elicited by hypoxia (112 \pm 3 , vs. saline: $99 \pm 5 \mathrm{mmHg}$ ). Anti-D $3 \mathrm{H}-\mathrm{SAP}$ into the $A 7$ region was also able to reduce hyperventilation (1513 \pm 167 vs saline: $\pm 1442333 \mathrm{ml} / \mathrm{kg} / \mathrm{min}$ ) elicited by hypercapnia (7\% CO2 - $10 \mathrm{~min}$ ) in unanesthetized rats. The results of the present study suggest that KF region, but not LPBN, have mechanisms to control the ventilation in resting, hypoxic or hypercapnic conditions in conscious rats.

Keywords: Kölliker-Fuse (KF). Lateral parabrachial nucleus (LPBN). Chemoreceptors. Cardiorespiratory. 


\section{LISTA DE ILUSTRAÇÕES}

Figura 1 - Esquema de um corte sagital da região pontina e bulbar, resumindo a localização dos neurônios respiratórios e os neurotransmissores. ........................... 18

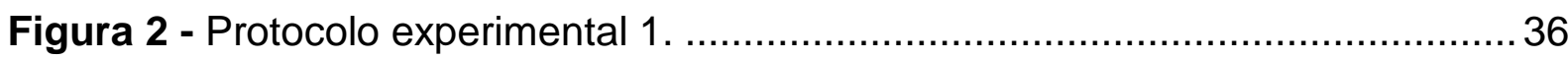

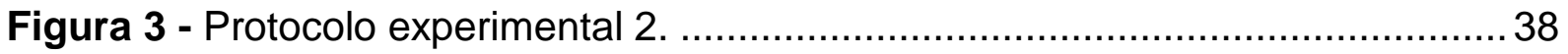

Figura 4 - Injeção bilateral na região do Kölliker-Fuse ...................................... 40

Figura 5 - Efeitos cardiorrespiratórios promovidos pela injeção bilateral de muscimol na região Kölliker-Fuse em animais que receberam injeção prévia de bicuculina. 42

Figura 6 - Efeitos cardiorrespiratórios produzidos pela estimulação dos quimiorreceptores periféricos em animais que receberam a injeção de bicuculina e muscimol na região do Kölliker-Fuse.......................................................... 44

Figura 7 - Efeitos cardiorrespiratórios produzidos pela estimulação dos quimiorreceptores centrais em animais que receberam a injeção de bicuculina e muscimol na região do Kölliker-Fuse. .46

Figura 8 - Identificação imunoistoquímica de neurônios noradren. .48

Figura 9 - Efeitos cardiorrespiratórios produzidos pela lesão do grupamento noradrenérgico A7 durante a hipóxia em animais não anestesiados. .50

Figura 10 - Efeitos cardiorrespiratórios produzidos pela lesão do grupamento noradrenérgico A7 durante a hipercapnia em animais não anestesiados .52

Figura 11 - Injeção bilateral na região do núcleo parabraquial lateral. .54

Figura 12 - Efeitos cardiorrespiratórios promovidos pela injeção bilateral de muscimol no núcleo parabraquial lateral 56

Figura 13 - Efeitos cardiorrespiratórios produzidos pela estimulação dos quimiorreceptores periféricos em animais que receberam a injeção de muscimol no núcleoparabraquial lateral. 58

Figura 14 - Efeitos cardiorrespiratórios produzidos pela estimulação dos quimiorreceptores centrais em animais que receberam a injeção de muscimol na região do núcleo parabraquial lateral

Figura 15 - Efeitos na pressão arterial, atividade simpática e respiratória produzidos pela estimulação dos quimiorreceptores periféricos em animais que receberam a injeção de muscimol na região do Kölliker-Fuse 
Figura 16 - Efeitos na pressão arterial, atividade simpática e respiratória produzidos pela estimulação dos quimiorreceptores centrais em animais que receberam a

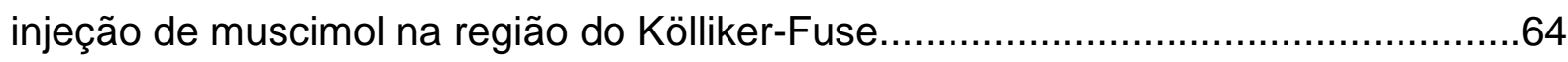
Figura 17 - Contribuição da região do Kölliker-Fuse no controle respiratório e

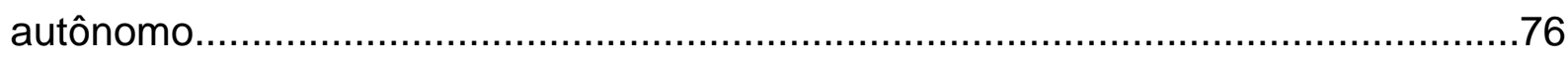




\section{LISTA DE ABREVIATURAS E SIGLAS}

\begin{tabular}{ll} 
Anti-DßH-SAP & Neurotoxina anti-dopamina $\beta$-hidroxilase \\
CVL & Região ventrolateral caudal do bulbo \\
fR & Frequência respiratória \\
i.p & Intraperitoneal \\
ITR & Região intertrigeminal \\
KCN & Cianeto de Potássio \\
KFIA7 & Grupamento noradrenérgico do Kölliker-Fuse \\
Mm & Milímetros \\
NTS & Núcleo do Trato Solitário \\
NPBL & Núcleo Parabraquial Lateral \\
PAP & Pressão arterial pulsátil \\
PAM & Pressão arterial média \\
Pao2 & Pressão parcial de oxigênio \\
Paco2 & Pressão parcial de dióxido de carbono \\
RTN/pFRG & Núcleo Retrotrapezóide/Grupamento Respiratório \\
RVL & Parafacial \\
Ve & Região ventrolateral rostral do bulbo \\
VT & Ventilação minuto \\
\hline
\end{tabular}




\section{SUMÁRIO}

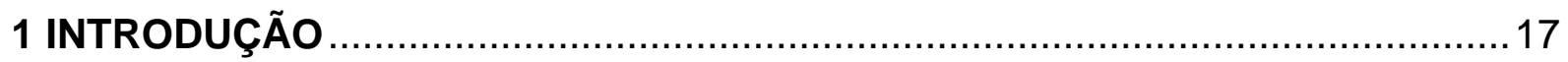

1.1 Mecanismos encefálicos de controle da respiração ...................................17

1.2 Núcleos pontinos envolvidos no controle respiratório e autônomo .............19

1.3 Participação de áreas pontinas na manutenção do padrão respiratório

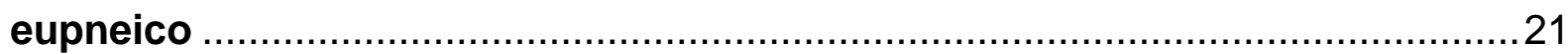

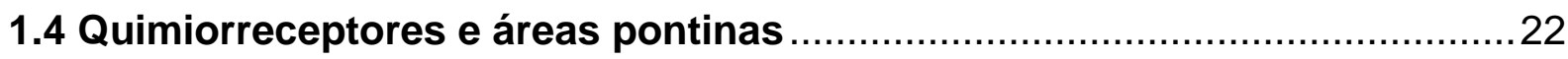

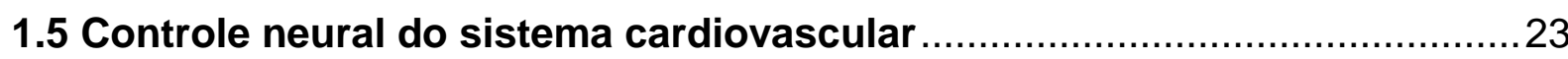

1.6 Participação de áreas pontinas na regulação cardiovascular .....................24

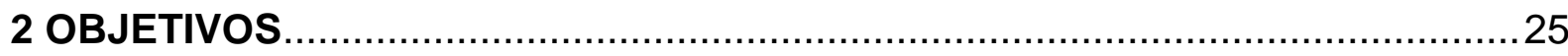

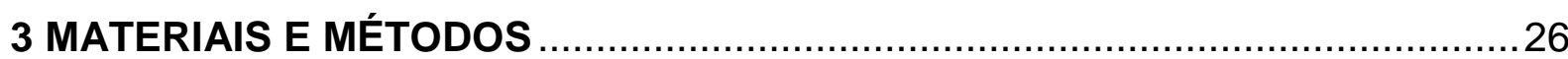

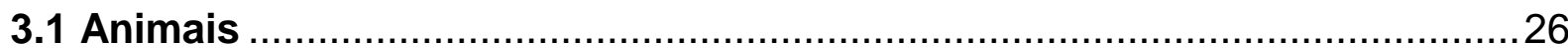

3.2 Experimentos realizados em animais não anestesiados .............................26

3.2.1 Implante de cânulas na ponte dorsolateral.................................................26

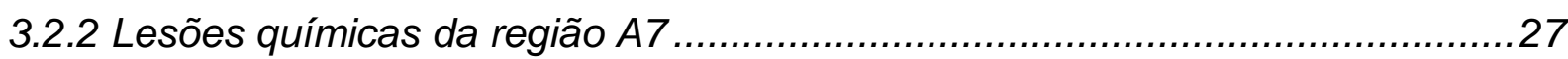

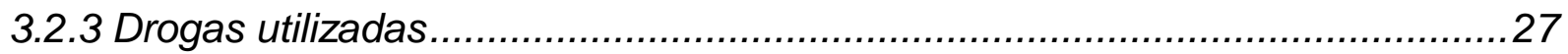

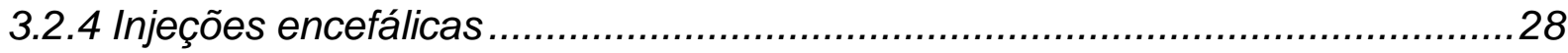

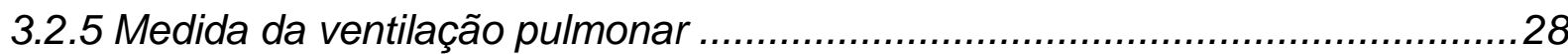

3.2.6 Registro da pressão arterial e da freqüência cardíaca.....................................29

3.2.7 Testes do quimiorreflexo central e periférico................................................... 30

3.3 Experimentos realizados em animais anestesiados ................................... 30

3.3.1 Procedimentos cirúrgicos em animais anestesiados....................................... 30

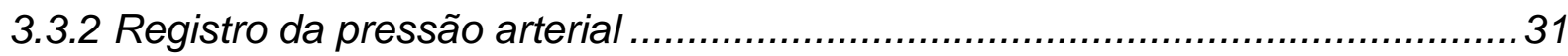

3.3.3 Medida da atividade elétrica do nervo frênico e do nervo esplâncnico .............31

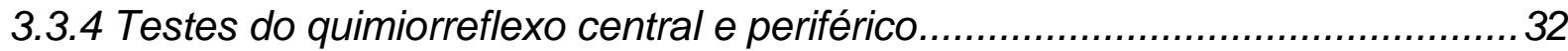

3.4 Histologia encefálica para confirmação dos pontos de injeção central ......32

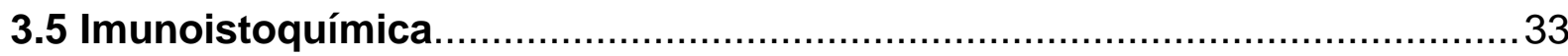

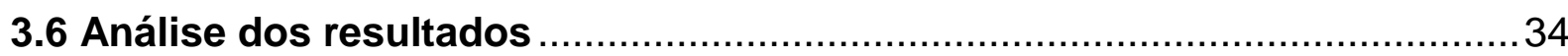

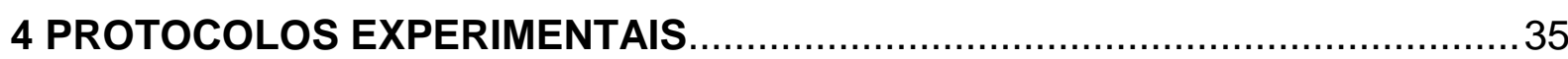

4.1 Efeitos cardiorrespiratórios produzidos pela inibição inespecífica da região Kölliker-Fuse ou do núcleo parabraquial lateral em animais não

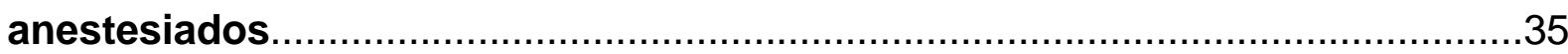


4.2 Efeitos cardiorrespiratórios produzidos pela estimulação dos quimiorreceptores centrais e periféricos após a inibição da região KöllikerFuse ou do núcleo parabraquial lateral. 35 4.3 Efeitos de injeções bilaterais de bicuculina combinada com injeções de muscimol na região Kölliker-Fuse sobre os parâmetros cardiorrespiratórios basais e produzidos pela estimulação dos quimiorreceptores centrais e periféricos em ratos não anestesiados 37

4.4 Efeitos cardiorrespiratórios produzidos pela inibição específica do grupamento noradrenérgico A7 em animais não anestesiados 38

4.5 Verificação da inibição da região do Kölliker-Fuse sobre os efeitos cardiorrespiratórios promovidos pela estimulação dos quimiorreceptores centrais ou periféricos

5 RESULTADOS 40

5.1 Análise histológica das injeções na área Kölliker-Fuse 40

5.2 Efeitos cardiorrespiratórios promovidos pela injeção bilateral de muscimol na região Kölliker-Fuse em animais que receberam injeção prévia de bicuculina.

5.3 Efeitos cardiorrespiratórios produzidos pela estimulação dos quimiorreceptores periféricos em animais que receberam a injeção de bicuculina e muscimol na região do Kölliker-Fuse ............................................4 43

5.4 Efeitos cardiorrespiratórios produzidos pela estimulação dos quimiorreceptores centrais em animais que receberam a injeção de bicuculina e muscimol na região do Kölliker-Fuse.

5.5 Lesão seletiva dos neurônios noradrenérgicos da região A7 com a toxina saporina anti-D $\beta H-S A P$

5.6 Efeitos cardiorrespiratórios produzidos pela lesão do grupamento noradrenérgico A7 durante a hipóxia em animais não anestesiados 49

5.7 Efeitos cardiorrespiratórios produzidos pela lesão do grupamento noradrenérgico A7 durante a hipercapnia em animais não anestesiados........51

5.8 Análise histológica das injeções no núcleo parabraquial lateral 53 5.8 Efeitos cardiorrespiratórios promovidos pela inibição do núcleo parabraquial lateral em animais não anestesiados. 55 
5.9 Efeitos cardiorrespiratórios produzidos pela estimulação dos quimiorreceptores periféricos após a inibição da região do núcleo parabraquial lateral.

5.10 Efeitos cardiorrespiratórios produzidos pela estimulação dos quimiorreceptores centrais após a inibição da região do núcleo parabraquial lateral 59

5.11 Respostas respiratórias e da atividade simpática à ativação do quimiorreflexo periférico após injeção bilateral de muscimol na região Kölliker-Fuse

5.12 Respostas respiratórias e da atividade simpática à ativação do quimiorreflexo central após injeção bilateral de muscimol na região KöllikerFuse 63

6 DISCUSSÃO 65

6.1 Envolvimento da região do Kölliker-Fuse na manutenção do padrão respiratório eupnéico 65

6.2 Participação da região do Kölliker-Fuse no quimiorreflexo central e periférico.

6.3 Participação da região do Kölliker-Fuse e do núcleo parabraquial lateral no controle cardiovascular

6.4 Participação da região do Kölliker-Fuse no controle da atividade simpática e no controle respiratório durante a ativação dos quimiorreceptores centrais e periféricos em animais anestesiados. 73

6.5 Possível interpretação da ativação do quimiorreflexo e a participação de estruturas pontinas .75

7 CONCLUSÃO 77

REFERÊNCIAS 78 


\section{INTRODUÇÃO}

\subsection{Mecanismos encefálicos de controle da respiração}

O sistema respiratório possui diversas funções, dentre as quais podemos destacar sua participação na manutenção da temperatura, na fonação e principalmente no processo de trocas gasosas na região dos alvéolos pulmonares, de forma a garantir o fornecimento adequado de oxigênio $\left(\mathrm{O}_{2}\right)$ para os tecidos assim como a remoção de dióxido de carbono $\left(\mathrm{CO}_{2}\right)$. De particular interesse, esta última função promove ainda a regulação do pH plasmático, mantendo-o dentro dos limites de normalidade fisiológica.

A musculatura respiratória trabalha de forma coordenada para assegurar as variações de pressão intrapleural e intra-alveolar, bem como um fluxo de ar adequado para os alvéolos pulmonares. Para tanto, o sistema nervoso central (SNC) participa ativamente no controle da musculatura respiratória, podendo exercer sua atividade de forma voluntária, por comandos gerados em áreas corticais superiores, ou involuntária, assim como a maioria dos comandos fundamentais para assegurar a sobrevivência ou integridade do indivíduo. Os comandos involuntários são gerados ou modulados por estruturas subcorticais, localizadas no diencéfalo e/ou no tronco encefálico (CEZARIO et al., 2008; GUYENET; STORNETTA; BAYLISS, 2010; SWANSON, 2000).

Mediante essa constelação de vias encefálicas ativadas a cada ciclo respiratório, é gerado um padrão respiratório classificado de "normal" ou eupneico. O padrão respiratório eupneico não é simplesmente uma oscilação entre a inspiração e expiração; ele é formado basicamente por 3 fases: inspiração, pós-inspiração (expiração passiva, estágio 1) e expiração ativa (estágio 2 da expiração) (RICHTER, 1982). O conhecimento desse padrão formado por 3 fases levou a uma série de estudos que se iniciaram em 1970 por Richter e colaboradores em gatos anestesiados utilizando registros intracelulares (RICHTER, 1982). Esses estudos demonstraram que, durante o processo respiratório, atividades fásicas são geradas na região ventral do bulbo sem a necessidade de uma retroalimentação periférica, envolvendo uma rede neuronal coordenada por interações sinápticas que foi chamada posteriormente de coluna respiratória ventral (SMITH et al., 1991). 
Figura 1 - Esquema de um corte sagital da região pontina e bulbar, resumindo a localização dos neurônios respiratórios e os neurotransmissores.

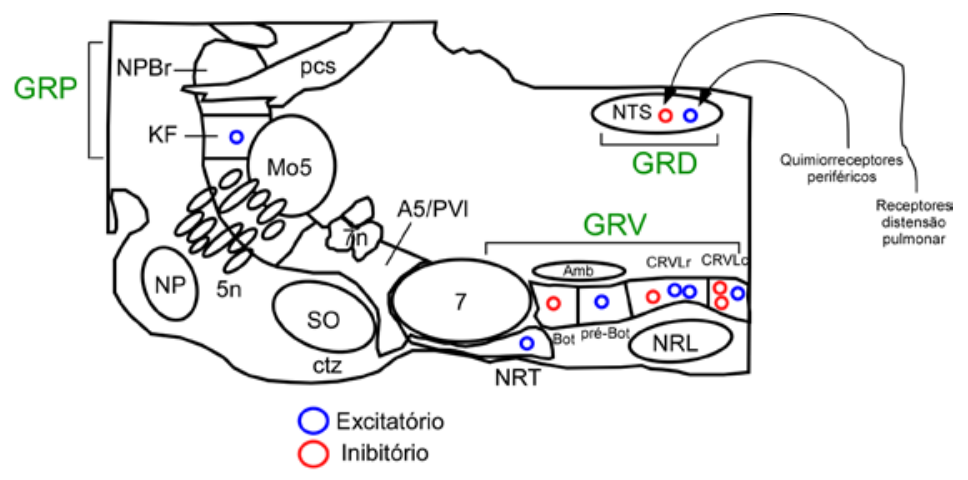

Abreviações: $5 n$, raiz motora do 5 par de nervos; 7 , núcleo motor do facial; $7 n$, nervo facial; A5/PV1, grupamento catecolaminérgico A5 da ponte ventrolateral; Amb, núcleo ambíguo; Bot; Complexo de Bötzinger; CRVLC; coluna respiratória ventrolateral caudal; CRVLr, coluna respiratória ventrolateral rostral; ctz, corpo trapezóide, KF, núcleo Kölliker Fuse; GRV, grupo respiratório ventral; MO5, núcleo motor do trigêmio; NP, núcleo pontino; NPBr, núcleo parabraquial; NTS, núcleo do trato solitário; NRL, núleo reticular lateral; NRT, núcleo retrotrapezóide; pcs, pedúnculo cerebelar superior, préBotC, complexo de pre-Bötzinger.

É possível formar um mapa funcional respiratório no sentido rostro-caudal da superfície ventral do bulbo, envolvendo todas as classes de diferentes neurônios respiratórios (MERRILL, 1981) (Fig. 1). Esse mapa funcional é composto pelas seguintes regiões:

1) Núcleo retrotrapezóide/grupamento respiratório parafacial (RTN/pFRG). O RTN possui neurônios sensíveis ao aumento da pressão parcial de $\mathrm{CO}_{2}\left(\mathrm{~Pa}_{\mathrm{CO} 2}\right)$ do líquido cefalorraquidiano e conseqüente redução do $\mathrm{pH}$; também recebem informações dos quimiorreceptores periféricos que detectam alterações de pressão parcial de $\mathrm{O}_{2}\left(\mathrm{PaO}_{2}\right)$ (GUYENET et al., 2005; MULKEY et al., 2004; TAKAKURA et al., 2006; WANG et al., 2013). Outros autores classificam o RTN como o grupamento parafacial. Esse grupamento foi descoberto em preparações de tronco encefálico de animais neonatos in vitro e possui neurônios classificados como pré-inspiratórios (ONIMARU; ARATA; HOMMA, 1988; ONIMARU; IKEDA; KAWAKAMI, 2012; ONIMARU; KUMAGAWA; HOMMA, 2006). Mais recentemente, a literatura tem mostrado que esses neurônios estariam envolvidos no controle da expiração ativa (FELDMAN; DEL NEGRO, 2006; FELDMAN; DEL NEGRO; GRAY, 2013).

2) Complexo Bötzinger, um grupamento que contém interneurônios inibitórios predominantemente expiratórios (EZURE, 1990; SCHREIHOFER; GUYENET, 1997). 
3) Complexo pré-Bötzinger, um grupamento de neurônios responsáveis pela geração do ritmo inspiratório (FELDMAN; DEL NEGRO, 2006; REKLING; FELDMAN, 1998; SMITH et al., 1991).

4) Grupamento respiratório ventrolateral rostral (GRVLr), um grupamento que possui neurônios pré-motores inspiratórios que se projetam para neurônios motores que dão origem ao nervo frênico e inervam o principal músculo respiratório, o diafragma (STORNETTA; SEVIGNY; GUYENET, 2003). Os neurônios do GRVLr são estimulados pelos neurônios excitatórios do pré-Bötzinger e são inibidos durante a expiração pelos neurônios inibitórios do Complexo Bötzinger (SMITH et al., 2007).

5) Grupamento respiratório ventrolateral caudal (GRVLc), um grupamento que possui neurônios pré-motores expiratórios que se projetam para neurônios motores da coluna torácica e lombar, controlando os movimentos expiratórios (EZURE, 1990; FORTUNA et al., 2008).

Além desses grupamentos da superfície ventral do bulbo, envolvendo diferentes classes de neurônios que controlam a respiração, a região dorsal do bulbo e a ponte também participam deste processo. Na região dorsal do bulbo, que corresponde à região do núcleo do trato solitário (NTS), estão localizados grupamentos de neurônios inspiratórios e expiratórios, os quais recebem aferências dos quimiorreceptores periféricos e dos receptores de distensão pulmonar (KUBIN et al., 2006; MCCRIMMON; MITCHELL; ALHEID, 2008). O papel desses neurônios no controle do ritmo respiratório ainda não está completamente esclarecido, mas estudos recentes da literatura sugerem uma possível participação do grupamento respiratório dorsal na modulação da atividade dos neurônios respiratórios dos grupamentos ventral e pontino (BIANCHI; DENAVIT-SAUBIE; CHAMPAGNAT, 1995; COSTA-SILVA; ZOCCAL; MACHADO, 2010; SUBRAMANIAN; HOLSTEGE, 2013). $\mathrm{Na}$ ponte, existem núcleos específicos, especialmente os núcleos parabraquial e Kölliker-Fuse (KF), que possuem neurônios pós-inspiratórios importantes para o encerramento da inspiração e para a manutenção do ritmo respiratório (SMITH et al., 2007).

\subsection{Núcleos pontinos envolvidos no controle respiratório e autônomo}

Os núcleos pontinos, envolvidos no controle respiratório e autônomo incluem o grupamento noradrenérgico $A 5$, a região intertrigeminal (ITR), o complexo parabraquial (núcleos parabraquial lateral e medial) e o núcleo Kölliker-Fuse. 
O grupamento neuronal A5 está envolvido na modulação da freqüência respiratória (HILAIRE et al., 2004) ou na adaptação respiratória em resposta a hipóxia e hipercapnia (HSIEH; SIEGEL; DICK, 2004; TAXINI et al., 2011). A região ITR é menos definida quanto à sua função. Estudos demonstraram o seu envolvimento na modulação do reflexo de apnéia (CHAMBERLIN; SAPER, 1998; RADULOVACKI et al., 2003), já que lesões unilaterais dessa região aumentaram a incidência de apnéia durante o sono. Dessa forma, fica claro que a sua integridade estabiliza o padrão respiratório e diminui a predisposição a essa desordem durante o sono (RADULOVACKI; PAVLOVIC; CARLEY, 2004).

O complexo parabraquial, que inclui o núcleo parabraquial lateral e medial, está envolvido no controle respiratório, cardiovascular, regulação do equilíbrio hidroeletrolítico e no processamento dos estímulos nociceptivos. A heterogeneidade de suas funções fisiológicas é suportada por sua complexa rede de conexões neurais, além de sua organização topográfica. Estudos revelaram que os núcleos do complexo parabraquial são os principais alvos do núcleo do trato solitário (NTS), o qual recebe aferências dos nervos vago e glossofaríngeo (LOEWY; BURTON, 1978). Projeções eferentes do complexo parabraquial promovem a inervação de neurônios envolvidos no controle respiratório, incluindo a área $A 5$, toda a coluna respiratória ventral, o NTS e o núcleo ambíguo (DOBBINS; FELDMAN, 1994).

O núcleo Kölliker-Fuse apresenta uma intensa projeção para toda a coluna respiratória ventral: o complexo de Bötzinger (GANG et al., 1995), o complexo préBötzinger (TAN et al., 2010), os neurônios pré-motores e motores do bulbo, além dos neurônios da medula espinal (BRUINSTROOP et al., 2012; EZURE, 2004; YOKOTA et al., 2004). Essa região parece também participar nas adaptações de alguns reflexos respiratórios, incluindo o reflexo de Hering-Breuer e o quimiorreflexo periférico (KOSHIYA; GUYENET, 1994; SONG; POON, 2004; SONG et al., 2012). Além do envolvimento nas modulações respiratórias, o núcleo KF também possui funções essenciais no controle da ingestão de sódio, motilidade gastro-intestinal e vômito (FUKUDA; FUKAI, 1986, 1988; GASPARINI et al., 2009).

Experimentos imunoistoquímicos ou de hibridização in situ revelaram muitos neurotransmisores e receptores na região pontina Kölliker-Fuse. O KF expressa receptores para glutamato (AMPA, NMDA e metabotrópicos), gaba, glicina, noradrenalina e serotonina. O KF apresenta populações de neurônios gabaérgicos, glicinérgicos e uma distinta população noradrenérgica, a região $A 7$, que se 
sobrepõem rostralmente ao KF (DUTSCHMANN; HERBERT, 1998, 2012; BRUINSTROOP et al., 2012). Devido esses neurônios noradrenérgicos também estarem contidos no núcleo do Kölliker-Fuse, alguns autores classificam essa região como grupamento noradrenérgico KF/A7 (GASPARINI et al., 2009). Essa região também tem um envolvimento no controle respiratório (Li; Nattie, 2006).

\subsection{Participação de áreas pontinas na manutenção do padrão respiratório eupneico}

A participação das áreas pontinas na modulação da fase de transição entre inspiração e expiração foi primeiramente demonstrada por Marckwald em 1887. Nesse estudo foi demonstrado que lesões bilaterais da ponte dorsolateral foram capazes de transformar um padrão respiratório normal em apneuse, padrão respiratório caracterizado por aumento na duração da inspiração. A prolongação da fase inspiratória indica uma ruptura do mecanismo central envolvido na transição entre inspiração e expiração. A partir desse estudo surgiu o interesse na participação de estruturas pontinas no controle respiratório.

Entretanto, Stella (1938) mostrou que após lesões pontinas, a apneuse ocorreu somente após vagotomia bilateral, pois se acredita que os neurônios respiratórios pontinos recebem inibições sinápticas dos receptores de estiramento pulmonar. Assim, sob condições de uma retroalimentação intacta dos mecanorreceptores pulmonares, a atividade pontina é inibida, contribuindo para a fase de transição entre inspiração e expiração (COHEN; FELDMAN, 1977; FELDMAN; GAUTIER, 1976).

Ao mesmo tempo, tem sido demonstrado que estimulação química ou elétrica do complexo parabraquial medial ou núcleo Kölliker-Fuse pode provocar a parada da inspiração e o início da expiração em animais com vagos intactos (CHAMBERLIN; SAPER, 1994; 1998; DUTSCHMANN; HERBERT, 1998; 2006; OKAZAKI et al., 2002; OKU; DICK, 1992).

O controle da fase de transição entre inspiração e expiração pelos mecanismos pontinos não está totalmente compreendido. Vários mecanismos responsáveis por este controle são descritos na literatura (MORSCHEL; DUTSCHMANN, 2009; RYBAK et al., 2007; RYBAK et al., 2004; SMITH et al., 2007) e de uma maneira geral, acredita-se que exista uma interação neuronal entre os 
neurônios pontinos e bulbares, envolvendo sinapses excitatórias e inibitórias. Os neurônios pontinos apresentam atividade tônica que modulariam os neurônios inibitórios e excitatórios de toda a coluna respiratória ventrolateral bulbar, modulando, assim, a transição entre a inspiração e a expiração. No entanto, ainda não foi demonstrado, de maneira precisa, quais seriam os tipos neuronais e quais seriam os fenótipos dos neurônios localizados na porção dorsolateral da ponte. Esses seriam experimentos cruciais para se determinar todo o circuito encefálico envolvendo a ponte e os neurônios da coluna respiratória bulbar.

\subsection{Quimiorreceptores e áreas pontinas}

Quimiorreceptores centrais são neurônios que possuem a função de detectar acidificações do fluido extracelular. Esses neurônios promovem a ativação dos neurônios responsáveis pela geração e manutenção do ritmo respiratório (MULKEY et al., 2004). O núcleo retrotrapezóide (RTN) é um importante grupamento neuronal com características quimiossensíveis (TAKAKURA et al., 2006; TAKAKURA et al., 2008). Já o NTS comissural participa no controle da respiração, recebendo aferências dos quimiorreceptores periféricos que detectam alterações da $\mathrm{PaO}_{2} \mathrm{e}$ da $\mathrm{PaCO}_{2}$ (ALHEID; MCCRIMMON, 2008). Evidências neuroanatômicas demonstram que o complexo Parabraquial/KF recebe projeções dos neurônios do RTN, bem como do NTS comissural, sugerindo assim a participação de áreas pontinas no quimiorreflexo (HERBERT; MOGA; SAPER, 1990; ROSIN; CHANG; GUYENET, 2006).

Estudos usando a proteína Fos como marcador de atividade neuronal revelou intensa ativação da região KF após hipóxia, hipercapnia ou estimulação do nervo do seio carotídeo (BERQUIN et al., 2000; BODINEAU; LARNICOL, 2001; TEPPEMA et al., 1997). Estudos em gatos e ratos anestesiados mostraram que após lesões bilaterais do complexo parabraquial e da região KF observou-se atenuação do aumento da respiração durante hipóxia ou hipercapnia (MIZUSAWA et al., 1995; ST JOHN; WANG, 1976). Dessa maneira, torna-se interessante investigar a possível contribuição do Complexo Parabraquial/Kölliker-Fuse durante a ativação dos quimiorreceptores periféricos ou centrais em animais não anestesiados. 


\subsection{Controle neural do sistema cardiovascular}

O controle do sistema nervoso central (SNC) sobre o sistema cardiovascular envolve a ativação de diferentes grupos de sensores periféricos (barorreceptores, receptores cardiopulmonares e quimiorreceptores), que projetam suas aferências para estruturas do SNC via nervos vago e glossofaríngeo. O processamento destas informações aferentes no SNC produz uma consequente regulação das vias autonômas eferentes, havendo o ajuste das variáveis cardiovasculares: frequência cardíaca, volume sistólico (força de contração) e a resistência periférica, as quais são determinantes da pressão arterial (PA) (GUYENET, 2006; MACHADO et al., 1997).

Os mecanorreceptores ou barorreceptores arteriais são os principais responsáveis pela regulação momento a momento da pressão arterial. São constituídos de terminações nervosas livres e estão estrategicamente localizados na curvatura da aorta (barorreceptores aórticos) e na bifurcação das carótidas (barorreceptores carotídeos). Os quimiorreceptores localizados nos corpúsculos aórticos e carotídeos detectam alterações na pressão parcial de oxigênio ( $\left.\mathrm{Pa}_{\mathrm{O} 2}\right)$, da pressão parcial de gás carbônico $\left(\mathrm{Pa}_{\mathrm{CO} 2}\right)$ e da concentração de hidrogeniônica $(\mathrm{pH})$ (AIRES, 2012).

Os nervos depressor aórtico e do seio carotídeo, cujas aferências têm acesso ao SNC através dos nervos vago e glossofaríngeo, respectivamente, são responsáveis pela condução das informações aferentes dos baro- e quimiorreceptores para o SNC, mais precisamente no bulbo, como parte integrante na regulação cardiovascular. Os corpos celulares destas fibras vagais e glossofaríngeas estão localizadas nos gânglios nodoso e petroso, respectivamente, tendo suas terminações no NTS (CIRIELLO; SCHULTZ; RODER, 1994; PALKOVITS; ZÁBORSZKY, 1977). A partir do NTS, as informações provenientes dos receptores periféricos, são distribuídas para áreas localizadas na superfície ventrolateral do bulbo que controlam o tônus vasomotor simpático e a pressão arterial: a região rostroventrolateral (RVL) e a região caudoventrolateral (CVL) (DAMPNEY, 1994; GUYENET, 2006). A região CVL é considerada uma região depressora, porque possui ação inibitória sobre a região do RVL, portanto sua atividade inibe o tônus simpático e a pressão arterial (CRAVO; MORRISON; REIS, 1991). 


\subsection{Participação de áreas pontinas na regulação cardiovascular}

Muitas são as evidências de que o Complexo Parabraquial/Kölliker-Fuse tem participação no controle cardiovascular. Estudos mostraram que o bloqueio da região do Kölliker-Fuse alterou as respostas cardiovasculares (respostas curtas de aumento da pressão arterial e bradicardia) produzidas por injeções de glutamato no núcleo cuneiforme, um núcleo reticular envolvido no controle cardiovascular e estress (MILLER et al., 2012; SHAFEl; NASIMI, 2011). O núcleo do Kölliker-fuse apresenta projeções para outros núcleos que têm um papel no controle cardiovascular, como o núcleo magnocelular, que controla a frequência cardíaca e a pressão arterial (LAl et al., 1999); a região pontina A5 (BYRUM; GUYENET, 1987); e o RVL, região pressora do bulbo ventrolateral rostral (DAMPNEY et al., 1987).

Trabalhos neuroanatômicos mostram que os neurônios do núcleo parabraquial lateral (NPBL) recebem aferências do NTS, sítio primário dos baro e quimiorreceptores periféricos (GRANATA; KITAI, 1989; HERBERT; MOGA; SAPER, 1990) e se projetam para a região pressora do bulbo ventrolateral (RVL) (FULWILER; SAPER, 1984; KUBO et al., 1998; MIURA; TAKAYAMA; OKADA, 1991). Adicionalmente, a inibição do NPBL com lidocaina foi capaz de promover uma redução da resposta pressora após ativação do quimiorreflexo periférico, sugerindo a participação das regiões pontinas no controle cardiovascular (HAIBARA et al., 2002). 


\section{OBJETIVOS}

A maioria dos procedimentos experimentais na literatura, envolvendo as estruturas pontinas no controle cardiorrespiratório, foi realizada em animais anestesiados. Dessa maneira, a nossa hipótese foi tentar esclarecer a real participação das estruturas pontinas, mais especificamente a região KF/A7 e parabraquial lateral na manutenção do padrão respiratório e qual seria a participação destas regiões durante a ativação dos quimiorreceptores periféricos ou centrais. Estudamos também as alterações cardiovasculares após manipulações experimentais da região KF/A7 e do núcleo parabraquial lateral (NPBL) uma vez que alterações respiratórias podem ser acompanhadas de alterações cardiovasculares.

Diante do que foi discutido acima, os objetivos específicos deste trabalho foram:

1- Avaliar os efeitos cardiorrespiratórios basais após a inibição do núcleo KöllikerFuse (KF) ou do núcleo parabraquial lateral (NPBL) em animais não anestesiados.

2- Avaliar as respostas cardiorrespiratórias produzidas por hipóxia $\left(8 \% \mathrm{O}_{2}\right.$, balanceado com $\left.\mathrm{N}_{2}\right)$ ou hipercapnia $\left(7 \% \mathrm{CO}_{2}, 21 \% \mathrm{O}_{2}\right.$, balanceado com $\left.\mathrm{N}_{2}\right)$ após a inibição do núcleo Kölliker-Fuse (KF) ou do NPBL em animais não anestesiados.

3- Avaliar a participação dos receptores GABAérgicos do sub-tipo A no núcleo Kölliker-Fuse (KF) nas alterações cardiorrespiratórias basais ou durante a ativação dos quimiorreceptores periféricos (hipóxia) ou centrais (hipercapnia) em animais não anestesiados.

4- Avaliar a participação dos neurônios noradrenérgicos do grupamento A7 nas respostas cardiorrespiratórias basais e induzidas por hipóxia e hipercapnia, por meio de lesão seletiva dos neurônios noradrenérgicos com a toxina saporina conjugada com anti-dopamina $\beta$-hidroxilase (anti-DßH-SAP) em animais não anestesiados.

5- Investigar os efeitos na freqüência e amplitude do nervo frênico e na atividade simpática do nervo esplâncnico (sSNA) após a inibição da região do KF em animais anestesiados.

6- Avaliar as respostas respiratórias e na atividade simpática produzidas por hipóxia (injeções endovenosas de cianeto de potássio) ou hipercapnia $\left(10 \% \mathrm{CO}_{2}, 93 \% \mathrm{O}_{2}\right.$, balanceado com $\mathrm{N}_{2}$ ) após a inibição do núcleo Kölliker-Fuse (KF) em animais anestesiados. 


\section{MATERIAIS E MÉTODOS}

\subsection{Animais}

Foram utilizados ratos Wistar, adultos, com peso variando entre 250 e 330 gramas, procedentes do Biotério Central do Instituto de Ciências Biomédicas (ICB) da Universidade de São Paulo. Os animais foram mantidos em caixas individuais com água e ração (Nuvlab) ad libitum. A temperatura e umidade do biotério foram controladas. O ciclo claro-escuro do biotério foi mantido como de 12 horas cada. Os protocolos experimentais estão de acordo com os Princípios Éticos de Experimentação Animal adotado pelo Colégio Brasileiro de Experimentação Animal (COBEA) e foram aprovados pelo Comitê de Ética no Uso de Animais do Instituto de Ciências Biomédicas da Universidade de São Paulo (ICB/USP) em 15/12/2009, registrado sob n 160, na fl. 79, do livro 02.

\section{Procedimentos cirúrgicos}

No presente estudo foram realizados experimentos em dois modelos experimentais: animais não anestesiados e animais anestesiados. Em todos os procedimentos cirúrgicos foram utilizados métodos assépticos para evitar os riscos de infecções.

\subsection{Experimentos realizados em animais não anestesiados}

\subsubsection{Implante de cânulas na ponte dorsolateral}

Primeiramente, os ratos foram anestesiados com quetamina (80 mg/kg de peso corporal) + xilazina ( $7 \mathrm{mg} / \mathrm{kg}$ de peso corporal) e adaptados a um aparelho estereotáxico (modelo Kopf 900, David Kopf Instruments, CA, USA). O lambda e o bregma foram utilizados como referência para nivelar a cabeça dos ratos. Utilizandose o bregma como referência, foram determinados os pontos de introdução das cânulas de aço inoxidável nas cabeças dos ratos. Nestes pontos foi feita uma trepanação do osso do crânio com uma broca esférica, abrindo um orifício de aproximadamente $1,5 \mathrm{~mm}$ de diâmetro. Para a área $\mathrm{KF}$, as cânulas guia de aço inoxidável foram posicionadas $8,9 \mathrm{~mm}$ caudal ao bregma; 2,3 lateral à linha mediana e 5,3 mm abaixo da dura-máter. As cânulas foram fixadas nas cabeças dos ratos 
com parafusos e resina acrílica. Para o NPBL, as cânulas guia de aço inoxidável foram posicionadas 9,4 mm caudal ao bregma; 2,0 lateral à linha mediana e 4,1 mm abaixo da dura-máter. As cânulas foram fixadas nas cabeças dos ratos com parafusos e resina acrílica. Após a cirurgia cerebral, os ratos receberam uma injeção intramuscular (0,2 ml/rato) de Pentabiótico Veterinário - Pequeno Porte (Fort Dodge Saúde Animal Ltda) e uma injeção subcutânea do analgésico/anti-inflamatório Ketoflex (cetoprofeno 1\%, 0,03 $\mathrm{ml} /$ rato).

\subsubsection{Lesões químicas da região A7}

Os animais foram, inicialmente, anestesiados intraperitonealmente (i.p) com quetamina (80 $\mathrm{mg} / \mathrm{kg}$ ) e xilasina $(7 \mathrm{mg} / \mathrm{kg})$ e adaptados a um aparelho estereotáxico Kopf (David Kopf Instruments, CA, USA). Após uma incisão longitudinal na pele e no tecido subcutâneo para a exposição da calota craniana, o lambda e o bregma foram utilizados como referência para nivelar as cabeças dos animais. As injeções bilaterais (volume de $200 \mathrm{nl}$ ) de saporina conjugada anti dopamina $\beta$-hidroxilase (anti-DßH-SAP) (Advanced Targeting Systems, San Diego, CA) ou Salina (controle) na região $A 7$ foram realizadas utilizando-se injetoras (0,3 $\mathrm{mm}$ diâmetro) acopladas a uma seringa Hamilton $(5 \mu l)$. Após as injeções da toxina, as cabeças dos animais foram suturadas, os animais receberam uma injeção intramuscular $(0,2 \mathrm{ml} / \mathrm{rato})$ de Pentabiótico Veterinário - Pequeno Porte (Fort Dodge Saúde Animal Ltda) e uma injeção subcutânea do analgésico/anti-inflamatório Ketoflex (cetoprofeno 1\%, 0,03 $\mathrm{ml} /$ rato). Os animais receberam água e ração ad libitum, e foram mantidos no biotério de experimentação do Departamento de Fisiologia e Biofísica com temperatura e umidade controladas. O ciclo claro-escuro do biotério foi mantido em 12 horas cada. Os animais permaneceram por um período de 15 dias.

\subsubsection{Drogas utilizadas}

- Muscimol: agonista GABAérgico do sub-tipo A (100 e 200 pmol/100 nl).

- Bicuculina: antagonista GABAérgico do sub-tipo A (1 nmol/100 nl).

O volume das injeções na área KF e no NPBL foi de 100 nl em cada lado (injeções bilaterais). Solução salina fisiológica ou uma mistura de propilenoglicol/água (2:1) foram injetadas nos experimentos controles. 
- Neurotoxina Saporina (anti-dopamina $\beta$-hidroxilase: anti $D \beta H$ ): toxina saporina seletiva para neurônios noradrenérgicos (2,1 ng/100 nl).

$\mathrm{O}$ volume das injeções na área KF/A7 foi de $100 \mathrm{nl}$ em cada lado (injeções bilaterais). O mesmo volume de salina fisiológica foi utilizado nos experimentos controles.

Todas as doses utilizadas foram baseadas em trabalhos anteriores que mostraram os efeitos dos agonistas e antagonistas GABAérgicos e da toxina saporina em áreas do tronco encefálico (GRAY et al., 2001; MOREIRA et al., 2011; TAKAKURA et al., 2013; TAKAKURA; MOREIRA, 2011; TAKAKURA et al., 2008; TSUKAMOTO; SVED, 1993).

\subsubsection{Injeções encefálicas}

As drogas, dissolvidas em solução salina fisiológica ou uma mistura de propilenoglicol/água (2:1), foram injetadas no encéfalo dos ratos utilizando-se uma seringa Hamilton $(5 \mu \mathrm{l})$, conectada com um tubo de polietileno PE-10 a uma agulha injetora que foi introduzida no encéfalo pela cânula guia previamente fixada no encéfalo. A cânula injetora ( $0,3 \mathrm{~mm}$ diâmetro) foi $1,5 \mathrm{~mm}$ mais longa do que a cânula guia.

\subsubsection{Medida da ventilação pulmonar}

As medidas de ventilação (Ve) foram obtidas por pletismografia de corpo inteiro (MENKES; DUBOIS, 1969). Este método é baseado no princípio de que um animal, dentro de uma câmara vedada, tem seu volume de ar corrente inspirado aquecido, da temperatura da câmara à temperatura corporal e saturado com vapor de água. Durante a expiração, seu volume de ar corrente é resfriado até a temperatura da câmara, havendo perda de vapor de água. Essas situações de aquecimento e umidificação do ar inspirado, bem como de resfriamento e desidratação do ar expirado são acompanhadas de pequenas mudanças de pressão, que podem ser detectadas por um transdutor diferencial de pressão (MLT1L Respiratory Flow Head, ADInstruments). A câmara de pletismografia consiste em uma caixa de acrílico de 5 litros, onde o animal é colocado e pode 
mover-se livremente. Ademais, a câmara tem um termômetro e uma seringa para calibração.

Durante a realização de cada medida de Ve, o fluxo de ar é interrompido e a câmara do animal permanece totalmente vedada por curtos períodos de tempo (aproximadamente 2 minutos). A caixa é conectada a um transdutor de pressão acoplado a um pré-amplificador (FE141 Spirometer, ADInstruments) e ao sistema de registro computadorizado Powerlab (modelo Powerlab 8SP ADInstruments) de 8 canais.

A calibração de volume é obtida durante cada experimento, injetando-se um volume de ar conhecido $(1 \mathrm{ml})$ dentro da câmara do animal. Duas variáveis respiratórias são medidas; a freqüência respiratória (fR) e o volume corrente (VT), sendo a última variável determinada pelas seguintes variáveis: volume de ar corrente; volume de ar injetado na câmara do animal para calibração, deflexão de pressão associada com cada volume de ar corrente, deflexão de pressão associada ao volume injetado para calibração, temperatura corporal (em Kelvin), temperatura do ar dentro da câmara do animal, pressão barométrica, pressão de vapor de água a temperatura corporal, pressão de vapor de água na câmara do animal e temperatura ambiente. A temperatura corporal foi obtida através de um termômetro retal no início e ao término do experimento.

A Ve é medida pelo produto entre fR e VT. A Ve e o VT foram apresentados nas condições de pressão barométrica ambiente, temperatura corporal e saturados com vapor de água.

\subsubsection{Registro da pressão arterial e da freqüência cardíaca}

Para o registro das variáveis cardiovasculares, os animais foram submetidos à canulação da artéria femoral com tubo de polietileno (PE-10 conectado a um PE50) para registro da pressão arterial pulsátil (PAP), pressão arterial média (PAM) e freqüência cardíaca (FC). A cânula da artéria femoral foi conectada a um transdutor de pressão (MLT0699, ADInstruments) acoplado a um pré-amplificador (FE221 Bridge Amp, ADInstruments) e ao sistema de registro computadorizado Powerlab (modelo Powerlab 8SP ADInstruments) de 8 canais. Foram registradas simultaneamente a PAP, PAM e FC. 


\subsubsection{Testes do quimiorreflexo central e periférico}

Hipercapnia $\left(7 \% \mathrm{CO}_{2}, 21 \% \mathrm{O}_{2}\right.$, balanceado com $\left.\mathrm{N}_{2}\right)$ foi produzida por adição da mistura gasosa dentro da caixa de plestismografia. Em cada rato, a hipercapnia foi mantida durante 10 min e, em seguida, substituído por $\mathrm{O}_{2}$ a 21\% (nomóxia e normocapnia). Cada rato foi submetido a duas sessões de hipercapnia: uma 10 minutos após as injeções bilaterais de salina na região KF ou NPBL, outra 10 minutos após injeções bilaterais de muscimol na região KF ou NPBL.

Hipóxia foi obtida utilizando uma mistura de $8 \% \mathrm{O}_{2}$, balanceado com $\mathrm{N}_{2}$ durante 10 minutos. As medidas realizadas foram semelhantes às supracitadas.

\subsection{Experimentos realizados em animais anestesiados}

\subsubsection{Procedimentos cirúrgicos em animais anestesiados}

Os animais foram anestesiados com halotano 5\% em 100\% de oxigênio. Posteriormente, traqueostomizados e colocados em ventilação artificial com 1,4 $1,5 \%$ de halotano em $100 \%$ de oxigênio para continuação dos procedimentos cirúrgicos. Em todos os experimentos foram realizados os seguintes procedimentos cirúrgicos:

1) canulação da artéria e veia femoral com tubo de polietileno (PE-10 conectado a um PE-50) para registro de pressão arterial média (PAM) e administração de drogas, respectivamente;

2) colocados em um aparelho estereotáxico (modelo Kopf 1760, David Kopf, CA, USA);

3) localização e exposição do nervo frênico e do nervo esplâncnico via posição dorsolateral (MOREIRA et al., 2006; TAKAKURA; MOREIRA, 2013; TAKAKURA et al., 2006; TAKAKURA et al., 2008; TAKAKURA et al., 2007);

4) todos os animais foram vagotomizados bilateralmente a fim de prevenir uma influência da ventilação na atividade do nervo frênico.

5) alguns animais $(n=8)$ sofreram desnervação bilateral dos baro e quimiorreceptores, seccionando-se os nervos laríngeo superior e o glossofaríngeo (região proximal com a junção da bifurcação carotídea), bem como a cadeia 
simpática, a fim de se estudar apenas os efeitos da estimulação dos quimiorreceptores centrais.

Após a finalização dos procedimentos cirúrgicos, o anestésico halotano foi substituído pelo anestésico endovenoso uretano (1,2 g/kg de peso corporal).

Todos os animais foram ventilados com $100 \%$ de oxigênio durante todo o período experimental. Os animais receberam uma sonda retal para monitorização da temperatura corpórea e sua temperatura foi mantida em $37^{\circ} \mathrm{C}$, utilizando-se um colchão com resistência interna para aquecimento. $\mathrm{O}$ índice de $\mathrm{CO}_{2}$-expirado foi monitorado durante todo o experimento por meio de um capnômetro (Columbus Instruments, Ohio, USA). O nível da anestesia foi sempre monitorado testando-se a ausência de efeitos no reflexo de retirada, ausência de mudanças na pressão arterial e na atividade do nervo frênico após o pinçamento da pata do animal. Satisfeito esses critérios, o relaxante muscular (pancurônio) foi administrado endovenosamente com uma dose inicial de $1 \mathrm{mg} / \mathrm{kg}$.

\subsubsection{Registro da pressão arterial}

Para o registro das variáveis cardiovasculares, a cânula da artéria femoral foi conectada a um transdutor de pressão (Physiological Pressure Transducer mod. MLT844, ADInstruments) acoplado a um pré-amplificador (Bridge Bio Amplifier mod. ML221, ADInstruments) e ao sistema de registro computadorizado Cambridge Electronic Design (CED-1401) de 4 canais. Foram registradas, simultaneamente, a pressão arterial pulsátil (PAP) e PAM.

\subsubsection{Medida da atividade elétrica do nervo frênico e do nervo esplâncnico}

Por meio de um modelo de abertura dorsolateral, o nervo frênico esquerdo foi exposto e isolado da divisão ventral do quinto plexo cervical. O nervo foi cortado distalmente e colocado num eletrodo bipolar em forma de gancho. A atividade do nervo frênico foi filtrada de 30 a $300 \mathrm{~Hz}$.

Por meio de um modelo de abertura retroperitoneal, o nervo esplâncnico esquerdo foi exposto na saída do gânglio supra-renal. A atividade simpática pósganglionar do nervo esplâncnico foi registrada utilizando-se um eletrodo bipolar em 
forma de gancho em configuração monopolar. A atividade simpática do nervo esplâncnico foi filtrada de 30 a $300 \mathrm{~Hz}$.

Os nervos e os eletrodos de registro foram cobertos com uma pasta de moldagem dental (Kwik-Cast Sealant, WPI, USP). O eletrodo bipolar em que os nervos foram colocados foi conectado a um conversor analógico-digital (modelo CED-1401) da Cambridge Electronics Design (CED, Cambridge, UK) de 8 canais. Este aparelho possui filtro passa-baixo, ligação AC-DC (corrente direta-alternada), filtro de corte, permite variação do ganho e possibilita correção da linha de base. A partir deste aparelho, o sinal foi copiado para um sistema de aquisição de dados versão 6 do Spike 2 software (CED). Os resultados foram gravados em CD para posterior análise dos resultados.

\subsubsection{Testes do quimiorreflexo central e periférico}

Hipercapnia foi promovida por adição de $\mathrm{CO}_{2}$ no ar fornecido pela ventilação artificial. Em cada rato, a adição de $\mathrm{CO}_{2}$ foi monitorizado para atingir no máximo entre 9,5 e $10 \%$ de $\mathrm{CO}_{2}$ no final da expiração, a hipercapnia foi mantida durante 5 min e, em seguida, substituído por $\mathrm{O}_{2}$ a 100\%. Cada rato foi submetido a três sessões de hipercapnia: uma, 10 minutos após injeções bilaterais de salina na região KF, outra 10 minutos após injeções bilaterais de muscimol na região KF e a terceira 120 minutos após a injeção de salina ou muscimol na região KF.

Hipóxia citotóxica foi induzida por injeções endovenosas de Cianeto de Potássio (KCN) $(40 \mu \mathrm{g} / 0,1 \mathrm{ml})$. Cada rato foi submetido a duas sessoes de hipóxia: uma 10 minutos apos após injeções bilaterais de salina ou muscimol na região do KF e outra 120 minutos após injeções bilaterais de salina ou muscimol na região KF.

\subsection{Histologia encefálica para confirmação dos pontos de injeção central}

Ao término dos experimentos, os ratos foram profundamente anestesiados, receberam injeções bilaterais de corante (azul de Evans, $100 \mathrm{nl}$ ) no KF ou no NPBL e foram submetidos a uma perfusão através de injeção no ventrículo cardíaco esquerdo de solução salina tamponada $(50 \mathrm{ml})$ seguida de solução de formalina a 10\% (50 ml). A seguir, os encéfalos foram retirados e fixados em formalina 10\% por alguns dias. Cortes transversais (40 $\mu \mathrm{m}$ de espessura) foram realizados nos pontos 
de injeção com auxílio de um micrótomo de congelamento (Leica SM2010R, Wetzlar, Alemanha). Os cortes histológicos, montados em lâminas foram corados com cresil violeta e analisados para se localizar os pontos das injeções na região do KF ou na região do NPBL de acordo com (PAXINOS; WATSON, 1998).

\subsection{Imunoistoquímica}

Ao término dos experimentos de lesões seletivas da região $A 7$, os animais foram profundamente anestesiados com pentobarbital de sódio (60 mg/kg) e perfundidos através do ventrículo cardíaco esquerdo com PBS $(\mathrm{pH} 7,4)$ seguido de formaldeído (4\% em 0,1 M de fosfato, $\mathrm{pH} \mathrm{7,4).} \mathrm{Os} \mathrm{encéfalos} \mathrm{foram} \mathrm{retirados} \mathrm{e}$ guardados nesse fixador por 24 horas a $4^{\circ} \mathrm{C}$. Os encéfalos foram cortados em microtómo numa espessura de $40 \mu \mathrm{m}$ e guardados em solução anti-congelante (solução crioprotetora: $20 \%$ de glicerol, 30\% de etileno glicol em 50 mM de fostato, $\mathrm{pH} 7,4)$ que preserva as qualidades do tecido encefálico para posterior tratamento imunoistoquímico (SCHREIHOFER; GUYENET, 1997).

Tirosina hidroxilase foi detectada com anticorpo de camundongo anti-TH (1:10.000, Chemicon, Temecula). O anticorpo primário foi detectado por incubação com anticorpo secundário marcado biotinilado de burro anti-camundongo (1:1000, Jackson), seguido pelo kit ABC (Vector, Burlingame, CA, EUA) e colorização subsequente com 3-3-diaminobenzidina (DAB). A especificidade dos anticorpos foi validada anteriormente (BARNA; TAKAKURA; MOREIRA, 2012; WANG; GERMANSON; GUYENET, 2002).

Um microscópio multifuncional Zeiss Axioskop 2 (campo claro, campo escuro) foi usado para todas as observações. Os neurônios marcados com TH foram plotados usando uma técnica descrita anteriormente de mapeamento assistida por computador baseado no uso de uma fase de microscópio motorizado controlada pelo software Neurolucida (STORNETTA; GUYENET, 1999). Os arquivos Neurolucida foram exportados para o software NeuroExplorer (MicroBrightfield, Colchester, VT) para contar os vários tipos de perfis neuronais dentro de uma área definida do tronco encefálico. Quando necessário, arquivos Neurolucida também foram exportados para o programa de desenho Canvas 9 software (ACD Systems of America, Miami, FL, EUA) para modificações finais. O alinhamento dos cortes foi feito em relação a uma secção de referência, utilizando como referência caudal os 
neurônios motores faciais (Bregma -10,4 mm), de acordo com o atlas de Paxinos e Watson (1998). As imagens foram tiradas com uma câmera SensiCam QE 12 bits CCDcamera (resolução 1376 × 1040 pixels, CookeCorp., Auburn Hills, MI, EUA). A nomenclatura neuroanatômica foi baseada segundo (PAXINOS; WATSON, 1998).

\subsection{Análise dos resultados}

Os resultados foram tabelados e posteriormente representados em gráficos como média \pm erro padrão da média. Teste t pareado e análise de variância, seguido do teste de Student-Newman-Keuls foi utilizado para comparação entre as médias. $\mathrm{O}$ índice de significância foi fixado em p<0,05. 


\section{PROTOCOLOS EXPERIMENTAIS}

\subsection{Efeitos cardiorrespiratórios produzidos pela inibição inespecífica da região Kölliker-Fuse ou do núcleo parabraquial lateral em animais não anestesiados}

Os animais sofreram os procedimentos cirúrgicos para o implante de cânulas de aço inoxidável na região do Kölliker-Fuse (KF) ou na região do núcleo parabraquial lateral (NPBL), bem como o implante de cânulas de polietileno na artéria femoral. No dia seguinte a canulação da artéria femoral, os animais foram colocados, individualmente, na câmara de pletismografia para registro simultâneo das variáveis cardiovasculares (pressão arterial e frequência cardíaca) e respiratórias (ventilação, frequência respiratória e volume corrente). Após as fases exploratórias, que variaram entre 30 e 45 minutos, as medidas de ventilação, da pressão arterial média (PAM) e frequência cardíaca (FC) basais foram efetuadas em animais não anestesiados. Após um período controle de registro das variáveis cardiovasculares e respiratórias, foram realizadas injeções bilaterais de salina (controle: $100 \mathrm{nl}$ ) ou do agonista GABAérgico do sub-tipo A muscimol no KF (100 ou 200 pmol/100 nl) ou no NPBL (200 pmol/100 nl) e foi aguardado um período de 10 minutos. Após este período, foram realizados novamente as medidas de pressão arterial, frequência cardíaca, ventilação, frequência respiratória e volume corrente.

\subsection{Efeitos cardiorrespiratórios produzidos pela estimulação dos quimiorreceptores centrais e periféricos após a inibição da região Kölliker-Fuse ou do núcleo parabraquial lateral}

Como já descrito no protocolo anterior, os animais foram submetidos ao implante com cânulas de aço inoxidável bilateralmente na região do KF ou na região do NPBL, bem como o implante de cânulas de polietileno na artéria femoral. No dia seguinte a canulação da artéria femoral, os animais foram colocados, individualmente, na câmara de pletismografia para registro simultâneo de pressão arterial, frequência cardíaca, ventilação, frequência respiratória e volume corrente. Após as fases exploratórias, que variam entre 30 e 45 minutos, as medidas de ventilação, da pressão arterial média (PAM) e frequência cardíaca (FC) basais foram 
efetuadas em animais não anestesiados. Após um período controle de registro das variáveis cardiovasculares e respiratórias, foi realizada a ativação dos quimiorreceptores centrais e periféricos 10 minutos após as injeções de salina (controle: $100 \mathrm{nl}$ ) ou do agonista GABAérgico do sub-tipo A muscimol no KF (100 ou 200 pmol/100 nl) ou no NPBL (200 pmol/100 nl). Os quimiorreceptores centrais foram ativados aumentando-se os valores de $\mathrm{CO}_{2}$ (mistura gasosa de $7 \% \mathrm{CO}_{2}, 21 \% \mathrm{O}_{2}$, balanceada com $\mathrm{N}_{2}$ ) dentro da caixa de pletismografia por um período de 10 minutos. Ao longo do período dos 10 minutos, foram realizadas as medidas das variáveis cardiorrespiratórias para avaliar os efeitos da inibição do KF ou do NPBL nas respostas de ativação dos quimiorreceptores centrais. Ao final dos 10 minutos, a câmara foi novamente ventilada com ar atmosférico durante 10 minutos e os parâmetros respiratórios e cardiovasculares foram mensurados novamente após a hipercapnia.

Os quimiorreceptores periféricos foram ativados reduzindo-se os valores de $\mathrm{O}_{2}$ (mistura gasosa de $8 \% \mathrm{O}_{2}$, balanceada com $\mathrm{N}_{2}$ ) dentro da caixa de pletismografia por um período de 10 minutos. Ao longo do período dos 10 minutos, foram realizadas as medidas das variáveis cardiorrespiratórias para avaliar os efeitos da inibição do KF ou do NPBL nas respostas de ativação dos quimiorreceptores periféricos. Ao final dos 10 minutos, a câmara foi novamente ventilada com ar atmosférico durante 10 minutos e os parâmetros respiratórios e cardiovasculares foram mensurados novamente após a hipóxia.A sequência da ativação dos quimiorreceptores centrais por hipercapnia e dos quimiorreceptores periféricos por hipóxia foi alternada nos diferentes animais. 
Figura 2 - Protocolo experimental 1.

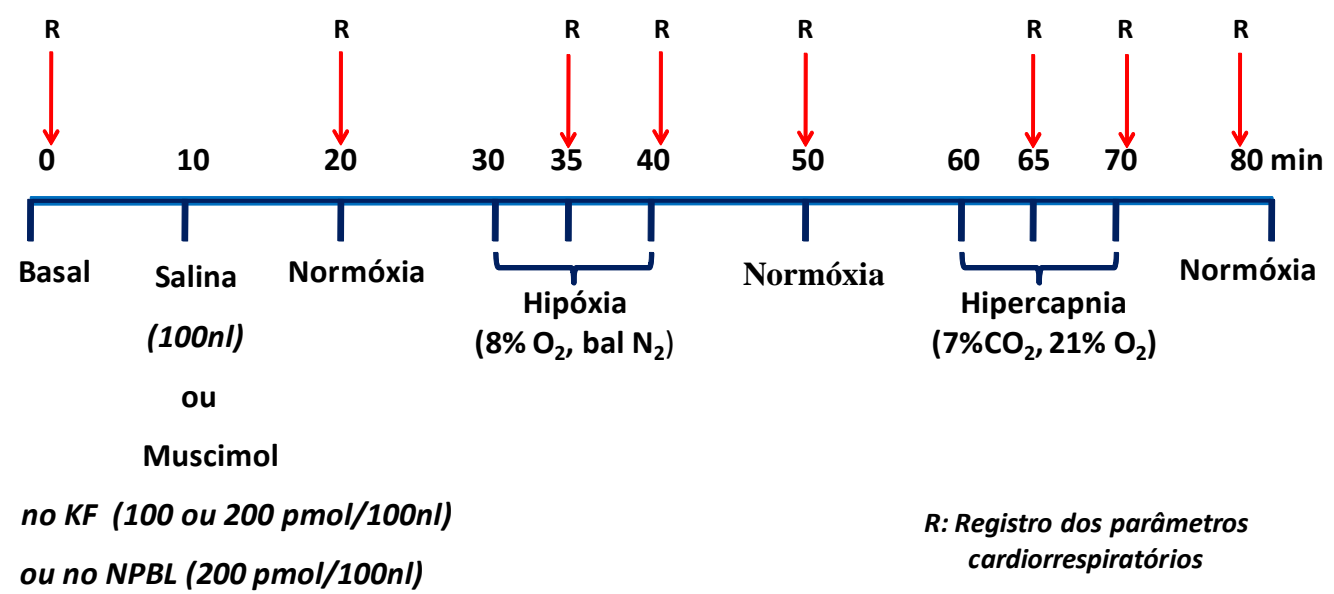

\subsection{Efeitos de injeções bilaterais de bicuculina combinada com injeções de muscimol na região Kölliker-Fuse sobre os parâmetros cardiorrespiratórios basais e produzidos pela estimulação dos quimiorreceptores centrais e periféricos em ratos não anestesiados}

Após todos os procedimentos cirúrgicos já relatados anteriormente, os animais foram colocados, individualmente, na câmara de pletismografia para registro simultâneo das variáveis cardiovasculares (pressão arterial e frequência cardíaca) e respiratórias (ventilação, frequência respiratória e volume corrente). Após as fases exploratórias, que variaram entre 30 e 45 minutos, as medidas de ventilação, da pressão arterial média (PAM) e frequência cardíaca (FC) basais foram efetuadas em animais não anestesiados. Após um período controle de registro das variáveis cardiovasculares e respiratórias, foram realizadas injeções bilaterais de veículo (controle: $100 \mathrm{nl}$ ) ou do antagonista GABAérgico do sub-tipo A bicuculina (1 nmol/100 nl) no KF. Dez minutos após as injeções bilaterais de veículo ou bicuculina, salina $(100 \mathrm{nl})$ ou muscimol (200 pmol/100 $\mathrm{nl})$ foi injetado bilateralmente no KF e foram realizados novamente as medidas de pressão arterial, frequência cardíaca, ventilação, frequência respiratória e volume corrente. Foi realizada a ativação dos quimiorreceptores centrais aumentando-se os valores de $\mathrm{CO}_{2}$ (mistura gasosa de $7 \% \mathrm{CO}_{2}, 21 \% \mathrm{O}_{2}$, balanceada com $\mathrm{N}_{2}$ ) dentro da caixa de pletismografia por um período de 10 minutos. Ao longo do período dos 10 minutos, foram realizadas as medidas das variáveis cardiorrespiratórias para avaliar os efeitos da 
participação dos receptores GABAérgicos do sub-tipo A nas respostas de ativação dos quimiorreceptores centrais. Ao final dos 10 minutos, a câmara foi novamente ventilada com ar atmosférico durante 10 minutos e os parâmetros respiratórios e cardiovasculares foram mensurados novamente após a hipercapnia.

A ativação dos quimiorreceptores periféricos foi realizada reduzindo-se os valores de $\mathrm{O}_{2}$ (mistura gasosa de $8 \% \mathrm{O}_{2}$, balanceada com $\mathrm{N}_{2}$ ) dentro da caixa de pletismografia por um período de 10 minutos. Ao longo do período dos 10 minutos, foram realizadas as medidas das variáveis cardiorrespiratórias para avaliar os efeitos da participação dos receptores GABAérgicos do sub-tipo A nas respostas de ativação dos quimiorreceptores periféricos. Ao final dos 10 minutos, a câmara foi novamente ventilada com ar atmosférico durante 10 minutos e os parâmetros respiratórios e cardiovasculares foram mensurados novamente após a hipóxia.

Figura 3 - Protocolo experimental 2.

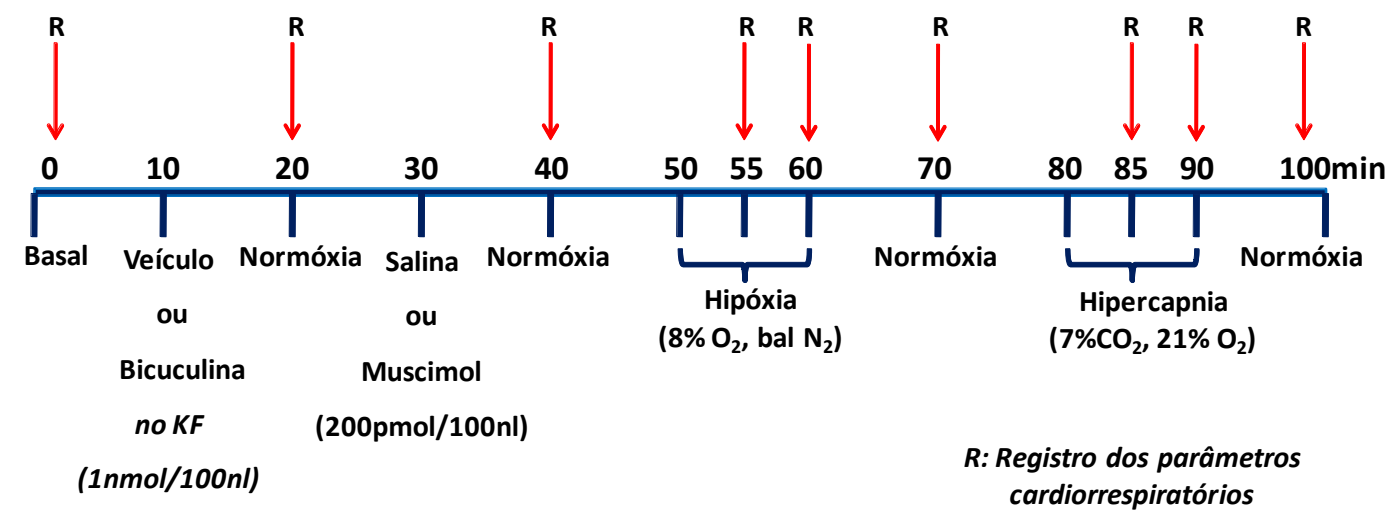

\subsection{Efeitos cardiorrespiratórios produzidos pela inibição específica do grupamento noradrenérgico A7 em animais não anestesiados}

Os animais sofreram lesões seletivas dos neurônios noradrenérgicos da região $A 7$, localizado na ponte dorsolateral, com a neurotoxina saporina antidopamina $\beta$-hidroxilase $(2,1 \mathrm{ng} / 100 \mathrm{nl})$. Essa imunotoxina consiste em um anticorpo conjugado com a dopamina $\beta$-hidroxilase, enzima que converte a dopamina em noradrenalina. A enzima $\mathrm{D} \beta \mathrm{H}$ está associada à membrana interna das vesículas, e, portanto, é exposta extracelularmente durante o processo de exocitose na liberação do neurotransmissor. Esta exposição permite que a porção do anticorpo da 
imunotoxina se ligue a $\mathrm{D} \beta \mathrm{H}$. Após a reciclagem vesicular por endocitose, a $\mathrm{D} \beta \mathrm{H}-$ SAP é levada para dentro do neurônio. Uma vez dentro do neurônio, a saporina inativa a subunidade 60s dos ribossomos, desta forma bloqueando a síntese celular, e causando morte celular (STIRPE; BARBIERI, 1986). Os neurônios não estão mais funcionais após 3-4 dias e fisicamente eliminados 12-15 dias após a injeção da toxina (GRAY et al., 2001; WANG et al., 2001). Após 15 dias, os animais foram colocados, individualmente, na câmara de pletismografia para registro simultâneo das variáveis cardiovasculares (pressão arterial e frequência cardíaca) e respiratórias (ventilação, frequência respiratória e volume corrente). Após as fases exploratórias, que variam entre 30 e 45 minutos, as medidas de ventilação, da pressão arterial média (PAM) e frequência cardíaca (FC) basais foram efetuadas em animais não anestesiados. Os animais também foram expostos a situações de hipóxia $\left(8 \% \mathrm{O}_{2}\right.$, balanceado com N2) ou hipercapnia $\left(7 \% \mathrm{CO}_{2}, 21 \% \mathrm{O}_{2}\right.$, balanceado com $\mathrm{N}_{2}$ ) durante 10 minutos cada para avaliar a participação dos neurônios noradrenérgicos nas respostas de ativação dos quimiorreceptores periféricos ou centrais. Os animais com lesões com a toxina saporina anti-dopamina $\beta$-hidroxilase, foram sempre comparados com os animais que receberam injeção de salina na região do KF, região que contém os neurônios noradrenérgicos $A 7$.

\subsection{Verificação da inibição da região do Kölliker-Fuse sobre os efeitos cardiorrespiratórios promovidos pela estimulação dos quimiorreceptores centrais ou periféricos}

Foi registrada a pressão arterial média, a atividade simpática do nervo esplâncnico e a atividade do nervo frênico. Salina (controle) ou muscimol (agonista GABAérgico do sub-tipo A) (200 pmol/ $50 \mathrm{nl}$ ) foi injetado bilateralmente no KF. Os efeitos cardiovasculares e respiratórios promovidos pela ativação dos quimiorreceptores centrais (aumento dos níveis de $\mathrm{CO}_{2}$ de 5 até 10\%) ou periféricos (redução dos níveis de $\mathrm{O}_{2}$ para 8\%) foram avaliados antes e após a inibição da região do KF. 


\section{RESULTADOS}

\subsection{Análise histológica das injeções na área Kölliker-Fuse}

A figura 4A mostra o local típico das injeções bilaterais na região do KöllikerFuse (KF). Mais precisamente, as injeções foram localizadas na região dorsolateral da ponte, ventral e lateral ao pedúnculo cerebelar superior. A figura B ilustra os neurônios noradrenérgicos localizados na região do KF, constituindo o grupamento pontino noradrenérgico A7 (tratamento imunoistoquímico para tirosina hidroxilase).

Figura 4 - Injeção bilateral na região do Kölliker-Fuse.
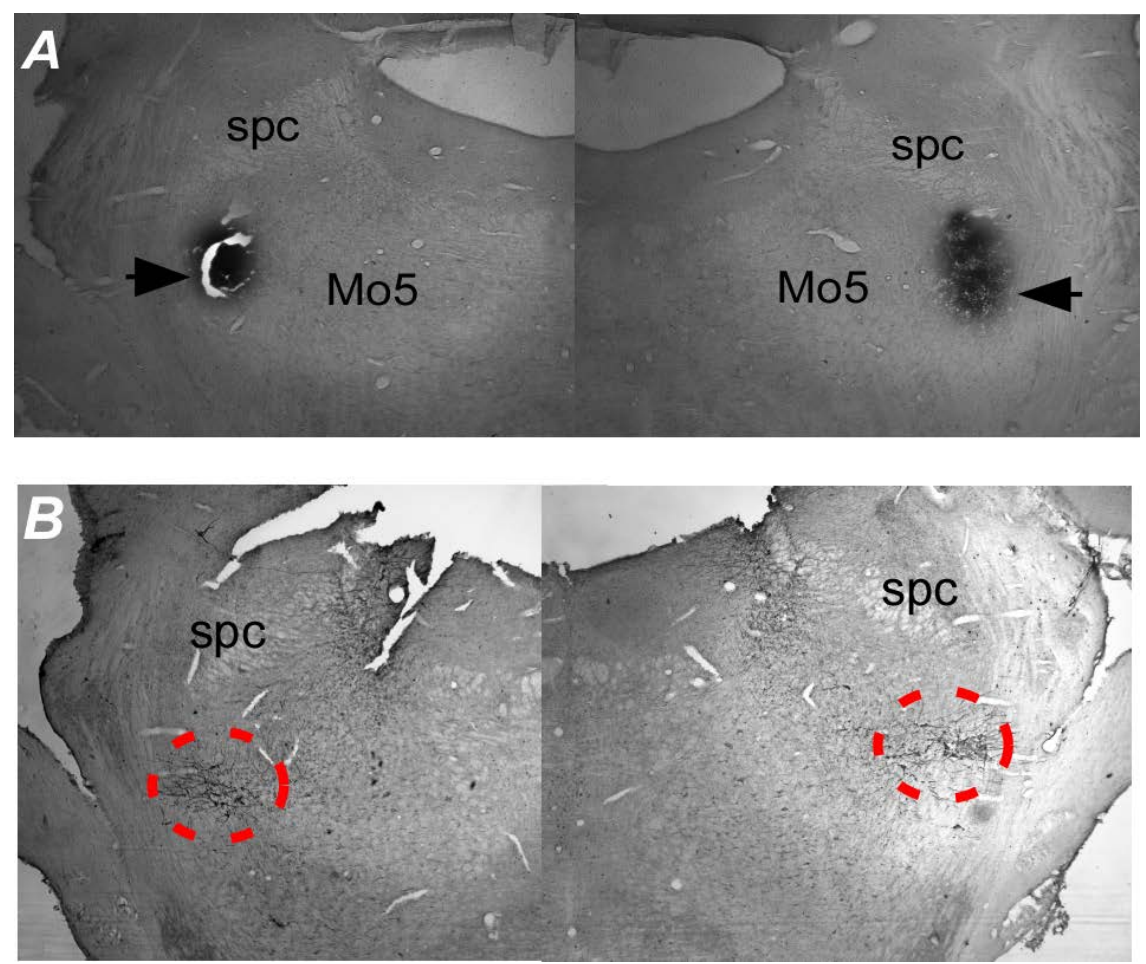

A) Fotomicrografia mostrando o local típico de uma injeção bilateral na região do Kölliker-Fuse (KF) (setas). B) Tratamento imunoistoquímico para tirosina hidroxilase, mostrando a localização do grupamento noradrenérgico $A 7$. O grupamento noradrenérgico A7 está praticamente na mesma região da região do KF. Abreviações: Mo5, núcleo motor mesencefálico; spc, pedúnculo cerebelar superior. Escala: $1 \mathrm{~mm}$. 


\subsection{Efeitos cardiorrespiratórios promovidos pela injeção bilateral de muscimol na região Kölliker-Fuse em animais que receberam injeção prévia de bicuculina}

A injeção bilateral de muscimol (100 e 200 pmol/100 nl) no KF reduziu o VT $(12,3 \pm 0,8$ e 11,2 \pm 1 , vs. salina: $14,7 \pm 0,6 \mathrm{ml} / \mathrm{kg}, \mathrm{p}<0,01)$, a fR $(92 \pm 0,6$ e $87 \pm 3$, vs. salina: $102 \pm 5$ ciclos respiratórios/min, p<0,05) e a Ve basal $(1140 \pm 68$ e $978 \pm$ 100, vs. salina: $1436 \pm 155 \mathrm{ml} / \mathrm{kg} / \mathrm{min}, \mathrm{p}<0,001$ ) (Figs. 5A-E). A injeção bilateral de muscimol no KF não alterou a PAM (109 \pm 3, $108 \pm 3$, vs. salina: $106 \pm 4$ mmHg, p>0,05) e a FC basal (318 $\pm 11,322 \pm 14$, vs. salina: $328 \pm 9$ bpm, p>0,05) (Figs. 5J e 5K). A inibição bilateral da região do KF com muscimol produziu um pequeno aumento do tempo de inspiração (Ti) $(275 \pm 5,281 \pm 4$, vs. salina: $249 \pm 6 \mathrm{~ms}$, $p<0,05)$ e um aumento muito maior no tempo de expiração (Te) $(576 \pm 15,592 \pm 24$, vs. salina: $452 \pm 19$ ms, p<0,05) (Figs. 5F e 5G). A injeção de muscimol reduziu o pico do fluxo inspiratório $(3,3 \pm 0,3,3 \pm 0,5$, vs. salina: $4,6 \pm 0,5 \mathrm{ml} / \mathrm{s}, \mathrm{p}<0,05)$ e 0 pico do fluxo expiratório $(2,3 \pm 0,9,1,6 \pm 0,4$, vs. salina: $5,7 \pm 0,7 \mathrm{ml} / \mathrm{s}, \mathrm{p}<0,01)$ (Figs. $5 \mathrm{H}$ e 5I).

O fato de não obtermos diferença estatística entre a dose de muscimol de 100 pmol quando comparada com a dose de $200 \operatorname{pmol}[F(1,18)=0,45, p>0,05]$, decidimos manter os nossos experimentos somente na dose de 200 pmol.

A injeção bilateral de bicuculina (1 nmol/100 nl) no KF foi capaz de reverter a redução no VT (14 \pm 1 , vs. muscimol: 11,2 $\pm 1 \mathrm{ml} / \mathrm{kg}, \mathrm{p}<0,05)$, na fR $(100 \pm 3$, vs. muscimol: $87 \pm 3$ ciclos respiratórios/min, $p<0,05)$, na Ve $(1418 \pm 138$, vs. muscimol: $978 \pm 100 \mathrm{ml} / \mathrm{kg} / \mathrm{min}, \mathrm{p}<0,001)$, no pico do fluxo inspiratório ( $5 \pm 1$, vs. muscimol: $3 \pm$ $0,5 \mathrm{ml} / \mathrm{s}, \mathrm{p}<0,01)$ e no pico do fluxo expiratório $(6,3 \pm 1,3$, vs. muscimol: 1,6 $\pm 0,4$ $\mathrm{ml} / \mathrm{s}, \mathrm{p}<0,001)$ promovidos pela injeção bilateral de muscimol $(200 \mathrm{pmol} / 100 \mathrm{nl}) \mathrm{no}$ KF (Figs. 3C-E; 3H e 3I). Bicuculina bilateral no KF também foi eficaz em reverter o aumento do Ti $(253 \pm 4$, vs. muscimol: $281 \pm 4$ ms, p<0,05) e do Te $(463 \pm 13$, vs. muscimol: $592 \pm 14$ ms, p<0,05) produzido pela injeção de muscimol no KF (Figs. $5 F$ e $5 G)$. 
Figura 5 - Efeitos cardiorrespiratórios promovidos pela injeção bilateral de muscimol na região Kölliker-Fuse em animais que receberam injeção prévia de bicuculina.

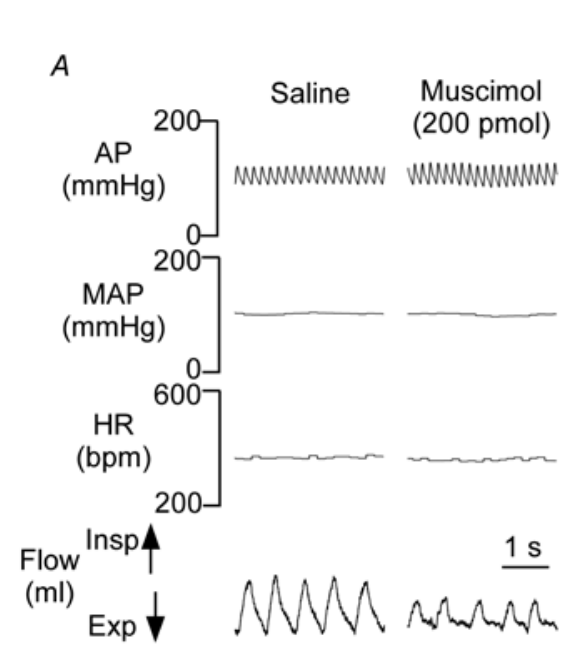

$B$

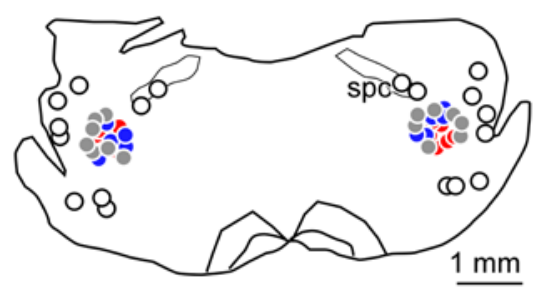

- Muscimol $100 \mathrm{pmol}(\mathrm{n}=5)$

- Muscimol $200 \mathrm{pmol}(\mathrm{n}=6)$

- Bicuculline 1nmol + Muscimol 200 pmol $(n=7)$

OMisplaced injections $(n=9)$

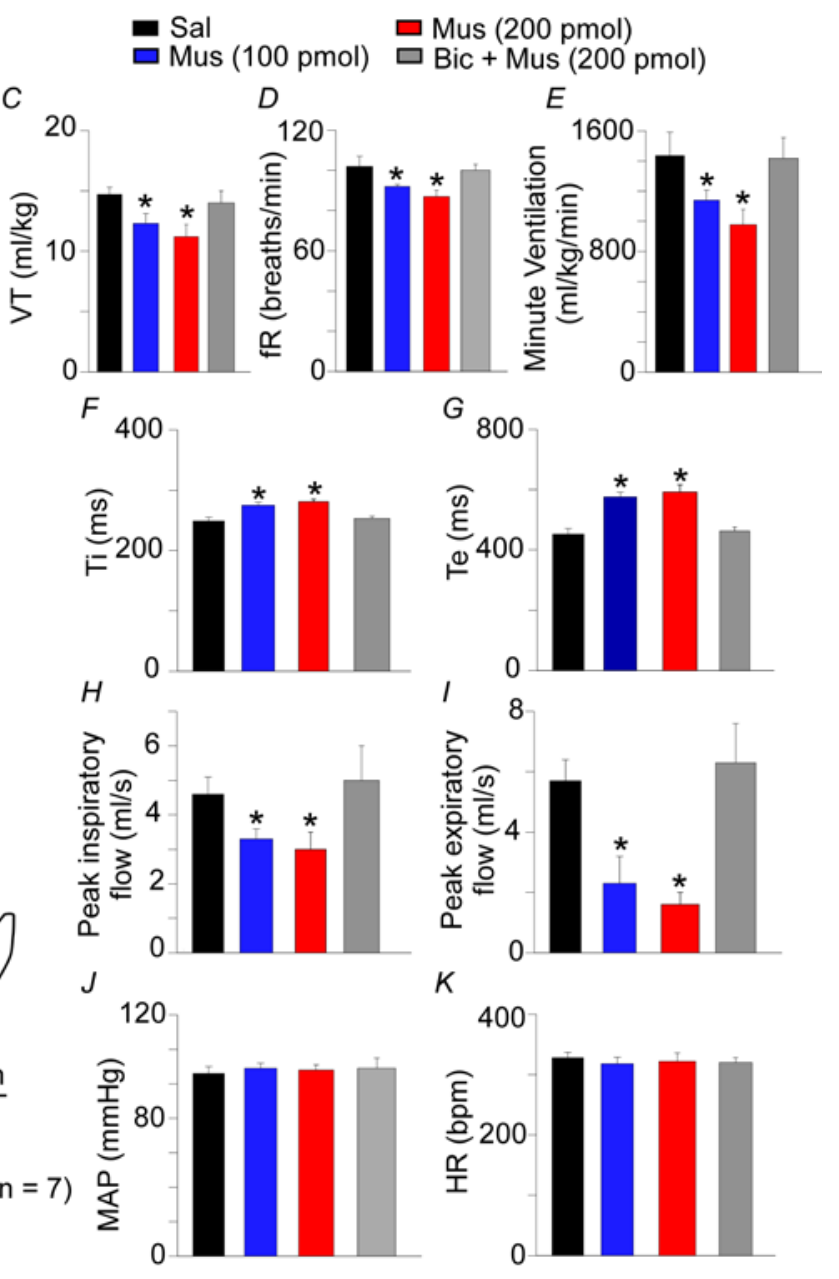

A) Registro típico de um animal representativo do grupo, mostrando pressão arterial (AP), pressão arterial média (MAP), freqüência cardíaca (HR) e fluxo de ar (inspiração, deflexão para cima e expiração, deflexão para baixo) após injeções bilaterais de salina ou muscimol (200 pmol/100 nl) na região Kölliker-Fuse (KF). B) Diagrama mostrando a localização das injeções na região do KF. Círculos azuis representam injeções de muscimol de 100 pmol/100 nl, os círculos vermelhos mostram injeções de muscimol de 200 pmol/100 nl e os círculos cinza mostram injeções da combinação de bicuculina+muscimol. Os círculos em branco representam as injeções localizadas fora da região do $\mathrm{KF}$. Alterações no C) volume corrente, D) frequência respiratória, E) ventilação minuto, F) tempo de inspiração, G) tempo de expiração, H) pico do fluxo inspiratório, I) pico do fluxo expiratório, J) pressão arterial média e K) freqüência cardíaca em animais não anestesiados que receberam a injeção bilateral de bicuculina seguida da injeção bilateral de muscimol na região KF. *diferente de salina $(p<0,05) . n=5-9 /$ grupo de ratos. 


\subsection{Efeitos cardiorrespiratórios produzidos pela estimulação dos quimiorreceptores periféricos em animais que receberam a injeção de bicuculina e muscimol na região do Kölliker-Fuse}

Hipóxia $\left(8 \% \mathrm{O}_{2}\right.$, balanceado com $\mathrm{N}_{2}$ ) durante 10 minutos produziu hipotensão (93 \pm 4 , vs. normóxia: $106 \pm 4 \mathrm{mmHg}, p<0,05)$, taquicardia ( $423 \pm 12$, vs. normóxia: $329 \pm 9 \mathrm{bpm}, \mathrm{p}<0,05)$, aumento do VT $(23 \pm 2,4$, vs. normóxia: $14 \pm 1,8 \mathrm{ml} / \mathrm{kg}$, $p<0,05)$, da fR $(136 \pm 5$, vs. normóxia: $99 \pm 6$ respiração/min, $p<0,05)$ e da Ve $(3179$ \pm 325 , vs. normóxia: $1402 \pm 103 \mathrm{ml} / \mathrm{kg} / \mathrm{min}, \mathrm{p}<0,05$ ) (Figs. 6A-F).

A injeção bilateral de muscimol (200 pmol/100 nl) no KF foi capaz de reduzir o aumento do VT ( $15 \pm 1$, vs. salina: $23 \pm 2,4 \mathrm{ml} / \mathrm{kg}, \mathrm{p}<0,05)$, da fR ( $115 \pm 3$, vs. salina: $136 \pm 5$ respiração/min, $p<0,05)$, da Ve $(1827 \pm 61$, vs. salina: $3179 \pm 325 \mathrm{ml} / \mathrm{kg} / \mathrm{min}$, $p<0,05)$ e a taquicardia (380 \pm 9 , vs. salina: $423 \pm 12 \mathrm{bpm}, \mathrm{p}<0,05)$ produzidos pela hipóxia em ratos não anestesiados (Figs. 4A, 4C-F). A injeção bilateral de muscimol não alterou a hipotensão ( $95 \pm 4$, vs. salina: $93 \pm 4 \mathrm{mmHg}, \mathrm{p}>0,05)$ produzida por hipóxia em ratos não anestesiados (Figs. 6A-B).

A injeção bilateral de bicuculina ( $1 \mathrm{nmol} / 100 \mathrm{nl})$ foi capaz de reverter o efeito do muscimol (200 pmol/100 nl) no VT $(18,5 \pm 0,6$, vs. muscimol: $15 \pm 1 \mathrm{ml} / \mathrm{kg}$, $p<0,05)$, na fR $(137 \pm 8$, vs. muscimol: $136 \pm 5$ respiração/min, $p<0,05)$, na Ve $(2527$ \pm 137 vs. muscimol: $1827 \pm 61 \mathrm{ml} / \mathrm{kg} / \mathrm{min}, \mathrm{p}<0,05)$ e na taquicardia $(427 \pm 21$, vs. muscimol: $380 \pm 9$ bpm, $p<0,05)$ produzida por hipóxia em ratos não anestesiados (Figs. 6C-F). 
Figura 6 - Efeitos cardiorrespiratórios produzidos pela estimulação dos quimiorreceptores periféricos em animais que receberam a injeção de bicuculina e muscimol na região do Kölliker-Fuse.

$A$

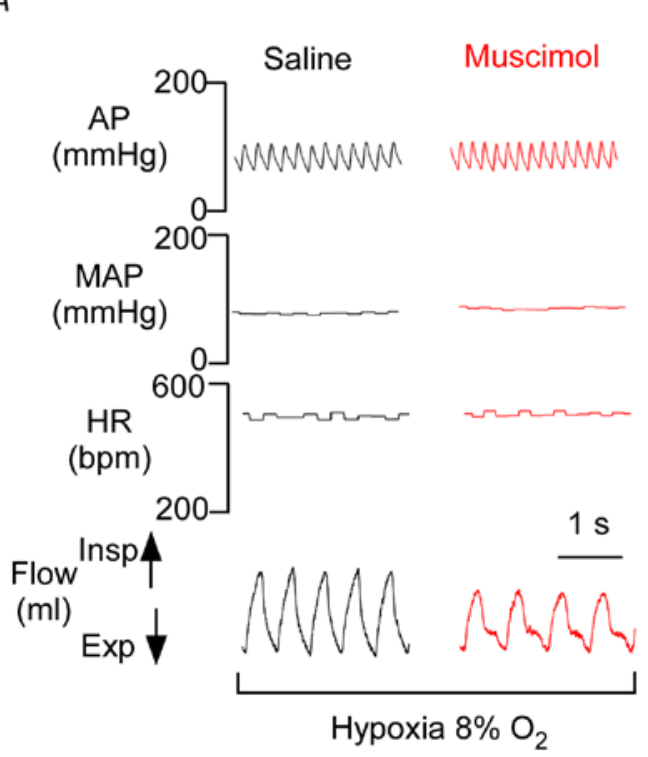

$\square$ Resting

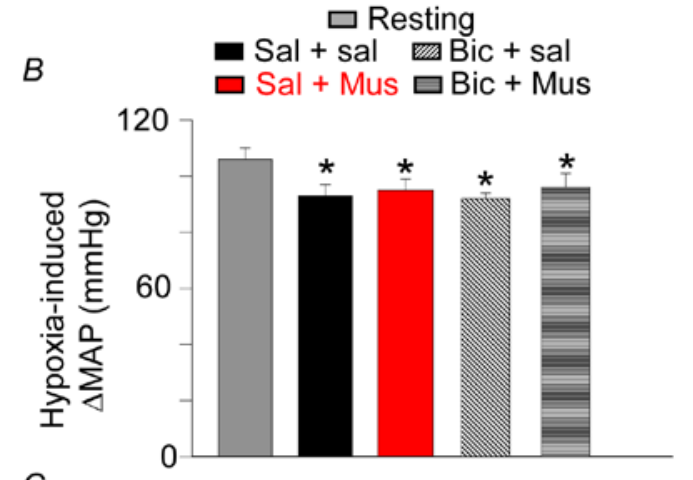

C

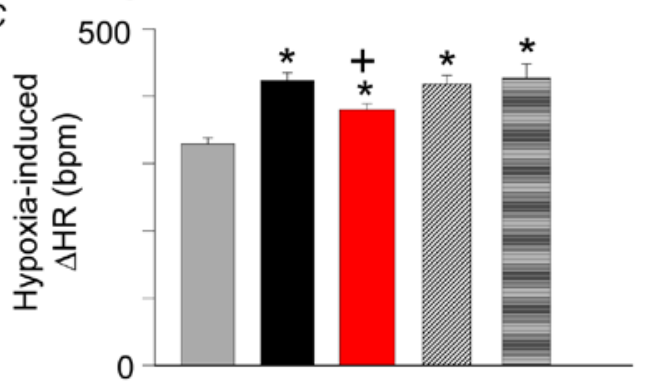

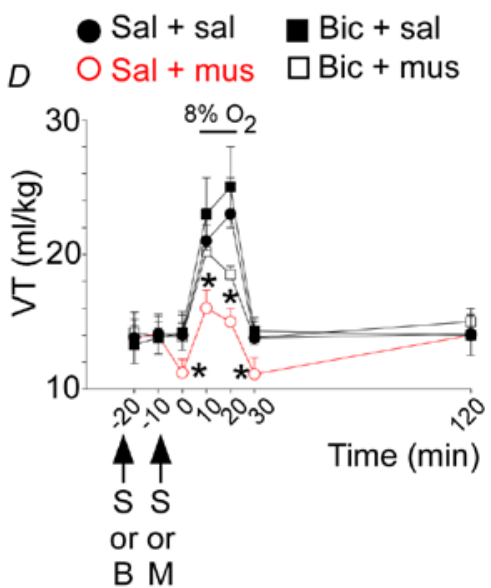
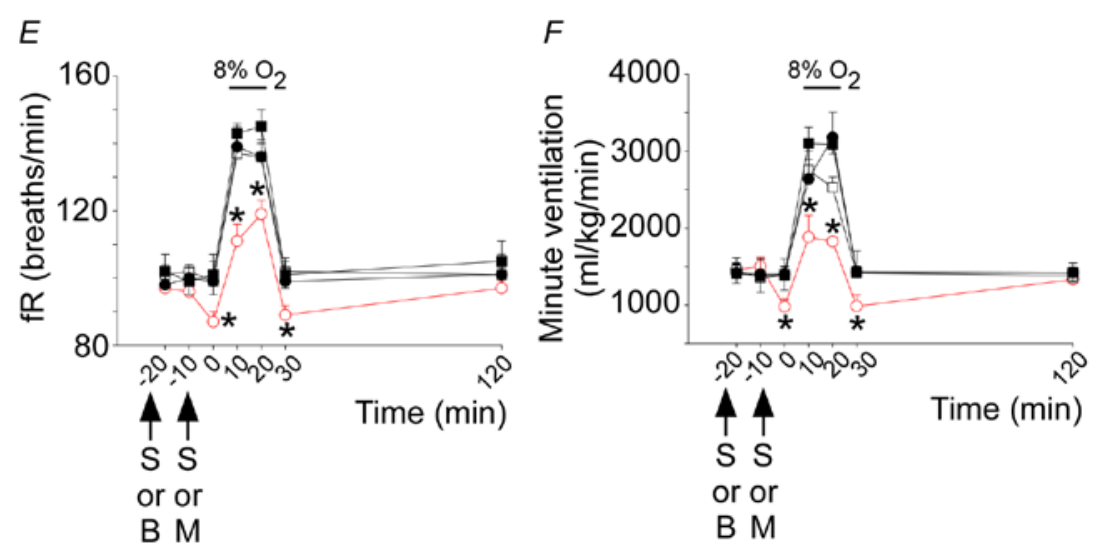

A) Registro típico de um animal representativo do grupo, mostrando pressão arterial (AP), pressão arterial média (MAP), freqüência cardíaca (HR) e fluxo de ar (inspiração deflexão para cima e expiração deflexão para baixo) após injeções bilaterais de salina ou muscimol (200 pmol/100 nl) na região Kölliker-Fuse (KF) durante a ativação dos quimiorreceptores periféricos (hipóxia: $8 \% \mathrm{O}_{2}$ ). Alterações na B) pressão arterial média, C) frequência cardíaca, D) volume corrente, E) frequência respiratória e $F$ ) volume minuto produzidos pela hipóxia em animais não anestesiados que receberam a injeção bilateral de salina ou bicuculina seguido de salina ou muscimol na região KF. *diferente do basal $(p<0,05)$; + diferente de salina; $\mathrm{n}=5-7 /$ grupo de ratos. 


\subsection{Efeitos cardiorrespiratórios produzidos pela estimulação dos quimiorreceptores centrais em animais que receberam a injeção de bicuculina e muscimol na região do Kölliker-Fuse}

Hipercapnia $\left(7 \% \mathrm{CO}_{2}\right.$, balanceado com $21 \% \mathrm{O}_{2}$ e $\left.\mathrm{N}_{2}\right)$ durante 10 minutos produziu aumento do VT ( $22 \pm 2$, vs. normóxia: $14 \pm 1,4 \mathrm{ml} / \mathrm{kg}, \mathrm{p}<0,05)$, da fR (136 \pm 13, vs. normóxia: $100 \pm 5$ respiração/min, $p<0,05)$ e da Ve $(3130 \pm 427$, vs. normóxia: $1408 \pm 274 \mathrm{ml} / \mathrm{kg} / \mathrm{min}, \mathrm{p}<0,05$ ) (Figs. 7A; 7D-F). Hipercapnia não promoveu alterações na PAM (103 \pm 2 , vs. normóxia: $106 \pm 4 \mathrm{mmHg}, \mathrm{p}>0,05)$ e FC basal (324 \pm 13 , vs. normóxia: $322 \pm 14$ bpm, p>0,05) (Figs. 7B e 7C).

A inibição bilateral de muscimol (200 pmol/100 nl) no KF foi capaz de reduzir o aumento do VT (11,4 $\pm 1,4$, vs. salina: $22 \pm 2 \mathrm{ml} / \mathrm{kg}, p<0,01)$, da fR (121 \pm 10 , vs. salina: $159 \pm 5$ respiração/min, $p<0,05)$ e da Ve $(1488 \pm 277$, vs. salina: $3539 \pm 374$ $\mathrm{ml} / \mathrm{kg} / \mathrm{min}, \mathrm{p}<0,05)$ produzidos pela hipercapnia em ratos não anestesiados (Figs. 7A, 7D-F).

A injeção bilateral de bicuculina ( $1 \mathrm{nmol} / 100 \mathrm{nl})$ foi capaz de reverter o efeito do muscimol (200 pmol/100 nl) no VT $(20 \pm 4$, vs. muscimol: $11,4 \pm 1,4 \mathrm{ml} / \mathrm{kg}$, p<0,05), na fR (148 \pm 5 , vs. muscimol: $121 \pm 10$ respiração/min, $p<0,05)$ e na Ve (2997 \pm 537 vs. muscimol: $1488 \pm 277 \mathrm{ml} / \mathrm{kg} / \mathrm{min}, \mathrm{p}<0,05)$ produzido por hipercapnia em ratos não anestesiados (Figs. 7D-F). 
Figura 7 - Efeitos cardiorrespiratórios produzidos pela estimulação dos quimiorreceptores centrais em animais que receberam a injeção de bicuculina e muscimol na região do Kölliker-Fuse.

$A$

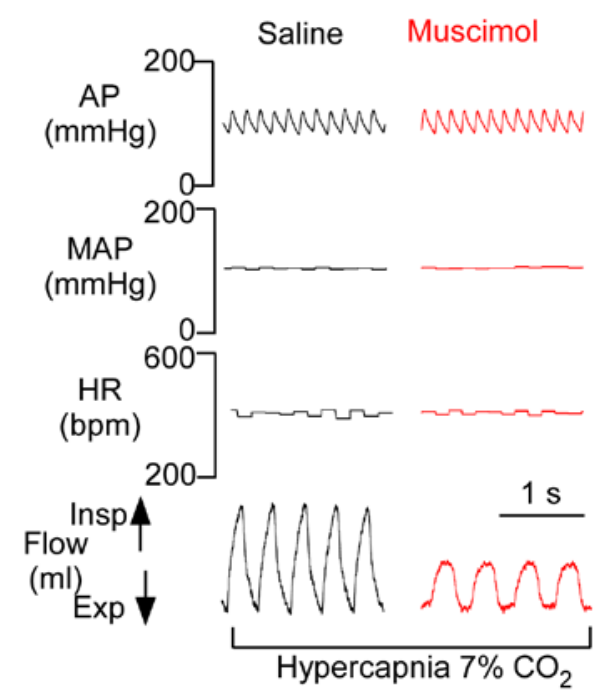

$\mathrm{Bic}+\mathrm{sal}$ $\square$ Bic + mus
$D$

- Sal + sal

O Sal + mus

E

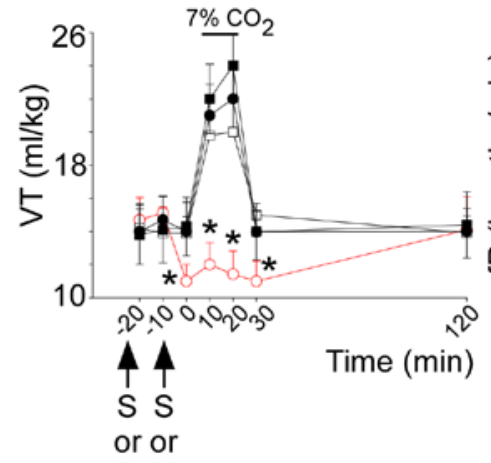

B M

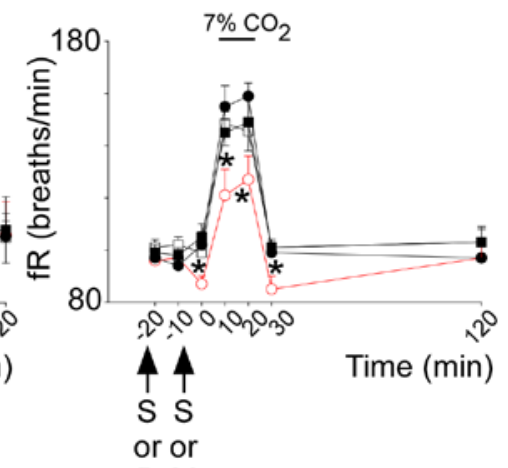

B M

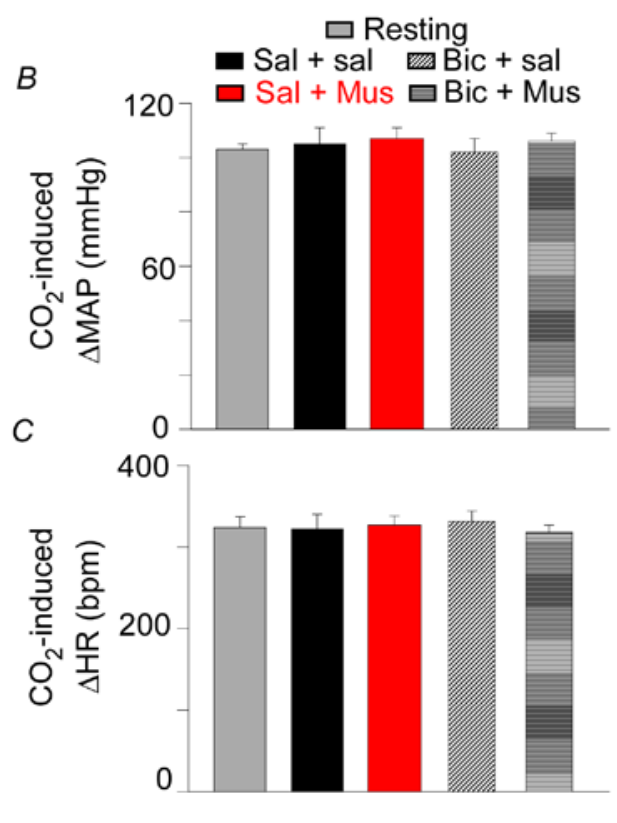

$F$

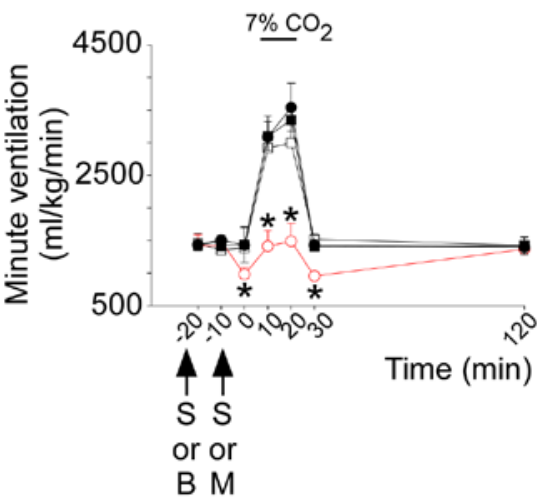

A) Registro típico de um animal representativo do grupo, mostrando pressão arterial (AP), pressão arterial média (MAP), freqüência cardíaca (HR) e fluxo de ar (inspiração deflexão para cima e expiração deflexão para baixo) após injeções bilaterais de salina ou muscimol (200 pmol/100 nl) na região Kölliker-Fuse (KF) durante a ativação dos quimiorreceptores centrais (hipercapnia: $7 \% \mathrm{CO}_{2}$ ). Alterações na B) pressão arterial média, C) frequência cardíaca, D) volume corrente, E) frequência respiratória e F) volume minuto produzidos pela hipercapia em animais não anestesiados que receberam a injeção bilateral de salina ou bicuculina seguido de salina ou muscimol na região KF. *diferente do basal $(p<0,05) ; n=5-7 / g r u p o$ de ratos. 


\subsection{Lesão seletiva dos neurônios noradrenérgicos da região A7 com a toxina saporina anti-D $\beta H-S A P$}

As figuras 8A-F representam fotomicrografias representativas de secções transversais de regiões pontinas. As figuras ilustram a imunorreatividade para neurônios noradrenérgicos $(T H)$, envolvendo as regiões noradrenérgicas (A-B), A5 (C-D) e A6 (E-F).

A toxina anti-DßH-SAP (injeção de $100 \mathrm{nl}$ contendo 2,1 ng de toxina) foi administrada bilateralmente na região $A 7$. Os neurônios imunorreativos para TH foram examinados na ponte dorsolateral e ventrolateral com o objetivo de avaliar o efeito da toxina sobre os neurônios positivos para TH. Os neurônios positivos para TH foram plotados e contados em onze secções coronais por rato e cada secção foi separada por $240 \mu \mathrm{m}$. Os neurônios positivos para TH estavam reduzidos na região A7 em ratos que tiveram a lesão com toxina anti-DBH-SAP (Figs. 8A-B e 8G), mas o número de neurônios imunorreativos para TH nas regiões $A 5$ e $A 6$ estavam intactos (Figs. 8C-F). A dose de 2,1 ng de toxina reduziu o número de neurônios positivos para $\mathrm{TH}$ contados nas onze secções em $90 \pm 5 \%$ (Figs. 8G). Para uma melhor avaliação da seletividade da toxina examinamos o efeito de 2,1 $\mathrm{ng}$ de anti-DBH-SAP em tipos específicos de neurônios localizados próximos da região A7. Baseado na imunorreatividade da colina-acetiltransferase (ChAT), a toxina não teve nenhum efeito sobre os neurônios motores do núcleo mesencefálico (dados não mostrados). 
Figura 8 - Identificação imunoistoquímica de neurônios catecolaminérgicos.

Saline
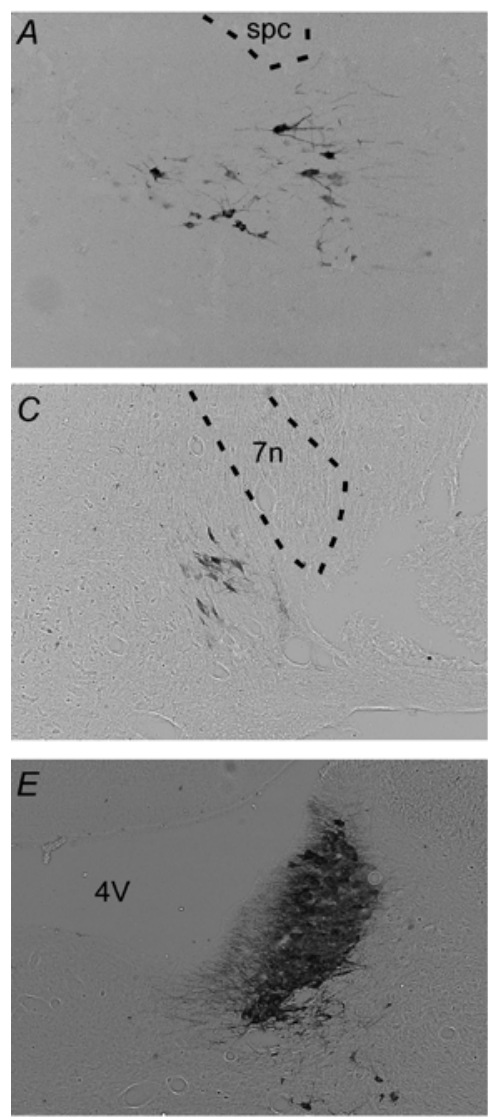

$G$

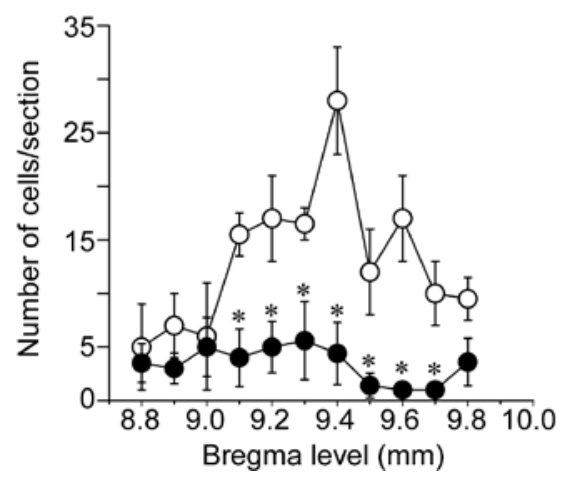

Anti-DBH-SAP
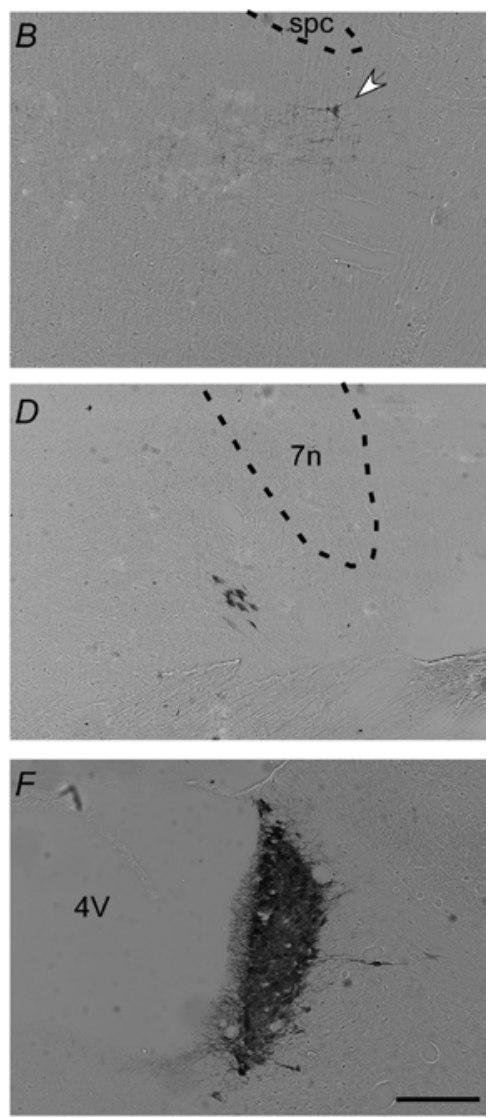

Fotomicrografia ilustrando a imunorreatividade para tirosina hidroxilase (TH) em animais controles (salina) (A, C, E) e animais que receberam a injeção bilateral da toxina saporina conjugada com anti$D \beta H-S A P$ na região $A 7(B, D, F)$. As figuras $A-B$ ilustram a região $A 7$. As figuras $C-D$ ilustram a região $A 5$ e as figuras E-F representam a região $A 6$. G) número de neurônios positivos para tirosina hidroxilase foi reduzido em ratos com a região $A 7$ lesada com anti-DBH-SAP. Abreviaturas: LSO, oliva lateral superior; $4 \mathrm{~V}$, quarto ventrículo; py, pirâmide, IO, oliva inferior; $7 \mathrm{n}$, raiz do nervo facial. A seta indica neurônios positivos para TH na região A7 que não foram depletados após anti DBH-SAP. * diferente de salina $(p<0,05)$. Escala em $F=50 \mu \mathrm{m}$. 


\subsection{Efeitos cardiorrespiratórios produzidos pela lesão do grupamento noradrenérgico A7 durante a hipóxia em animais não anestesiados}

No grupo de animais que receberam injeção de salina na área A7, a hipóxia ( $8 \% \mathrm{O}_{2}$, balanceado com $\mathrm{N}_{2}$ ) durante 10 minutos induziu hipotensão ( $99 \pm 5$, vs. normóxia: $115 \pm 2 \mathrm{mmHg}, \mathrm{p}<0,05)$, taquicardia ( $509 \pm 12$, vs. normóxia: $402 \pm 7 \mathrm{bpm}$, $p<0,05)$, aumento do VT $(17,4 \pm 2,4$ vs. normóxia: $11,6 \pm 1,4 \mathrm{ml} / \mathrm{kg}, \mathrm{p}<0,05)$, da fR (127 \pm 8 , vs. normóxia: $109 \pm 12$ respiração/min, $p<0,05)$ e da Ve $(2209 \pm 358$, vs. normóxia: $1205 \pm 90 \mathrm{ml} / \mathrm{kg} / \mathrm{min}, \mathrm{p}<0,05)$ (Figs. 9A-E).

A lesão dos neurônios noradrenérgicos da região $A 7$ não foi capaz de promover alterações na PAM, FC, VT, fR e Ve basais (dados não apresentados). No entanto, a lesão dos neurônios noradrenérgicos do grupamento $A 7$ com a toxina saporina conjugada com anti-DBH-SAP foi capaz de reduzir o aumento do VT (12,9 $\pm 0,7$, vs. salina: $17,4 \pm 2,4 \mathrm{ml} / \mathrm{kg}, \mathrm{p}<0,05)$, da Ve $(1675 \pm 175$, vs. salina: $2209 \pm 358$ $\mathrm{ml} / \mathrm{kg} / \mathrm{min}, \mathrm{p}<0,05)$ e a hipotensão $(112 \pm 3$, vs. salina: $99 \pm 5 \mathrm{mmHg}, p<0,05)$ produzidos pela hipóxia em ratos não anestesiados (Figs. 9C, 9E e 9A). A injeção de anti DBH-SAP não alterou a taquicardia $(471 \pm 18$, vs. salina: $509 \pm 12$ bpm, $p>0,05)$ e o aumento da $f R(128 \pm 8$, vs. salina: $127 \pm 8$ respiração/min, $p>0,05)$ produzida por hipóxia em ratos não anestesiados (Figs. 9B e 9D). 
Figura 9 - Efeitos cardiorrespiratórios produzidos pela lesão do grupamento noradrenérgico A7 durante a hipóxia em animais não anestesiados.
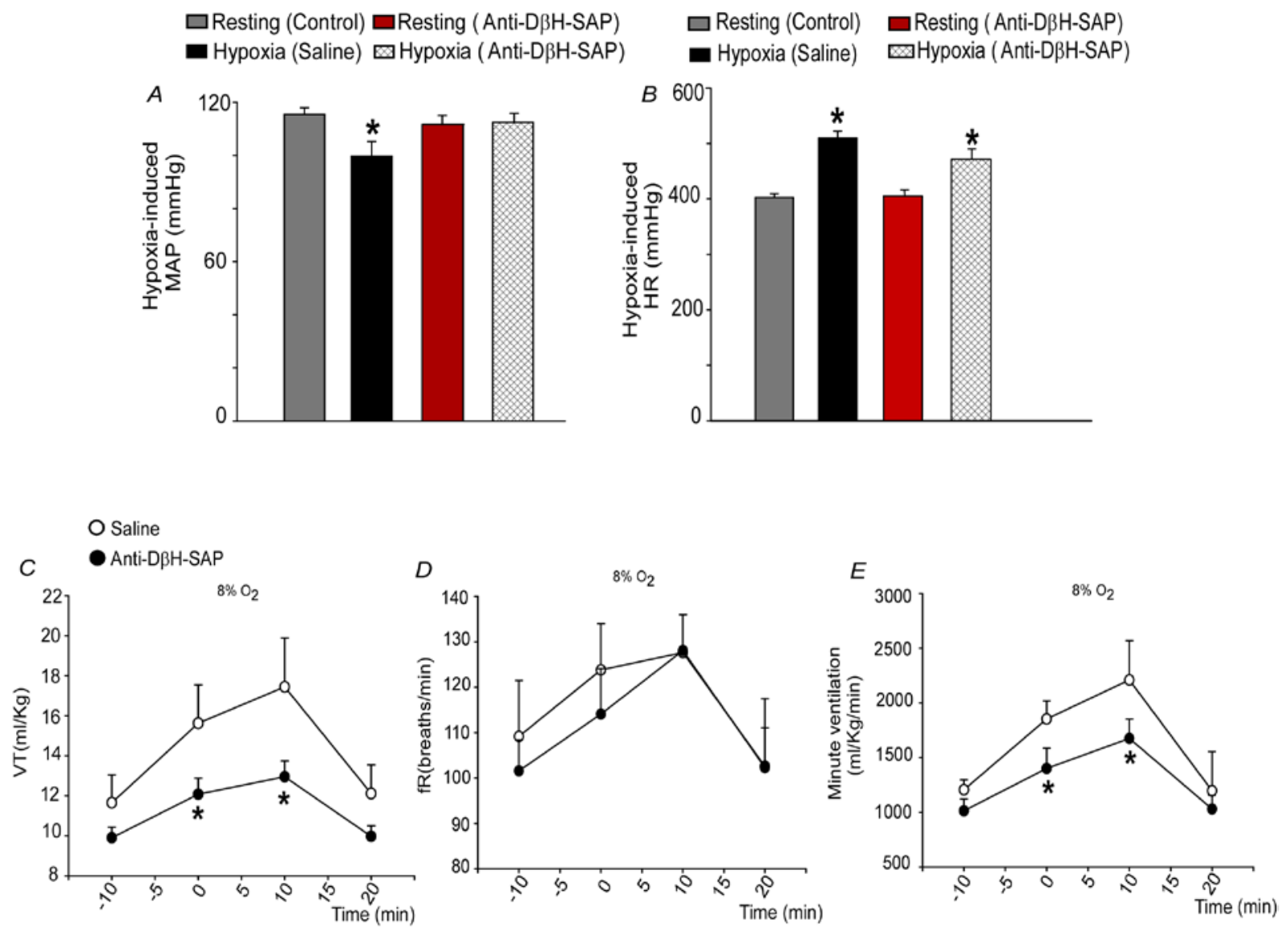

Alterações na A) pressão arterial média, B) frequência cardíaca, C) volume corrente, D) frequência respiratória e $\mathrm{E})$ volume minuto produzidos pela hipóxia $\left(8 \% \mathrm{O}_{2}\right.$, balanceado com $\left.\mathrm{N}_{2}\right)$ em animais não anestesiados que receberam a injeção bilateral de salina ou anti-DßH-SAP no grupamento noradrenérgico $A 7$, *diferente de salina $(p<0,05) ; n=6 /$ grupo de ratos. 


\subsection{Efeitos cardiorrespiratórios produzidos pela lesão do grupamento noradrenérgico A7 durante a hipercapnia em animais não anestesiados}

No grupo de animais que recebeu injeção de salina na área A7, a hipercapnia ( $7 \% \mathrm{CO}_{2}, 21 \% \mathrm{O}_{2}$, balanceado com $\mathrm{N}_{2}$ ) durante 10 minutos promoveu aumento do VT (17,4 $\pm 1,4$, vs. normóxia: $12 \pm 1,4 \mathrm{ml} / \mathrm{kg}, \mathrm{p}<0,05)$, da fR (136 \pm 8 , vs. normóxia: $102 \pm 14$ respiração/min, p<0,05) e da Ve $(2333 \pm 144$, vs. normóxia: $1196 \pm 145$ $\mathrm{ml} / \mathrm{kg} / \mathrm{min}, \mathrm{p}<0,05)$. Hipercapnia não promoveu alterações na PAM (113 \pm 4 , vs. normóxia: $111 \pm 3 \mathrm{mmHg}, \mathrm{p}>0,05)$ e $\mathrm{FC}$ basal $(393 \pm 12$, vs. normóxia: $410 \pm 14$ bpm, $p>0,05$ ) (Figs. 10A-E).

A lesão dos neurônios noradrenérgicos da região $A 7$ não foi capaz de promover alterações na PAM, FC, VT, fR e Ve basais (dados não apresentados). A lesão dos neurônios noradrenérgicos do grupamento $A 7$ com anti DBH-SAP foi capaz de reduzir o aumento do VT (12,7 \pm 1 , vs. salina: $17,4 \pm 1,4 \mathrm{ml} / \mathrm{kg}, p<0,05)$, e da Ve $(1513 \pm 167$ vs. salina: $2333 \pm 144 \mathrm{ml} / \mathrm{kg} / \mathrm{min}, p<0,05)$ produzidos pela hipercapnia em ratos não anestesiados (Figs. 10C-E). A injeção de anti D $\beta H$-SAP não alterou o aumento da fR promovida pela hipercapnia em ratos não anestesiados (Fig.10D). 
Figura 10 - Efeitos cardiorrespiratórios produzidos pela lesão do grupamento noradrenérgico A7 durante a hipercapnia em animais não anestesiados.
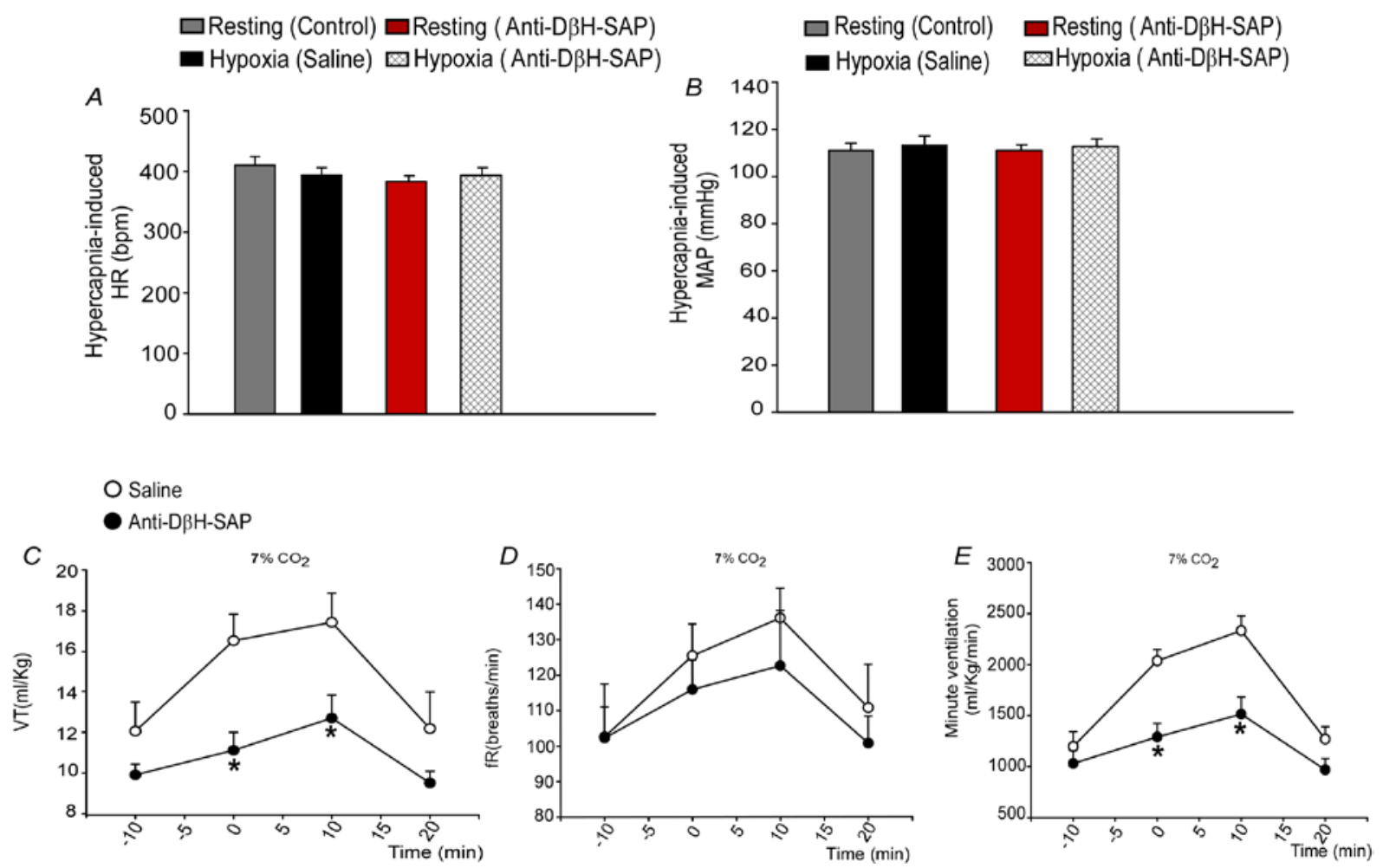

Alterações na A) pressão arterial média, B) frequência cardíaca, C) volume corrente, D) frequência respiratória e E) volume minuto produzidos pela hipercapnia $\left(7 \% \mathrm{CO}_{2}, 21 \% \mathrm{O}_{2}\right.$, balanceado com $\left.\mathrm{N}_{2}\right)$ em animais não anestesiados que receberam a injeção bilateral de salina ou anti-DBH-SAP no grupamento noradrenérgico $A 7$, *diferente de salina $(p<0,05) ; n=6 /$ grupo de ratos. 


\subsection{Análise histológica das injeções no núcleo parabraquial lateral}

A figura 11A mostra o local típico das injeções bilaterais no núcleo parabraquial lateral (NPBL). As injeções no NPBL foram localizadas na região dorsolateral da ponte e dorsais ao pedúnculo cerebelar superior. Na figura 9B está ilustrado um diagrama mostrando a localização das injeções no NPBL, mais especificamente na porção dorsomedial do NPBL, contituindo os subnúcleos central e lateral (seção coronal $=-9,3 \mathrm{~mm}$ caudal do Bregma de acordo com o Atlas de Paxinos e Watson). Escala $=1 \mathrm{~mm}$. 
Figura 11 - Injeção bilateral na região do núcleo parabraquial lateral.
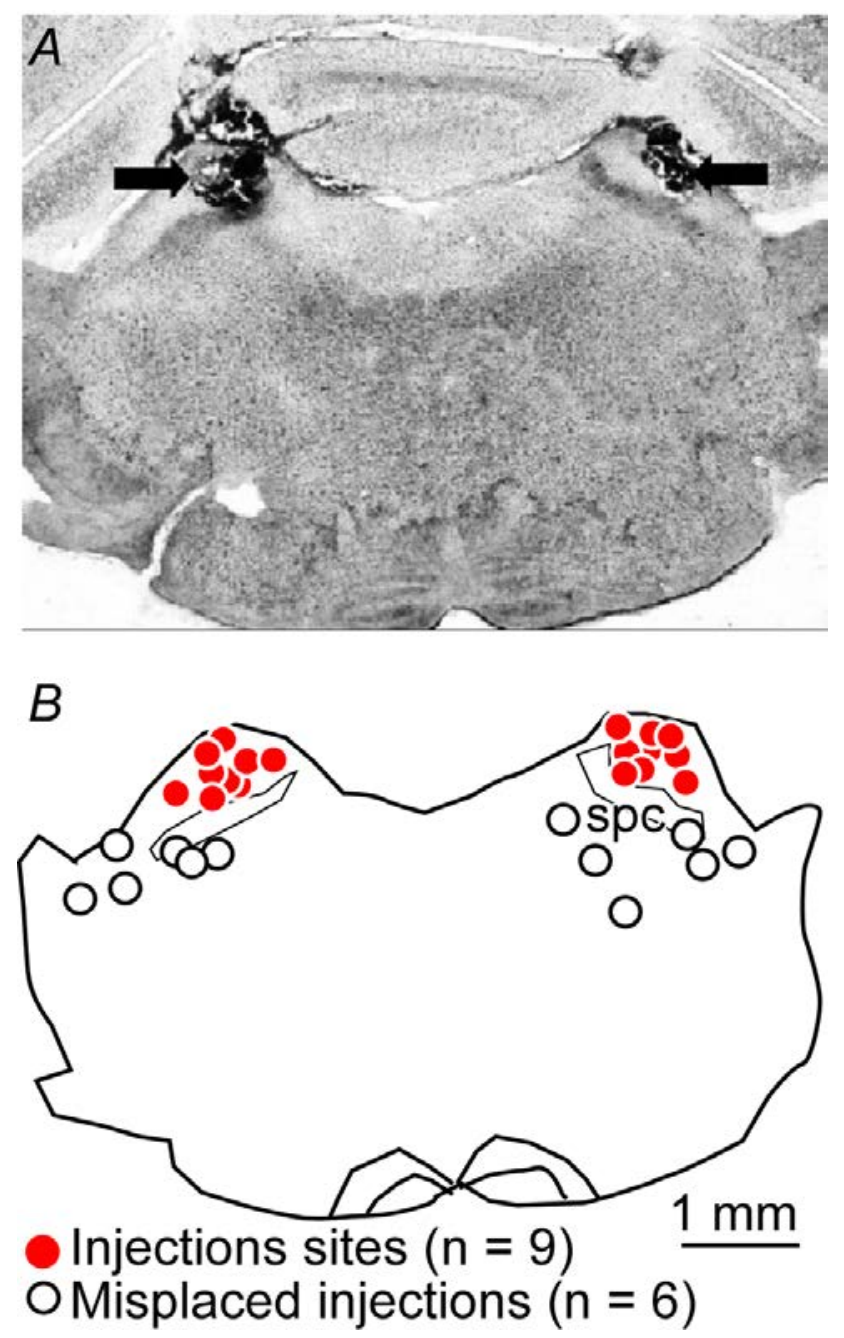

A) Fotomicrografia mostrando o local típico de uma injeção bilateral na região do núcleo parabraquial lateral (NPBL) (setas). B) Diagrama ilustrando as injeções bilaterais na região do NPBL $(n=9)$. Abreviações: spc, pedúnculo cerebelar superior. Escala $=1 \mathrm{~mm}$ 


\subsection{Efeitos cardiorrespiratórios promovidos pela inibição do núcleo parabraquial lateral em animais não anestesiados}

A injeção bilateral de muscimol (200 pmol/100 nl) no NPBL não alterou o VT $(14,4 \pm 1,6$, vs. salina: 13,8 $\pm 1,6 \mathrm{ml} / \mathrm{kg}, \mathrm{p}>0,05)$, a fR (99 \pm 6 , vs. salina: $102 \pm 4$ ciclo respiratório/min, $p>0,05)$ e a Ve $(1389 \pm 55$, vs. salina: $1399 \pm 32 \mathrm{ml} / \mathrm{kg} / \mathrm{min}$, $p>0,05)$ (Figs. 12A-C).

A inibição bilateral do NPBL também não alterou o Ti (253 \pm 6 , vs. salina: 255 $\pm 4 \mathrm{~ms}, \mathrm{p}>0,05)$ e o tempo de expiração Te (436 \pm 33 , vs. salina: $441 \pm 27 \mathrm{~ms}$, $p>0,05)$ (Figs. 12D e 12E). A injeção de muscimol também não alterou o pico do fluxo inspiratório $(5,8 \pm 0,6$, vs. salina: $5,3 \pm 0,3 \mathrm{ml} / \mathrm{s}, \mathrm{p}>0,05)$ e o pico do fluxo expiratório (8,5 \pm 0.7 , vs. salina: 8,9 $\pm 1 \mathrm{ml} / \mathrm{s}, \mathrm{p}>0,05)$ (Figs. 12F e 12G).

A injeção bilateral de muscimol no NPBL promoveu um aumento de PAM (119 \pm 2 , vs. salina: $104 \pm 2 \mathrm{mmHg}, \mathrm{p}<0,05)$, mas sem alteração na FC basal $(333 \pm 13$, vs. salina: $336 \pm 24 \mathrm{mmHg}, \mathrm{p}>0,05)$ (Figs. $12 \mathrm{H}$ e 12I). 
Figura 12 - Efeitos cardiorrespiratórios promovidos pela injeção bilateral de muscimol no núcleo parabraquial lateral.

A

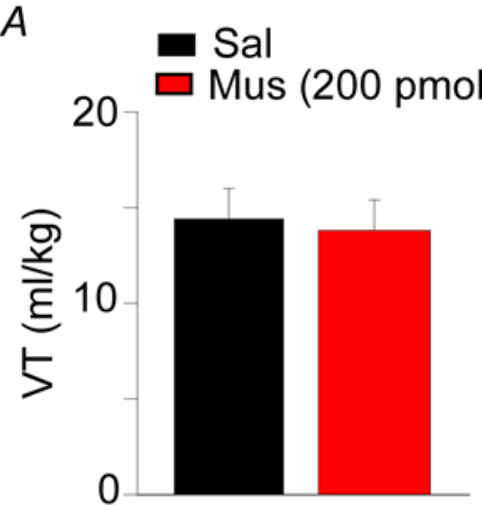

$D$

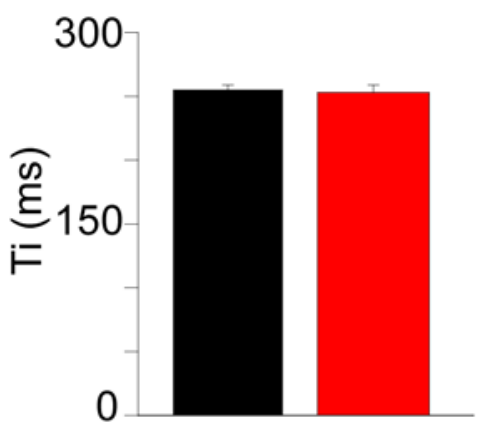

G

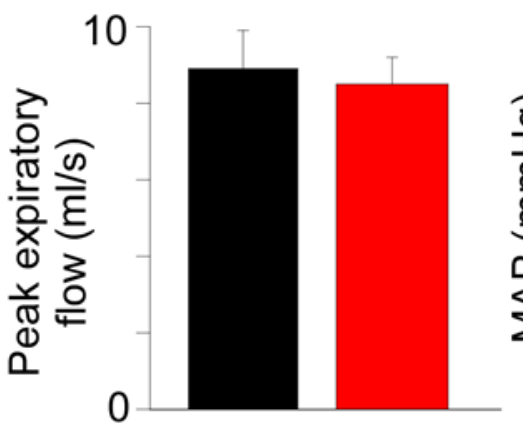

$B$

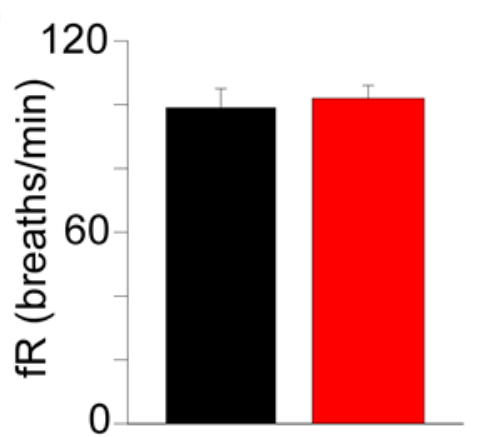

E

500
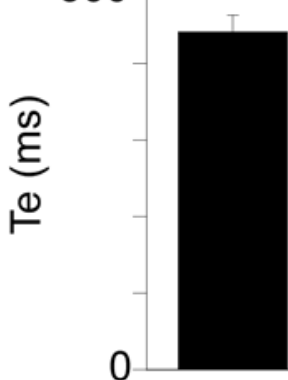

H

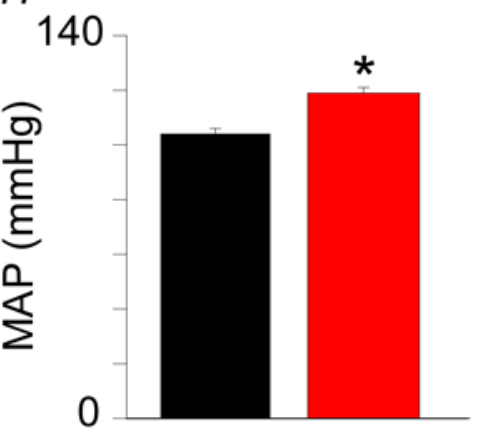

C

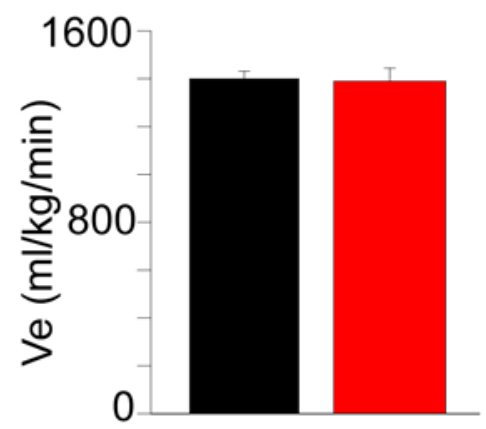

$F$

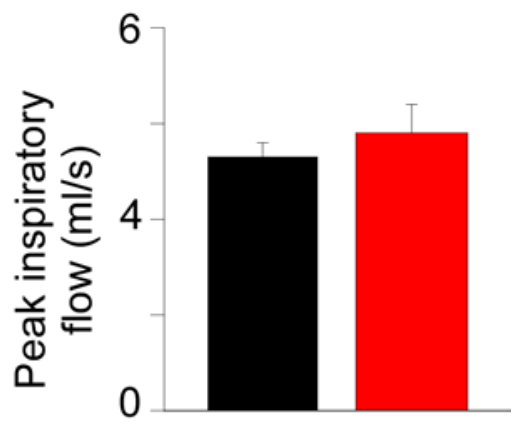

I

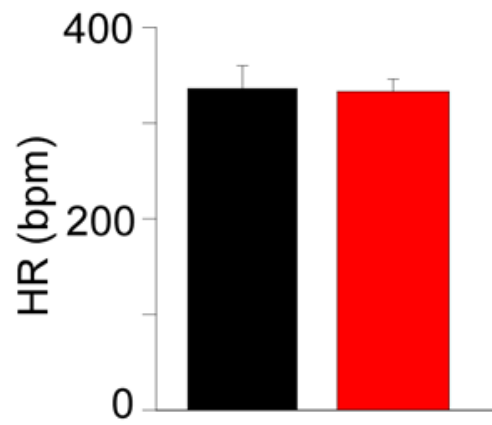

Alterações no A) volume corrente, B) frequência respiratória, C) ventilação minuto, D) tempo de inspiração, E) tempo expiratório, F) pico do fluxo inspiratório, G) pico do fluxo expiratório, H) pressão arterial média e l) freqüência cardíaca em animais não anestesiados que receberam a injeção bilateral de muscimol no NPBL. *diferente de salina $(p<0,05) . n=6-9 / g r u p o$ de ratos. 


\subsection{Efeitos cardiorrespiratórios produzidos pela estimulação dos quimiorreceptores periféricos após a inibição da região do núcleo parabraquial lateral}

Da mesma maneira que foi realizado em protocolos anteriores, hipóxia (8\% $\mathrm{O}_{2}$, balanceado com $\mathrm{N}_{2}$ ) durante 10 minutos produziu hipotensão (86 \pm 4 , vs. normóxia: $101 \pm 5 \mathrm{mmHg}, \mathrm{p}<0,05)$, taquicardia (418 \pm 15 , vs. normóxia: $331 \pm 16$ bpm, p<0,05), aumento do VT (23 $\pm 2,3$, vs. normóxia: 13,8 $\pm 1,3 \mathrm{ml} / \mathrm{kg}, \mathrm{p}<0,05)$, da fR $(149 \pm 3$, vs. normóxia: $102 \pm 5$ respiração/min, $p<0,05)$ e da Ve $(3012 \pm 44$, vs. normóxia: $1401 \pm 93 \mathrm{ml} / \mathrm{kg} / \mathrm{min}, \mathrm{p}<0,05$ ) (Figs 13A-E). A injeção bilateral de muscimol (200 pmol/100 nl) no NPBL não alterou a taquicardia (423 \pm 12 , vs. salina: $418 \pm 15$ bpm, p>0,05), o aumento do VT (21 $\pm 1,3$, vs. salina: $23 \pm 2,3 \mathrm{ml} / \mathrm{kg}$, $p>0,05), f R(141 \pm 5$, vs. salina: $149 \pm 3$ respiração/min, p>0,05) e da Ve $(2826 \pm 61$, vs. salina: $3012 \pm 44 \mathrm{ml} / \mathrm{kg} / \mathrm{min}, \mathrm{p}>0,05)$ produzida por hipóxia em ratos não anestesiados (Figs. 13B-E). A injeção bilateral de muscimol (200 pmol/100 nl) no NPBL foi capaz de reduzir a hipotensão (96 \pm 3 , vs. salina: $86 \pm 4 \mathrm{mmHg}, \mathrm{p}>0,05)$ produzida por hipóxia (Fig. 13A). 
Figura 13 - Efeitos cardiorrespiratórios produzidos pela estimulação dos quimiorreceptores periféricos em animais que receberam a injeção de muscimol no núcleo parabraquial lateral.
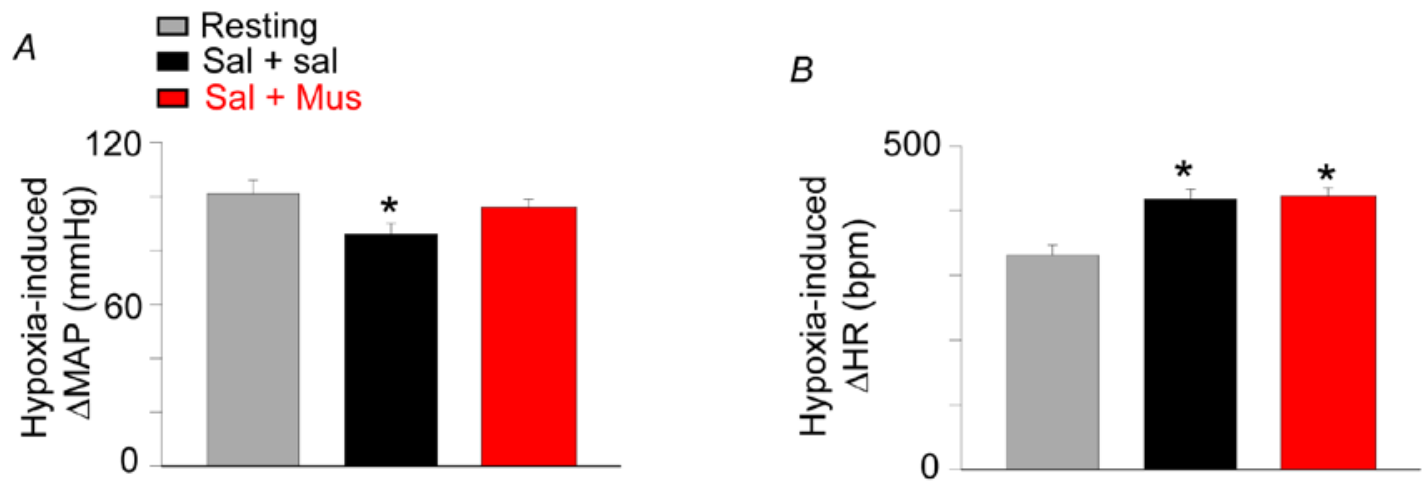

C

Sal + sal

$D$

E
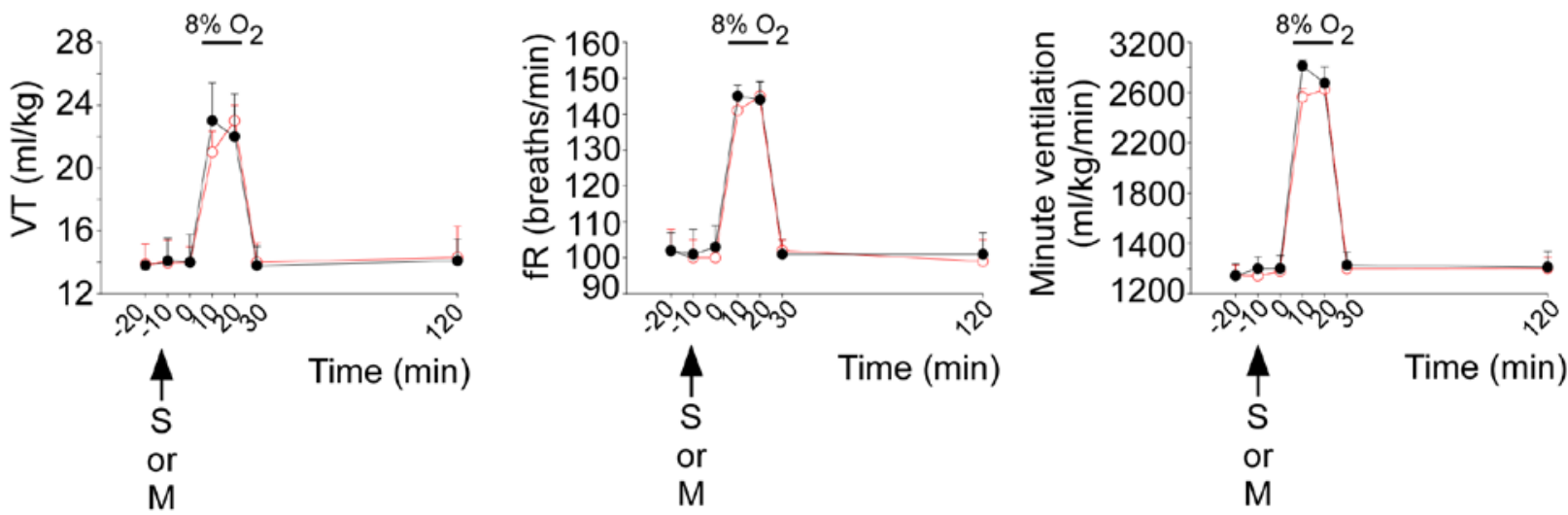

Alterações na A) pressão arterial média, B) frequência cardíaca, C) volume corrente, D) frequência respiratória e E) volume minuto produzidos pela hipóxia em animais não anestesiados que receberam a injeção bilateral de salina ou muscimol no NPBL. *diferente do basal $(p<0,05) . n=6-9 / g r u p o$ de ratos. 
5.10 Efeitos cardiorrespiratórios produzidos pela estimulação dos quimiorreceptores centrais após a inibição da região do núcleo parabraquial lateral

A exposição dos animais a um ambiente hipercápnico $\left(7 \% \mathrm{CO}_{2}, 21 \% \mathrm{O}_{2}\right.$, balanceado com $\mathrm{N}_{2}$ ) durante 10 minutos produziu aumento do VT (24 \pm 2 , vs. normóxia: 13,8 $\pm 1,3 \mathrm{ml} / \mathrm{kg}, \mathrm{p}<0,05)$, da fR $(136 \pm 4$, vs. normóxia: $102 \pm 4$ respiração/min, $p<0,05)$ e da Ve $(3088 \pm 88$, vs. normóxia: $1399 \pm 32 \mathrm{ml} / \mathrm{kg} / \mathrm{min}$, p<0,05), sem alterações na PAM (104 \pm 5, vs. normóxia: $103 \pm 4$ mmHg, p>0,05) e FC basal (329 \pm 9, vs. normóxia: $328 \pm 7$ bpm, p>0,05) (Figs. 14A-E).

A injeção bilateral de muscimol (200 pmol/100 nl) no NPBL não alterou o aumento do VT (23 \pm 1 , vs. salina: $24 \pm 2 \mathrm{ml} / \mathrm{kg}, \mathrm{p}>0,05)$, fR (134 \pm 9 , vs. salina: 136 \pm 4 respiração/min, $p>0,05)$ e da Ve $(3124 \pm 78$, vs. salina: $3088 \pm 88 \mathrm{ml} / \mathrm{kg} / \mathrm{min}$, p>0,05) produzida por hipercapnia em ratos não anestesiados (Figs. 14C-E). A injeção de muscimol no NPBL também não promoveu alterações na PAM (103 \pm 3 , vs. salina: $101 \pm 2 \mathrm{mmHg}, \mathrm{p}>0,05)$ e FC (332 \pm 16 , vs. salina: $237 \pm 11$ bpm, p>0,05) em resposta a uma situação de hipercapnia (Figs. 14A e 14B). 
Figura 14 - Efeitos cardiorrespiratórios produzidos pela estimulação dos quimiorreceptores centrais em animais que receberam a injeção de muscimol na região do núcleo parabraquial lateral.

$A$

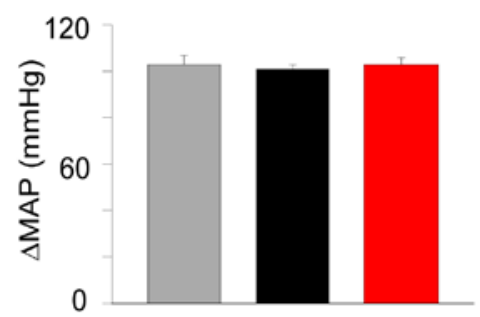

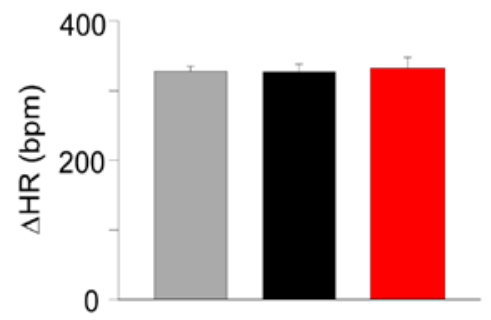
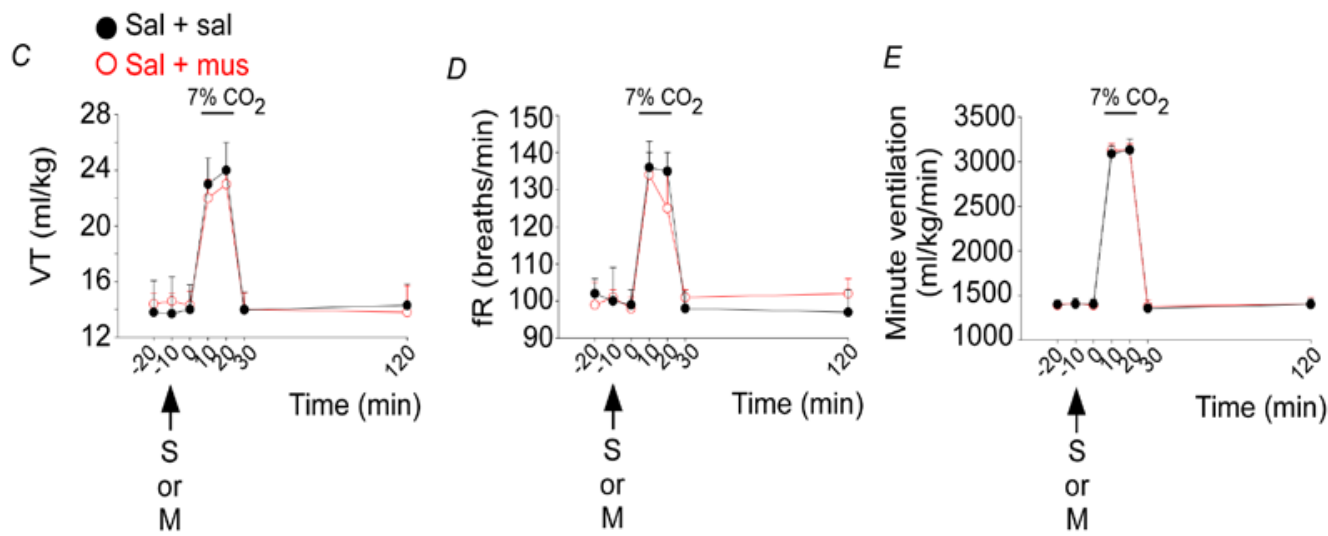

Alterações na A) pressão arterial média, B) frequência cardíaca, C) volume corrente, D) frequência respiratória e E) volume minuto produzidos pela hipercapnia em animais não anestesiados que receberam a injeção bilateral de salina ou muscimol no NPBL. $n=6-9 / g r u p o$ de ratos. 


\subsection{Respostas respiratórias e da atividade simpática à ativação do quimiorreflexo periférico após injeção bilateral de muscimol na região Kölliker-Fuse}

A injeção bilateral de muscimol (200 pmol - $50 \mathrm{~nL})$ na região do KF em 7 ratos vagotomizados anestesiados com uretano e com os nervos do seio carotídeo intactos não alterou a PAM basal (115 $\pm 9 \mathrm{mmHg}$, vs. salina: $117 \pm 4 \mathrm{mmHg}, \mathrm{p}>0,05)$ e sSNA (98 $\pm 4 \%$ do controle, $p>0,05)$ (Fig. 15A). No entanto, a inibição da região do KF foi capaz de promover um aumento da amplitude $(129 \pm 6 \%$ do controle, $p<0,05)$ e uma redução da frequência $(59 \pm 3 \%$ do controle, $p<0,01)$ do nervo frênico (Fig. 15A). As alterações observadas na atividade do nervo frênico foram devido a um aumento no Ti $(0,61 \pm 0,07 \mathrm{~s}$, vs. saline $0,43 \pm 0,02 \mathrm{~s}, \mathrm{p}<0,01)$ e no Te $(1,37 \pm 0,08$ s, vs. saline: $0,93 \pm 0,05 \mathrm{~s}, \mathrm{p}<0,05)$.

A injeção bilateral de muscimol na região do KF atenuou o aumento da PAM ( $\Delta=14 \pm 3 \mathrm{mmHg}$, vs salina: $\Delta=23 \pm 3 \mathrm{mmHg}, \mathrm{p}<0,05)$ produzido por injeção endovenosa de $\mathrm{KCN}$ (40 $\mu \mathrm{g} / 0,1 \mathrm{ml}$ ) (Figs. 15A e 15B). Injeções de muscimol na região do KF reduziram o aumento da sSNA $(\Delta=127 \pm 11 \%$, vs salina: $\Delta=184 \pm$ $18 \%, \mathrm{p}<0,05)$ da amplitude $(\Delta=+85 \pm 7 \%$ vs. salina: $\Delta=+103 \pm 7 \%, \mathrm{p}<0,05)$ e frequência ( $\Delta=+84 \pm 4 \%$ vs. salina: $\Delta=+123 \pm 6 \%, p<0,05$ ) do nervo frênico produzida pela ativação do quimiorreflexo periférico (Figs 15A-E). 
Figura 15 - Efeitos na pressão arterial, atividade simpática e respiratória produzidos pela estimulação dos quimiorreceptores periféricos em animais que receberam a injeção de muscimol na região do Kölliker-Fuse.

A

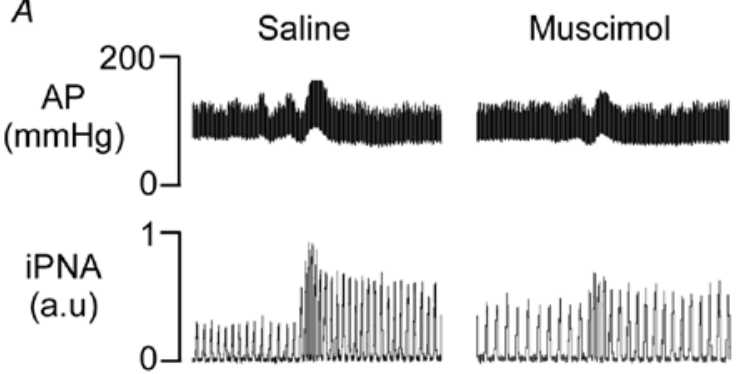

SNA

(mV)

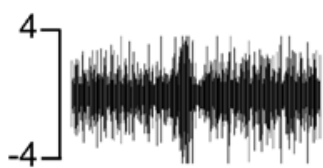

4

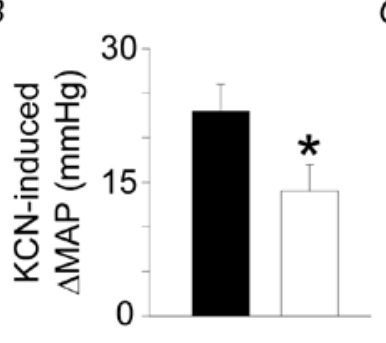

$D$

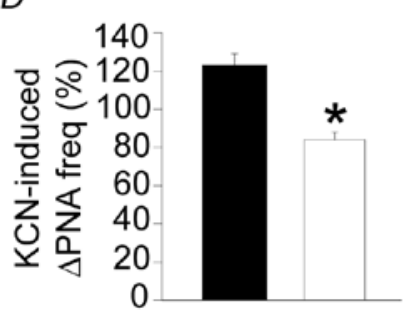

C

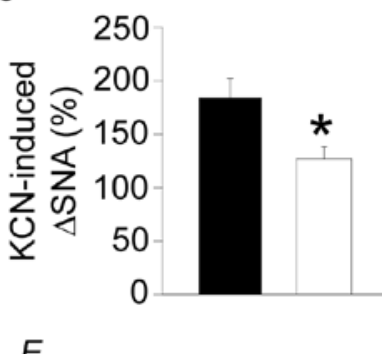

E

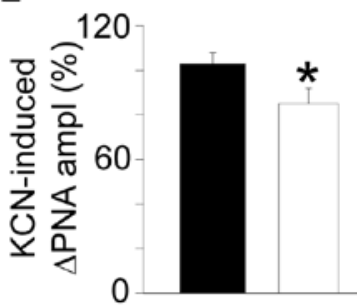

A) Registro típico de um animal representativo do grupo, mostrando pressão arterial (AP), atividade elétrica do nervo frênico (iPNA) e atividade elétrica do nervo esplâncnico (SNA) após injeções bilaterais de salina ou muscimol (200 pmol/50 nl) na região Kölliker-Fuse (KF) durante a ativação dos quimiorreceptores periféricos (injeção endovenosa de $\mathrm{KCN}$ - $40 \mu \mathrm{g} / 0,1 \mathrm{ml}$ ). Alterações na B) pressão arterial média (PAM), C) atividade simpática (SNA), D) frequência respiratória (PNA freq) e amplitude respiratória (PNA amp) produzidos pela hipóxia em animais anestesiados que receberam a injeção bilateral de salina ou muscimol na região KF. *diferente de salina; $n=7 /$ grupo de ratos. 


\subsection{Respostas respiratórias e da atividade simpática à ativação do quimiorreflexo central após injeção bilateral de muscimol na região Kölliker-Fuse}

Os experimentos foram realizados para investigar se a inibição bilateral da região KF é capaz de suprimir o efeito estimulador da ativação de quimiorreceptores centrais na atividade simpática e do nervo frênico.

As injeções bilaterais de muscimol (200 pmol - $50 \mathrm{~nL}$ ) na região do $\mathrm{KF}$ foram feitas em 8 ratos completamente desnervados. A injeção de muscimol não produziu nenhum efeito sobre a PAM (118 $\pm 6 \mathrm{mmHg}$, vs. saline: $121 \pm 4 \mathrm{mmHg}, \mathrm{p}>0,05)$ e a sSNA (99 $\pm 11 \%$ do controle, $p>0,05)$ basal, mas foi capaz de promover um aumento da amplitude (126 $\pm 9 \%$ do controle, $p<0,05)$ e uma redução da frequência ( $62 \pm 6 \%$ do controle, $p<0,01$ ) do nervo frênico (Fig. 16A). As alterações observadas na atividade do nervo frênico foram devido a um aumento no Ti $(0,71 \pm 0,07 \mathrm{~s}$, vs. salina $0,54 \pm 0,04 \mathrm{~s}, \mathrm{p}<0,05)$ e no Te $(1,42 \pm 0,08 \mathrm{~s}$, vs. salina: $1,12 \pm 0,05 \mathrm{~s}, \mathrm{p}<0,05)$.

A injeção bilateral de muscimol na região do KF atenuou o aumento da PAM ( $\Delta$ $=18 \pm 6 \mathrm{mmHg}$, vs. salina: $\Delta=30 \pm 5 \mathrm{mmHg}, \mathrm{p}<0,05)$, sSNA ( $\Delta=63 \pm 5 \%$, vs salina: $\Delta=88 \pm 9 \%, p<0,05)$, frequência ( $\Delta=78 \pm 11 \%$ vs. salina: $\Delta=104 \pm 3 \%, p<0,01)$ e amplitude do nervo frênico ( $\Delta=72 \pm 4 \%$ vs. salina: $\Delta=98 \pm 2 \%$, $p<0,05)$ produzido pela hipercapnia (Figs. 16A-E). A injeção de muscimol não teve nenhum efeito sobre a hipotensão inicial produzido por hipercapnia (Figs. 16A). A recuperação completa dos efeitos de muscimol ocorreu dentro de 120 min (dados não mostrados). 
Figura 16 - Efeitos na pressão arterial, atividade simpática e respiratória produzidos pela estimulação dos quimiorreceptores centrais em animais que receberam a injeção de muscimol na região do Kölliker-Fuse.

$A$

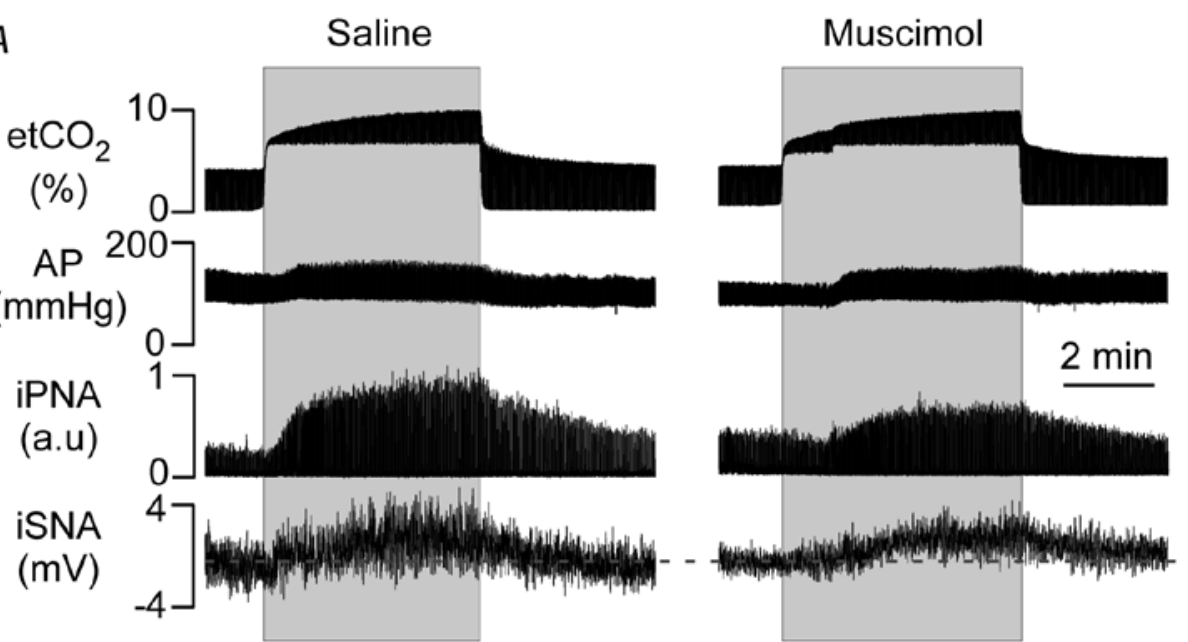

$B$

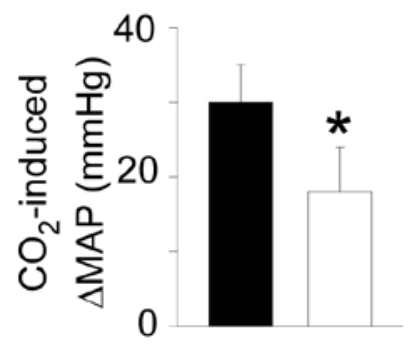

C

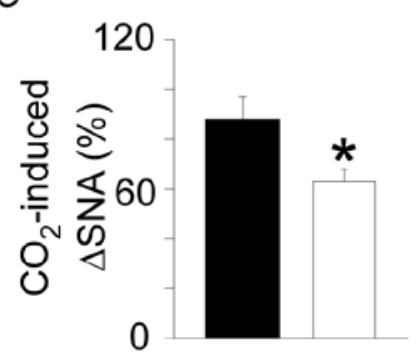

$D$

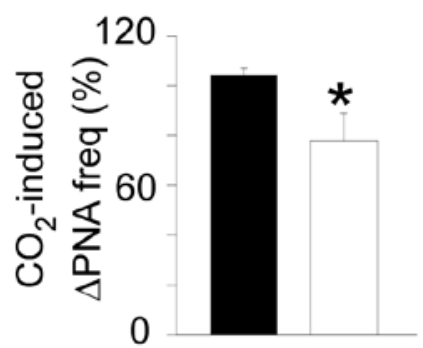

E

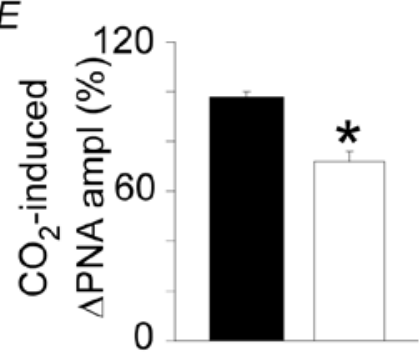

A) Registro típico de um animal representativo do grupo, mostrando CO2 expirado (etCO2), pressão arterial (AP), atividade elétrica do nervo frênico (iPNA) e atividade elétrica do nervo esplâncnico (SNA) após injeções bilaterais de salina ou muscimol $(200$ pmol/50 nl) na região Kölliker-Fuse (KF) durante a ativação dos quimiorreceptores centrais (aumento dos níveis de $\mathrm{CO}_{2}$ de $3-4 \%$ para $10 \%$ ). Alterações na $B$ ) pressão arterial média (PAM), C) atividade simpática (SNA), D) frequência respiratória (PNA freq) e amplitude respiratória (PNA amp) produzidos pela hipercapnia em animais anestesiados que receberam a injeção bilateral de salina ou muscimol na região KF. *diferente de salina; $\mathrm{n}=8 /$ grupo de ratos. 


\section{DISCUSSÃO}

Os resultados obtidos no presente estudo mostram que a inibição inespecífica dos neurônios localizados na região do KF, produziu alterações significantes na ventilação devido a reduções do volume corrente e da freqüência respiratória. A inibição do KF também promoveu um aumento considerável do tempo de expiração, sugerindo uma possível redução da atividade dos neurônios pós-inspiratórios, que seriam os responsáveis pela transição da inspiração para a expiração (FELDMAN; DEL NEGRO, 2006). A injeção bilateral de muscimol ou a lesão seletiva dos neurônios noradrenérgicos no KF foi capaz de reduzir o aumento da ventilação promovida pela estimulação dos quimiorreceptores centrais e periféricos mediante a uma redução principalmente do volume corrente . Vale ressaltar que a redução do volume corrente foi muito mais intensa do que a redução da frequência respiratória. Observamos também que a injeção bilateral do antagonista de receptores GABAérgicos do sub-tipo A na região do KF foi capaz de reverter os efeitos inibitórios na atividade respiratória promovida pela injeção de muscimol, sugerindo o envolvimento dos receptores GABA-A nessas respostas mediadas por estruturas pontinas.

Os nossos dados mostraram também que a inibição bilateral de outra estrutura pontina dorsolateral, o núcleo parabraquial lateral (NPBL), não foi eficaz em promover alterações significantes nos parâmetros respiratórios basais e durante a ativação dos quimiorreceptores centrais e periféricos em animais não anestesiados.

Em outro modelo experimental, os nossos experimentos também mostraram que a inibição da região do KF foi capaz de promover uma atenuação no aumento da atividade simpática do nervo esplâncnico e do nervo frênico provocado pela ativação do quimiorreflexo central e periférico em ratos anestesiados.

\subsection{Envolvimento da região do Kölliker-Fuse na manutenção do padrão respiratório eupnéico}

Várias são as evidências experimentais de que os núcleos pontinos apresentam uma importante contribuição na organização da respiração normal, também chamada de eupneica. Secções bilaterais do nervo vago combinada com 
transecções encefálicas, localizadas caudais aos colículos encefálicos, produziam consideradas alterações respiratórias incluindo o prolongamento do tempo de inspiração caracterizando um padrão respiratório chamado de padrão apnêustico (MARKWALD, 1887).

Os núcleos da ponte constituem uma extensão rostral e lateral da coluna respiratória ventral bulbar e estão envolvidos em diferentes modulações na atividade respiratória (DUTSCHMANN; DICK, 2012; SMITH et al., 2007). Dependendo da localização pontina, facilitações ou inibições respiratórias podem ser observadas mediante manipulações em núcleos específicos. Tais respostas incluem taquipnéia, bradipnéia, apnêuse e apnéia (ALHEID; MILSOM; MCCRIMMON, 2004; CHAMBERLIN, 2004). Um estudo recente da literatura relatou que lesões eletrolíticas bilaterais no KF foram capazes de promover apnéia, e não apnêuse, em ratos anestesiados e vagotomizados (SONG; TIN; POON, 2010). Esses resultados mostraram claramente que dependendo da região da ponte dorsolateral afetada podemos obter resultados diferentes e contraditórios. Nossos resultados demonstraram que a injeção bilateral com muscimol no KF promoveu uma alteração no padrão respiratório caracterizado por uma redução do volume corrente e da freqüência respiratória basal, promovendo uma redução marcante do volume minuto. Ademais, a inibição da região do KF promoveu uma redução do fluxo inspiratório e expiratório e um prolongamento do tempo de expiração, sugerindo uma possível inibição dos neurônios pós-inspiratórios dessa região. O mesmo padrão de resposta também foi observado em animais anestesiados. Nesses experimentos observamos que a inibição bilateral com muscimol na região do KF foi capaz de alterar o padrão respiratório analisando-se a atividade elétrica do nervo frênico. Em outras palavras, a inibição da região do KF foi capaz de promover uma redução da frequência respiratória e um aumento da amplitude da respiração.

Sabe-se que a ponte desempenha uma contribuição relevante na fase de transição entre inspiração e expiração (COHEN; FELDMAN, 1977; FELDMAN; GAUTIER, 1976), no entanto, ainda são necessários estudos para comprovar essa hipótese. De acordo com nossos resultados, o KF parece ser um excelente candidato para contribuir na modulação do padrão respiratório em animais não anestesiados. Sabe-se também que o complexo parabraquial, que inclui o NPBL, está envolvido no controle respiratório, cardiovascular, regulação do equilíbrio hidroeletrolítico e no processamento dos estímulos nociceptivos (BRUINSTROOP et 
al., 2012; CALLERA et al., 2005; CHAMBERLIN, 2004). No entanto, os nossos experimentos mostraram que após inibições bilaterais do NPBL o padrão respiratório não foi alterado. Esse dado reforça ainda mais a nossa hipótese da participação do KF na modulação do padrão respiratório, isto é, na manutenção da fase de transição entre a inspiração e a expiração. Ademais, os nossos dados separaram regiões específicas da ponte dorsolateral no controle respiratório, pois a maioria dos estudos da literatura procura englobar o NPBL e o KF como uma única estrutura envolvida no controle respiratório.

Manipulações farmacológicas no complexo parabraquial e na região KF são capazes de alterar a fase de transição entre a inspiração e a expiração em animais vagotomizados e anestesiados. Um exemplo disso é que o bloqueio de receptores glutamatérgicos do sub-tipo NMDA foi capaz de reduzir a fase de transição entre inspiração e expiração (BIANCHI; DENAVIT-SAUBIE; CHAMPAGNAT, 1995; BONHAM, 1995; ST-JOHN, 1998), promovendo um padrão respiratório apnêustico similar àquele encontrado em lesões pontinas (BORDAY et al., 1998; CONNELLY; OTTO-SMITH; FELDMAN, 1992; DUTSCHMANN et al., 2004; HARRIS; MILSOM, 2003). No entanto, é impossível determinar com clareza quais as vias ascendentes e descendentes entre a ponte e o bulbo que estariam sendo interrompidas durante esse bloqueio. Uma possível hipótese é que o bloqueio de receptores NMDA interromperia a transmissão ascendente glutamatérgica dos núcleos respiratórios bulbares para a ponte, em particular para a região KF (DUTSCHMANN et al., 2009; SONG; POON, 2004; WANG; FUNG; ST JOHN, 1993). Fica difícil a comparação entre esses experimentos descritos acima e os presentes resultados, pois devemos considerar que 1) os nossos experimentos foram realizados em animais não anestesiados e que a anestesia pode certamente influenciar os diversos padrões respiratórios, prejudicando uma interpretação correta dos resultados; 2) os nossos experimentos mostraram claramente a participação do KF e não do NPBL no controle da atividade respiratória basal e 3) deve-se considerar que o volume das injeções utilizadas no presente estudo foi de $100 \mathrm{nl}$, ao passo que a maioria dos experimentos envolvendo áreas pontinas dorsolaterais utilizam-se de volumes muito maiores, por volta de 200 nl. Certamente a utilização de um volume maior promove uma maior difusão de substâncias no sistema nervoso central, o que acarreta na perda de controle histológico de quais áreas estariam sendo ativadas. Deve-se lembrar de que a região do KF está muito próxima dos núcleos do complexo 
parabraquial. A região do KF está localizada $400 \mu \mathrm{m}$ mais rostral e $100 \mu \mathrm{m}$ lateral ao complexo parabraquial. Essa proximidade entre as regiões faz com que muitos autores classifiquem a região do KF como parte integrante do complexo parabraquial (FULWILER; SAPER, 1984; HERBERT; MOGA; SAPER, 1990). No entanto, vale ressaltar que inibições bilaterais do KF foram capazes de alterar os parâmetros respiratórios basais, ao passo que inibições do NPBL não promoveram nenhuma alteração respiratória.

As catecolaminas são classificadas como importantes neurotransmissores/neuromoduladores no SNC e periférico (ZANELLA et al., 2014). A norepinefrina e a epinefrina não somente modulam a emoção e a excitabilidade neuronal, mas também regulam a função respiratória e cardiovascular (GUYENET et al., 1993; LI; NATTIE, 2006; ZANELLA et al., 2014). A região do KF contém um importante grupamento noradrenérgico pontino (região A7). No presente estudo, a lesão seletiva dos neurônios da região $A 7$ com a toxina saporina conjugada com anti-dopamina $\beta$ hidroxilase (anti-D $\beta H-S A P)$ não foi capaz de promover alterações significantes nos parâmetros respiratórios basais. A lesão do grupamento A7 foi eficaz em reduzir o aumento do volume corrente e da ventilação promovido pela ativação dos quimiorreceptores periféricos e centrais.

A técnica do uso da toxina saporina conjugada com anti-dopamina $\beta$ hidroxilase está bem descrito na literatura (ABDALA; SCHOORLEMMER; COLOMBARI, 2006; NATTIE; LI, 2002; PERRY; HODGES; GRAY, 2001; TAXINI et al., 2011; WANG et al., 2001). Essa imunotoxina consiste em um anticorpo conjugado com a dopamina $\beta$-hidroxilase, enzima que converte a dopamina em noradrenalina. A enzima $D \beta H$ está associada à membrana interna das vesículas, e, portanto, é exposta extracelularmente durante o processo de exocitose na liberação do neurotransmissor. Esta exposição permite que a porção do anticorpo da imunotoxina se ligue a $\mathrm{D} \beta \mathrm{H}$. Após a reciclagem vesicular por endocitose, a anti-D $\beta \mathrm{H}-$ SAP é levada para dentro do neurônio. Uma vez dentro do neurônio, a saporina inativa a subunidade 60 s dos ribossomos, desta forma bloqueando a síntese celular, e causando morte celular (STIRPE; BARBIERI, 1986). Os neurônios não estão mais funcionais após 3-4 dias e fisicamente eliminados em aproximadamente 12 dias após a injeção da toxina (PERRY; HODGES; GRAY, 2001; WANG et al., 2001). É importante salientar que a injeção apenas da saporina (IgG-SAP) no SNC não promove nenhuma destruição neuronal (BLESSING; LAPPI; WILEY, 1998; MADDEN 
et al., 1999). No entanto, um recente estudo mostrou que apenas a injeção de IgGSAP foi capaz de eliminar as células gliais (astrócitos), mantendo intacto os neurônios (LIN et al., 2013). Não avaliamos a presença de astrócitos na região da ponte dorsolateral e, portanto, futuros estudos são necessários para avaliar a contribuição dos astrócitos no controle da atividade dos neurônios da região da ponte dorsolateral durante a quimiorrecepção.

A extensão da lesão pela anti-DßH-SAP foi estimada analisando-se a quantidade de imunorreatividade dos receptores catecolaminérgicos (TH) em toda a extensão da região pontina através da técnica de imunoistoquímica. Nossos dados estão de acordo com estudos anteriores, dos quais injeções de anti-DßH-SAP no $4^{\circ}$ ventrículo de ratos promoveu uma redução de $73 \%$ dos neurônios do grupamento A7 e uma redução da ventilação durante a hipercapnia (LI; NATTIE, 2006).

\subsection{Participação da região do Kölliker-Fuse no quimiorreflexo central e periférico}

A literatura apresenta poucos relatos que tentam elucidar o papel do grupamento pontino no quimiorreflexo periférico e central em animais não anestesiados. Por outro lado, experimentos realizados em animais anestesiados mostraram que lesões de toda a região pontina dorsolateral foram capazes de aumentar o tempo inspiratório, o tempo expiratório e o volume corrente numa situação basal e após uma situação de hipercapnia (GAUTIER; BERTRAND, 1975). Estudos com lesões químicas, restrita ao complexo parabraquial e região KF, mostraram que não houve alteração da ventilação em ar ambiente. No entanto, houve uma redução do aumento da ventilação após a estimulação hipercápnica ou hipóxica devido a uma diminuição do aumento da freqüência respiratória e do volume corrente (MIZUSAWA et al., 1995). Em nossos experimentos, a inibição bilateral do KF promoveu uma redução do aumento ventilatório mediante a uma redução, em especial, do aumento do volume corrente. Observamos também alterações na taquipnéia promovida pela estimulação dos quimiorreceptores periféricos (hipóxia) ou quimiorreceptores centrais (hipercapnia) após a inibição bilateral do KF em animais não anestesiados, mas essa redução foi de menor magnitude,comparando-se com as alterações no volume corrente. 
A exposição dos animais a um ambiente hipóxico $\left(8 \% \mathrm{O}_{2}\right)$ ou hipercápnico $\left(7 \% \mathrm{CO}_{2}\right)$ promove respostas cardiorrespiratórias e comportamentais, envolvendo diversas áreas encefálicas (FAVERO et al., 2011; MILLER et al., 2012). A queda da $\mathrm{PaO}_{2}$ arterial leva a uma ativação dos corpúsculos carotídeos que mandam informações para a primeira estação sináptica do sistema nervoso central na região dorsal do bulbo chamada de núcleo do trato solitário (NTS). A partir do NTS, uma constelação de projeções atinge diversas regiões envolvidas no controle respiratório como o núcleo retrotrapezóide (NRT), o complexo de pré-Bötzinger (CPB) e os neurônios pré-motores da coluna respiratória ventrolateral rostral (CRVLr). Durante uma hipercapnia, neurônios com características de quimiorreceptores centrais detectam as alterações nos níveis de $\mathrm{CO}_{2} / \mathrm{pH}$ e promovem a ativação de diversas áreas encefálicas envolvidas no controle respiratório como o CPB e a CRVLr. Além das regiões clássicas bulbares ativadas por uma hipóxia ou hipercapnia, existem também regiões pontinas e prosencefálicas que são ativadas durante o quimiorreflexo como o núcleo paraventricular do hipotálamo, lócus coeruleus (região A6), região pontina ventrolateral A5 e o complexo parabraquial/KF (MILLER et al., 2012).

Evidências neuroanatômicas suportam a nossa hipótese de que o KF está envolvido na ativação do quimiorreflexo central e periférico (SONG et al., 2011; TEPPEMA et al., 1997). Um estudo da literatura mostrou que ao utilizar o marcador de atividade neuronal, a proteína Fos, e um traçador retrógrado (cólera toxina B CTB), os neurônios ativados por hipóxia no NTS também se projetam para a região KF (SONG et al., 2011). Ademais, um outro estudo mostrou que neurônios localizados no KF projetam-se monossinapticamente para o NRT (LI; SONG, 2001; ROSIN; CHANG; GUYENET, 2006). A literatura ilustra também várias evidências de que o controle da freqüência respiratória é normalmente exercido por regiões localizadas no bulbo ventrolateral, enquanto que o controle do volume respiratório é exercido pelas regiões pontinas.(FELDMAN; DEL NEGRO, 2013; DUTSCHMANN; HERBERT, 2006; DUTSCHMANN; DICK, 2012. Dessa maneira, durante uma hipóxia ou hipercapnia, os neurônios responsáveis pela geração do ritmo respiratório estão intactos e procuram manter o mínimo de funcionalidade a fim de evitar uma possível parada respiratória. Por outro lado, as regiões envolvidas no controle de volume, mais especificamente o KF, mas não o NPBL, estão inibidas após o 
bloqueio bilateral, levando a uma redução das respostas de aumento da ventilação após a estimulação dos quimiorreceptores periféricos e centrais.

Foi curioso também observar que após uma hipóxia observamos hipotensão e taquicardia, diferentemente do que a literatura mostra que a ativação do quimiorreflexo periférico promove um aumento de atividade simpática e parassimpática, levando a um aumento da pressão arterial e redução da frequência cardíaca (FAVERO et al., 2011). No nosso protocolo experimental, a hipóxia foi por um período prolongado (10 minutos), fazendo com que promovesse uma resposta hipotensora, taquicárdica e uma hipotermia (BOCHORISHVILI et al., 2012; SCARPELLINI et al., 2009; TAN et al., 2010). Essas respostas são clássicas de uma situação não fisiológica, levando a uma redução do metabolismo do animal a fim de manter um mínimo de energia necessária para a sobrevivência. A injeção de muscimol no KF não foi capaz de bloquear a hipotensão promovida pela hipóxia em animais não anestesiados. Aparentemente, a região do KF não estaria envolvida nas respostas vasodilatadoras promovidas pela hipóxia. Diante disso, os nossos resultados em animais acordados, sugerem que a região KF não estaria participando no controle das vias neurais de controle da pressão arterial durante a estimulação do quimiorreflexo periférico. Ademais, a região KF parece apresentar um papel modulatório nas respostas de controle da frequência cardíaca, uma vez que a inibição do KF reduziu a taquicardia promovida pela hipóxia. Existem evidências de que o KF possui conexões com o núcleo ambíguo e com o núcleo motor dorsal do vago (SONG et al., 2012; TAN et al., 2010) regiões importantes no controle da atividade cardíaca.

Como já discutido anteriormente, o KF apresenta uma hodologia neural complexa, envolvendo conexões recíprocas com o NTS, a região ventrolateral do bulbo, a região pontina A5 e o núcleo paraventricular do hipotálamo. Essas regiões estão amplamente envolvidas no controle cardiovascular durante a ativação do quimiorreflexo periférico (GUYENET, 2006; TAXINI et al., 2011). Mais recentemente, um trabalho da literatura mostrou que os neurônios da região do KF não estariam sendo ativados em situações de alterações sustentadas de pressão arterial e frequência cardíaca (MILLER et al., 2012). Por outro lado, esse trabalho mostrou que o complexo parabraquial, mais precisamente a porção lateral externa constitui o principal grupamento pontino ativado mediante alterações sustentadas de pressão arterial e frequência cardíaca (MILLER et al., 2012). Esse trabalho está em total 
acordo com os resultados obtidos no presente estudo, haja vista que a inibição da região do KF não foi capaz de promover alterações na pressão arterial. Por outro lado, injeções de muscimol no NPBL promoveram alterações significantes de pressão arterial basal.

Os nossos resultados também mostraram que a inibição do NPBL foi capaz de reduzir a hipotensão promovida por hipóxia, possivelmente por um mecanismo de retirada de vias inibitórias do NPBL, uma vez que a inibição do NPBL completamente aboliu a hipotensão. Interessante notar que a inibição do NPBL não alterou a resposta taquicárdica promovida pela hipóxia. No entanto, mais experimentos precisam ser realizados para tentar elucidar melhor o papel dessas estruturas pontinas no controle cardiovascular.

\subsection{Participação da região do Kölliker-Fuse e do núcleo parabraquial lateral no controle cardiovascular}

Os nossos resultados mostraram que a inibição bilateral da região KF não alterou a PAM e FC basais em ratos não anestesiados, sugerindo que a região KF não participa do controle tônico das variáveis cardiovasculares estudadas no presente estudo. Por outro lado, injeções de muscimol no NPBL foi capaz de aumentar discretamente a PAM (aproximadamente $15 \mathrm{mmHg}$ ) sem alterar a FC. Respostas pressoras já foram descritas após injeções de glutamato, de metisergida (antagonista serotonérgico) ou do agonista GABAérgico muscimol no NPBL de ratos não anestesiados (CALLERA et al., 2005; CHAMBERLIN; SAPER, 1992; DAWID MILNER; LARA; LOPEZ DE MIGUEL; et al., 2003; MENANI; THUNHORST; JOHNSON, 1996). No caso dos efeitos pressores da metisergida e do muscimol no NPBL, a sugestão é que eles seriam devidos a uma retirada da inibição proveniente de barorreceptores ou receptores de volume (HAYWARD; FELDER, 1998; LARA et al., 1994; LEN; CHAN; CHAN, 2000). Esses sinais inibitórios dos barorreceptores ou de receptores de volume seriam os mesmos que inibiriam a ingestão de água e de sódio e, portanto, haveria coerência entre os efeitos cardiovasculares e na ingestão de água e sódio produzidos por esses tratamentos no NPBL. Conexões recíprocas do NPBL com diferentes áreas encefálicas, como núcleos hipotalâmicos, NTS, área A5, área rostroventrolateral do bulbo ajudam a explicar seu envolvimento com o controle cardiovascular (FULWILER; SAPER, 1984; GRANATA; KITAI, 1989; 
GUYENET; YOUNG, 1987; JHAMANDAS; HARRIS, 1992; LOEWY; WALLACH; MCKELLAR, 1981; MIURA; REIS, 1969; SHAPIRO; MISELIS, 1985). Trabalhos neuronatômicos também mostraram que neurônios do NPBL projetam-se para a área rostroventrolateral do bulbo, a qual possui um papel crucial no controle cardiovascular por ser a principal área no SNC de onde originam-se os neurônios pré-motores simpáticos que promovem a inervação do coração e vasos (KUBO et al., 1998; MIURA; TAKAYAMA; OKADA, 1991). O complexo parabraquial também está conectado à área A5 (SAPER; LOEWY, 1980), a qual possui neurônios catecolaminérgicos que enviam projeções para os neurônios pré-ganglionares da coluna intermediolateral (BYRUM; STORNETTA; GUYENET, 1984; LOEWY; MCKELLAR; SAPER, 1979; STRACK et al., 1989). Sabe-se que a área A5 modula as respostas cardiovasculares geradas pela ativação do complexo parabraquial em ratos anestesiados, pois injeções de muscimol na área A5 diminuem a resposta pressora e o aumento do ritmo respiratório causado pela estimulação elétrica ou por glutamato no NPBL (DAWID MILNER; LARA; LÓPEZ DE MIGUEL; et al., 2003).

\subsection{Participação da região do Kölliker-Fuse no controle da atividade simpática e no controle respiratório durante a ativação dos quimiorreceptores centrais e periféricos em animais anestesiados}

Os nossos resultados em animais anestesiados adicionam um novo entendimento na participação dos neurônios do KF no controle da atividade simpática e respiratória durante a ativação dos quimiorreceptores centrais e periféricos. Observamos que a inibição não seletiva (injeção bilateral de muscimol) dos neurônios do KF atenuou o aumento da atividade simpática, da PAM e da atividade respiratória produzido pela ativação do quimiorreflexo central. Como a inibição dos neurônios da região KF reduziu a simpatoexcitação induzida pela hipercapnia, esperávamos ter uma hipotensão mais intensa produzida pela hipercapnia. No entanto, a hipotensão não foi modificada pela inibição da região KF. Talvez uma razão para a manutenção da hipotensão é o fato de os neurônios do KF não estarem envolvidos na vasodilatação induzida por $\mathrm{CO}_{2}$ e estudos futuros são necessários para compreender as alterações vasculares induzidas pelo $\mathrm{CO}_{2}$.

A redução da resposta simpatoexcitatória, promovida pela ativação dos quimiorreceptores centrais, após a inibição da região do KF, sugere que os efeitos 
cardiovasculares e simpáticos causados pelo quimiorreflexo central são apenas parcialmente mediados pela região KF em animais anestesiados. Esses efeitos são diferentes dos efeitos observados em animais não anestesiados (Figs. 7,10 e 16).

Observamos também uma redução da atividade do nervo frênico (amplitude e frequência) durante a estimulação dos quimiorreceptores centrais após a inibição bilateral da região do KF. As alterações respiratórias observadas em animais anestesiados e não anestesiados foram similares (Figs. 7,10 e 16). Após a inibição do $\mathrm{KF}$, a resposta respiratória foi reduzida em aproximadamente 30\%. É possível que a anestesia não exerça um efeito muito marcante nos neurônios localizados na região do $\mathrm{KF}$, diferentemente de áreas localizadas no bulbo (ACCORSI-MENDONÇA et al., 2007; MACHADO; BONAGAMBA, 1992). Evidências preliminares do nosso laboratório mostraram que a $\mathrm{Pa}_{\mathrm{cO} 2}$ de animais anestesiados e não anestesiados expostos de 7 a $10 \%$ de $\mathrm{CO}_{2}$, sofreu as mesmas variações ao redor de 61 a 78 mmHg (MOREIRA e TAKAKURA, dados ainda não publicados). Uma possível explicação para a redução da simpatoexcitação e da atividade respiratória promovida pela hipercapnia, após a inibição da região KF, seria a redução da excitabilidade de neurônios após a remoção de sinais facilitatórios da região KF e não a redução de sinais para estes neurônios.

A resposta pressora e simpatoexcitatória produzida pela ativação do quimiorreflexo periférico foi atenuada pela inibição da região KF com muscimol, corroborando estudos prévios (KOSHIYA; GUYENET, 1994), os nossos dados em animais não anestesiados e resultados do laboratório que mostraram que a inibição da ponte ventrolateral também atenuou os efeitos simpáticos e pressores da ativação do quimiorreflexo periférico (TAXINI et al., 2011). Outro estudo mostrou que, além do NTS, os neurônios localizados na região do KF, projetam-se para a região do RVL e são ativados pelos quimiorreceptores periféricos (SONG et al., 2011). Esse resultado mostra que a região pontina do KF faz parte do circuito neural de ativação dos quimiorreceptores periféricos. É possível que os neurônios do KF sejam ativados pelo estímulo hipóxico ao invés de uma ativação secundária promovida pelo aumento da pressão arterial, pois trabalhos na literatura mostraram que poucos neurônios na região do KF são ativados após um aumento da pressão arterial (HIROOKA et al., 1997).

Sabe-se que os neurônios da região do KF estão envolvidos no controle da atividade respiratória (FELDMAN; DEL NEGRO; GRAY, 2013; SONG et al., 2011) e 
que esses neurônios projetam-se para toda a coluna respiratória bulbar. Diante disso, é bem plausível que esses neurônios estejam envolvidos no controle da atividade respiratória durante a ativação do quimiorreflexo periférico. Os nossos dados em animais anestesiados apenas confirmam os nossos achados em animais não anestesiados. O fato dos neurônios do KF fazerem parte do circuito neuroanatômico de ativação autônoma e respiratória, durante a estimulação dos quimiorreceptores, sugere uma participação dessa estrutura bulbar na vias de despertar, características do estresse (ABBOTT et al., 2013; MARTELLI; STANIĆ; DUTSCHMANN, 2013).

\subsection{Possível interpretação da ativação do quimiorreflexo e a participação de estruturas pontinas}

A percepção da necessidade de respirar pode ser experimentalmente detectada realizando-se um protocolo de hipóxia e/ou hipercapnia. Portanto, os quimiorreceptores centrais e periféricos podem estar envolvidos nas respostas de alerta, promovendo a ativação de mecanismos respiratórios, simpáticos e comportamentais. A percepção de falta de ar, levando a ativação de vias de alerta, está associado com a ativação do sistema límbico, no entanto, conexões com estuturas pontinas já foram descritas como sendo um ponto de integração entre estuturas bulbares e prosencefálicas (MARTELLI; STANIĆ; DUTSCHMANN, 2013). Neurônios localizados na região do KF são ativados durante a estimulação dos quimiorreceptores centrais e periféricos e a inibição do KF reduz respostas autônomas e respiratórias (HIROOKA et al., 1997; MIZUSAWA et al., 1995). Adicionalmente, os neurônios do KF projetam-se para regiões de controle autônomo e respiratório, bem como recebem aferências polissinápticas do corpúsculo carotídeo, de neurônios da lâmina 1 da medula espinal e dos qumiorrecptores centrais localizados no RTN (KUBIN et al., 2006; SONG et al., 2011). Além disso, sabe-se que os neurônios do KF projetam-se também para o prosencéfalo, incluindo estruturas hipotalâmicas, amígdala e substância cinzenta periaquedutal (FULWILER; SAPER, 1984). Todas essas conexões podem certamente serem parte da via neural durante a ativação dos quimiorreceptores centrais e periféricos (Fig. 17). 
Figura 17 - Contribuição da região do Kölliker-Fuse no controle respiratório e autônomo

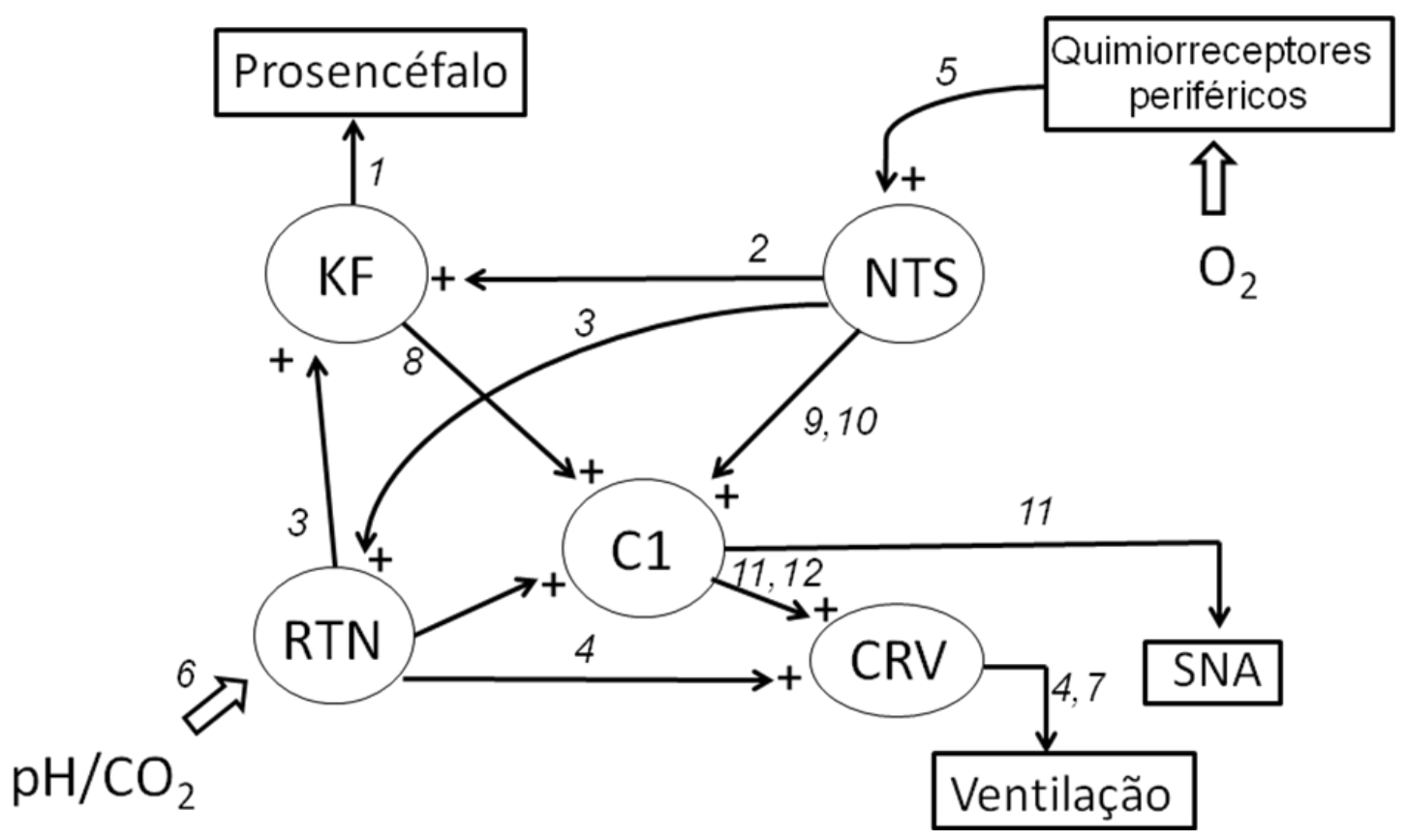

Quimiorreceptores centrais e periféricos são classificados como sensores que detectam alterações químicas no sangue arterial. Essas alterações seriam a hipercapnia e a hipóxia. Os quimiorreceptores enviam projeções para o bulbo ventrolateral ativando neurônios da coluna respiratória ventral, bem como neurônios pré-motores simpáticos localizados na região catecolaminérgica C1. As informações dos quimiorreceptores também projetam-se para regiões pontinas como a região do Kölliker-Fuse, onde as informações são integradas e distribuídas para o prosencéfalo. Referências: 1 - FULWILER; SAPER, 1884; 2 - SONG et al., 2011; 3 - ROSIN et al., 2006; 4 - STORNETTA et al., 2003; 5 ALHEID et al., 2008; 6 - TAKAKURA et al., 2006; 7 - EZURE, 1990; 8 - DAMPNEY et al., 1987; 9DAMPNEY, 1994; 10 - GUYENET, 2006; 11 - ABBOT et al., 2013; 12 - GUYENET et al., 2013. 


\section{CONCLUSÃO}

No presente trabalho, mostramos a distinta participação de duas importantes áreas pontinas no controle cardiorrespiratório em situações basais e durante a ativação dos quimiorreceptores. A literatura procura postular que essas regiões formam o chamado complexo Parabraquial/Kölliker-Fuse, mas os nossos resultados mostram pela primeira vez que neurônios localizados nessas regiões apresentam características distintas no que diz respeito ao controle cardiorrespiratório. Nossos experimentos mostram a participação da região KF e do grupamento noradrenérgico A7, e não do NPBL, no controle do padrão respiratório eupneico e durante uma situação de hipóxia e hipercapnia em animais não anestesiados e anestesiados. 


\section{REFERÊNCIAS ${ }^{1}$}

ABBOTT, S. B. et al. Optogenetic stimulation of C1 and retrotrapezoid nucleus neurons causes sleep state-dependent cardiorespiratory stimulation and arousal in rats. Hypertension, v. 61, n. 4, p. 835 - 841, 2013.

ABDALA, A. P.; SCHOORLEMMER, G. H.; COLOMBARI, E. Ablation of NK1 receptor bearing neurons in the nucleus of the solitary tract blunts cardiovascular reflexes in awake rats. Brain Res., v. 1119, n. 1, p. 165 - 173, 2006.

ACCORSI-MENDONÇA, D. et al. Urethane inhibits the gabaergic neurotransmission in the nucleus of the solitary tract of rat brain stem slices. Am. J. Physiol. Regul. Integr. Comp. Physiol., v. 292, n. 1, p. R396 - 402, 2007.

AIRES, M. D. M. Fisiologia. Rio de Janeiro: Guanabara Koogan, 2012.

ALHEID, G. F.; MCCRIMMON, D. R. The chemical neuroanatomy of breathing. Respir. Physiol. Neurobiol., v. 164, n. 1 - 2, p. 3 - 11, 2008.

ALHEID, G. F.; MILSOM, W. K.; MCCRIMMON, D. R. Pontine influences on breathing: an overview. Respir. Physiol. Neurobiol., v. 143, n. 2 - 3, p. 105 - 114, 2004.

BARNA, B. F.; TAKAKURA, A. C.; MOREIRA, T. S. Pontomedullary and hypothalamic distribution of fos-like immunoreactive neurons after acute exercise in rats. Neuroscience, v. 212, p. 120 - 130, 2012.

BERQUIN, P. et al. Postnatal changes in fos-like immunoreactivity evoked by hypoxia in the rat brainstem and hypothalamus. Brain Res., v. 877, n. 2, p. 149 $159,2000$.

BIANCHI, A. L.; DENAVIT-SAUBIE, M.; CHAMPAGNAT, J. Central control of breathing in mammals: neuronal circuitry, membrane properties, and neurotransmitters. Physiol. Rev., v. 75, n. 1, p. 1 - 45, 1995.

BLESSING, W. W.; LAPPI, D. A.; WILEY, R. G. Destruction of locus coeruleus neuronal perikarya after injection of anti-dopamine-b-hydroxylase immunotoxin into the olfactory bulb of the rat. Neurosci. Lett., v. 243, n. 1 - 3, p. 85 - 88, 1998.

BOCHORISHVILI, G. et al. Pre-Bötzinger complex receives glutamatergic innervation from galaninergic and other retrotrapezoid nucleus neurons. J. Comp. Neurol., v. 520, n. 5, p. 1047 - 1061, 2012.

BODINEAU, L.; LARNICOL, N. Brainstem and hypothalamic areas activated by tissue hypoxia: Fos-like immunoreactivity induced by carbon monoxide inhalation in the rat. Neuroscience, v. 108, n. 4, p. 643 - 653, 2001.

\footnotetext{
${ }^{1}$ De acordo com: ASSOCIAÇÃO BRASILEIRA DE NORMAS TÉCNICAS. NBR 6023: informação e documentação: referências: elaboração. Rio de Janeiro, 2002.
} 
BONHAM, A. C. Neurotransmitters in the CNS control of breathing. Respir. Physiol., v. 101, n. 3, p. 219 - 230, 1995.

BORDAY, V. et al. Respiratory effects of glutamate receptor antagonists in neonate and adult mammals. Eur. J. Pharmacol., v. 348, n. 2-3, p. 235 - 246, 1998.

BRUINSTROOP, E. et al. Spinal projections of the A5, A6 (locus coeruleus), and A7 noradrenergic cell groups in rats. J. Comp. Neurol., v. 520, n. 9, p.1985 - 2001, 2012.

BYRUM, C. E.; GUYENET, P. G. Afferent and efferent connections of the A5 noradrenergic cell group in the rat. J. Comp. Neurol., v. 261, n. 4, p. $529-542$, 1987.

BYRUM, C. E.; STORNETTA, R.; GUYENET, P. G. Electrophysiological properties of spinally-projecting A5 noradrenergic neurons. Brain Res., v. 303, n. 1, p. 15 - 29, 1984.

CALLERA, J. C. et al. Gaba(A) receptor activation in the lateral parabrachial nucleus induces water and hypertonic $\mathrm{NaCl}$ intake. Neuroscience, v. 134, n. 3, p. 725 - 735, 2005.

CEZARIO, A. F. et al. Hypothalamic sites responding to predator threats-the role of the dorsal premammillary nucleus in unconditioned and conditioned antipredatory defensive behavior. Eur. J. Neurosci., v. 28, n. 5, p. 1003 - 1015, 2008.

CHAMBERLIN, N. L. Functional organization of the parabrachial complex and intertrigeminal region in the control of breathing. Respir. Physiol. Neurobiol., v. 143, n. 2-3, p. 115 - 125, 2004.

CHAMBERLIN, N. L.; SAPER, C. B. Topographic organization of cardiovascular responses to electrical and glutamate microstimulation of the parabrachial nucleus in the rat. J. Comp. Neurol., v. 326, n. 2, p. 245 - 262, 1992.

CHAMBERLIN, N. L.; SAPER, C. B. Topographic organization of respiratory responses to glutamate microstimulation of the parabrachial nucleus in the cat. $\mathbf{J}$. Neurosci., v. 14, n. 11, pt. 1, p. 6500 - 6510, 1994.

CHAMBERLIN, N. L.; SAPER, C. B. A brainstem network mediating apneic reflexes in the rat. J. Neurosci., v. 18, n. 15, p. 6048 - 6056, 1998.

CIRIELLO, J.; SCHULTZ, C. G.; RODER, S. Collateral axonal projections from ventrolateral medullary non-catecholaminergic neurons to central nucleus of the amygdala. Brain Res., v. 663, n. 2, p. 346 - 351, 1994.

COHEN, M. I.; FELDMAN, J. L. Models of respiratory phase-switching. Fed Proc., v. 36, n. 10, p. 2367 - 2374, 1977. 
CONNELLY, C. A.; OTTO-SMITH, M. R.; FELDMAN, J. L. Blockade of NMDA receptorchannels by MK-801 alters breathing in adult rats. Brain Res., v. 596, n.1 2, p. 99-110, 1992.

COSTA-SILVA, J. H.; ZOCCAL, D. B.; MACHADO, B. H. Glutamatergic antagonism in the NTS decreases post-inspiratory drive and changes phrenic and sympathetic coupling during chemoreflex activation. J. Neurophysiol., v. 103, n. 4, p. 2095 2106, 2010.

CRAVO, S. L.; MORRISON, S. F.; REIS, D. J. Differentiation of two cardiovascular regions within caudal ventrolateral medulla. Am. J. Physiol., v. 261, n. 4, pt. 2, p. R985 - 994, 1991.

DAMPNEY, R. A. Functional organization of central pathways regulating the cardiovascular system. Physiol. Rev., v. 74, n. 2, p. 323 - 364, 1994.

DAMPNEY, R. A. et al. Afferent connections and spinal projections of the pressor region in the rostral ventrolateral medulla of the cat. J. Auton. Nerv. Syst., v. 20, n. 1, p. 73 - 86, 1987.

DAWID MILNER, M. S. et al. A5 region modulation of the cardiorespiratory responses evoked from parabrachial cell bodies in the anaesthetised rat. Brain Res., v. 982, n. 1, p. 108 - 118, 2003.

DOBBINS, E. G.; FELDMAN, J. L. Brainstem network controlling descending drive to phrenic motoneurons in rat. J. Comp. Neurol., v. 347, n. 1, p. 64 - 86, 1994.

DUTSCHMANN, M.; DICK T. E. Pontine mechanisms of respiratory control. J. Comprehensive Physiology, v. 2, n. 4, p. 2443 - 69, 2012.

DUTSCHMANN, M.; HERBERT, H. NMDA and GABAA receptors in the rat köllikerfuse area control cardiorespiratory responses evoked by trigeminal ethmoidal nerve stimulation. J. Physiol., v. 510, pt. 3, p. 793 - 804, 1998.

DUTSCHMANN, M.; HERBERT, $H$. The kölliker-fuse nucleus gates the postinspiratory phase of the respiratory cycle to control inspiratory off-switch and upper airway resistance in rat. Eur. J. Neurosci., v. 24, n. 4, p. 1071 - 1084, 2006.

DUTSCHMANN, M. et al. Development of adaptive behaviour of the respiratory network: Implications for the pontine Kölliker-Fuse nucleus. Respir. Physiol. Neurobiol., v. 143, n. 2-3, p. 155 - 165, 2004.

DUTSCHMANN, M. et al. Learning to breathe: Control of the inspiratory-expiratory phase transition shifts from sensory- to central-dominated during postnatal development in rats. J. Physiol., v. 587, pt. 20, p. 4931 - 4948, 2009.

EZURE, K. Synaptic connections between medullary respiratory neurons and considerations on the genesis of respiratory rhythm. Prog. Neurobiol., v. 35, n. 6, p. 429 - 450, 1990. 
EZURE, K. Respiration-related afferents to parabrachial pontine regions. Respir. Physiol. Neurobiol., v. 143, n. 2-3, p. 167 - 175, 2004.

FAVERO, M. T. et al. Chemosensory control by commissural nucleus of the solitary tract in rats. Respir. Physiol. Neurobiol., v. 179, n. 2-3, p. 227 - 234, 2011.

FELDMAN, J. L.; DEL NEGRO, C. A. Looking for inspiration: New perspectives on respiratory rhythm. Nat. Rev. Neurosci., v. 7, n. 3, p. 232 - 242, 2006.

FELDMAN, J. L.; DEL NEGRO, C. A.; GRAY, P. A. Understanding the rhythm of breathing: So near, yet so far. Annu. Rev. Physiol., v. 75, p. 423 - 452, 2013.

FELDMAN, J. L.; GAUTIER, H. Interaction of pulmonary afferents and pneumotaxic center in control of respiratory pattern in cats. J. Neurophysiol., v. 39, n. 1, p. 31 44, 1976.

FORTUNA, M. G. et al. Botzinger expiratory-augmenting neurons and the parafacial respiratory group. J. Neurosci., v. 28, n. 10, p. 2506 - 2515, 2008.

FUKUDA, H.; FUKAI, K. Location of the reflex centre for straining elicited by activation of pelvic afferent fibres of decerebrate dogs. Brain Res., v. 380, n. 2, p. 287 - 296, 1986.

FUKUDA, H.; FUKAI, K. Discharges of bulbar respiratory neurons during rhythmic straining evoked by activation of pelvic afferent fibers in dogs. Brain Res., v. 449, $n$. 1-2, p. 157 - 166, 1988.

FULWILER, C. E.; SAPER, C. B. Subnuclear organization of the efferent connections of the parabrachial nucleus in the rat. Brain Res., v. 319, n. 3, p. 229 - 259, 1984.

GANG, S. et al. Afferent projections to the botzinger complex from the upper cervical cord and other respiratory related structures in the brainstem in cats: retrograde WGA-HRP tracing. J. Auton. Nerv. Syst., v. 56, n. 1-2, p. 1 - 7, 1995.

GASPARINI, S. et al. Adrenergic mechanisms of the kölliker-fuse/A7 area on the control of water and sodium intake. Neuroscience, v. 164, n. 2, p. 370 - 379, 2009.

GAUTIER, H.; BERTRAND, F. Respiratory effects of pneumotaxic center lesions and subsequent vagotomy in chronic cats. Respir. Physiol., v. 23, n. 1, p. 71 - 85, 1975.

GRANATA, A. R.; KITAI, S. T. Intracellular study of nucleus parabrachialis and nucleus tractus solitarii interconnections. Brain Res., v. 492, n. 1 - 2, p. 281-292, 1989.

GRAY, P. A. et al. Normal breathing requires preBötzinger complex neurokinin-1 receptor-expressing neurons. Nat. Neurosci., v. 4, n. 9, p. 927 - 930, 2001.

GUYENET, P. G. The sympathetic control of blood pressure. Nat. Rev. Neurosci., v. 7, n. 5, p. 335 - 346, 2006. 
GUYENET, P. G. et al. Central respiratory control of A5 and A6 pontine noradrenergic neurons. Am. J. Physiol., v. 264, n. 6 Pt 2, p. R1035 - 1044, 1993.

GUYENET, P. G.; STORNETTA, R. L.; BAYLISS, D. A. Central respiratory chemoreception. J. Comp. Neurol., v. 518, n. 19, p. 3883 - 3906, 2010.

GUYENET, P. G. et al. Retrotrapezoid nucleus: A litmus test for the identification of central chemoreceptors. Exp. Physiol., v. 90, n. 3, p. 247 - 253, 2005.

GUYENET, P. G.; YOUNG, B. S. Projections of nucleus paragigantocellularis lateralis to locus coeruleus and. Brain Res., v. 406, n. 1-2, p. 171 - 184, 1987.

HAIBARA, A. S. et al. Involvement of the parabrachial nucleus in the pressor response to chemoreflex activation in awake rats. Auton. Neurosci., v. 101, n. 1 - 2, p. $60-67,2002$.

HARRIS, M. B.; MILSOM, W. K. Apneusis follows disruption of NMDA-type glutamate receptors in vagotomized groud squirrels. Respir. Physiol. Neurobiol., v. 134, n. 3, p. 191 - 207, 2003.

HAYWARD, L. F.; FELDER, R. B. Lateral parabrachial nucleus modulates baroreflex regulation of sympathetic nerve activity. Am. J. Physiol., v. 274, n. 5, pt. 2, p. R1274 - 1282, 1998.

HERBERT, H.; MOGA, M. M.; SAPER, C. B. Connections of the parabrachial nucleus with the nucleus of the solitary tract and the medullary reticular formation in the rat. J. Comp. Neurol., v. 293, n. 4, p. 540 - 580, 1990.

HILAIRE, G. et al. Modulation of the respiratory rhythm generator by the pontine noradrenergic A5 and A6 groups in rodents. Respir. Physiol. Neurobiol., v. 143, n. 2-3, p. 187-197, 2004.

HIROOKA, Y. et al. Hypoxia-induced fos expression in neurons projecting to the pressor region in the rostral ventrolateral medulla. Neuroscience, v. 80, n. 4, p. 1209 $-1224,1997$.

HSIEH, Y. H.; SIEGEL, R. E.; DICK, T. E. Pontine GABAergic pathways: role and plasticity in the hypoxic ventilatory response. Respir. Physiol. Neurobiol., v. 143, n. 2-3, p. 141 - 153, 2004.

JHAMANDAS, J. H.; HARRIS, K. H. Influence of nucleus tractus solitarius stimulation and baroreceptor activation on rat parabrachial neurons. Brain Res. Bull., v. 28, n. 4, p. 565 - 571, 1992.

KOSHIYA, N.; GUYENET, P. G. Role of the pons in the carotid sympathetic chemoreflex. Am. J. Physiol., v. 267, n. 2, pt. 2, p. R508 - 518, 1994.

KUBIN, L. et al. Central pathways of pulmonary and lower airway vagal afferents. J. Appl. Physiol. (1985), v. 101, n. 2, p. 618 - 627, 2006. 
KUBO, T. et al. Evidence for involvement of the lateral parabrachial nucleus in mediation of cholinergic inputs to neurons in the rostral ventrolateral medulla of the rat. Brain Res., v. 789, n. 1, p. 23 - 31, 1998.

LAI, Y. Y. et al. Brainstem projections to the ventromedial medulla in cat: Retrograde transport horseradish peroxidase and immunohistochemical studies. J. Comp. Neurol., v. 408, n. 3, p. 419 - 436, 1999.

LARA, J. P. et al. Cardiovascular and respiratory effects of stimulation of cell bodies of the parabrachial nuclei in the anaesthetized rat. J. Physiol., v. 477, pt. 2, p. 321329, 1994.

LEN, W.; CHAN, S. H.; CHAN, J. Y. Parabrachial nucleus induces suppression of baroreflex bradycardia by the release of glutamate in the rostral ventrolateral medulla of the rat. J. Biomed. Sci., v. 7, n. 5, p. $401-411,2000$.

LI, A.; NATTIE, E. Catecholamine neurones in rats modulate sleep, breathing, central chemoreception and breathing variability. J. Physiol., v. 570, pt. 2, p. 385 - 396, 2006.

LI, Q.; SONG, G. Afferent projection to the retrotrapezoid nucleus from respiratory related structures in the brainstem of rabbit - a retrograde CB-HRP tracing study. Sheng Li Xue Bao., v. 53, n. 5, p. 401 - 404, 2001.

LIN L. H. et al. Astrocytes in the rat nucleus tractus solitarii are critical for cardiovascular reflex control. J. Neurosci. v. 33, n. 47, p. 18608 - 18617, 2013.

LOEWY, A. D.; BURTON, H. Nuclei of the solitary tract: Efferent projections to the lower brain stem and spinal cord of the cat. J. Comp. Neurol., v. 181, n. 2, p. 421449, 1978.

LOEWY, A. D.; McKELLAR, S.; SAPER, C. B. Direct projections from the A5 catecholamine cell group to the intermediolateral cell column. Brain Res., v. 174, n. 2, p. 309 - 314, 1979.

LOEWY, A. D.; WALLACH, J. H.; MCKELLAR, S. Efferent connections of the ventral medulla oblongata in the rat. Brain Res., v. 228, n. 1, p. $63-80,1981$.

MARKWALD, M. Die athembewegungen und deren innervation beim kaninchen. $\mathbf{Z}$. Biol., v. 23, p. 149 - 283, 1887.

MACHADO, B. H.; BONAGAMBA, L. G. Microinjection of I-glutamate into the nucleus tractus solitarii increases arterial pressure in conscious rats. Brain Res., v. 576, n. 1, p. 131 - 138, 1992.

MACHADO, B. H. et al. Autonomic processing of the cardiovascular reflexes in the nucleus tractus solitarii. Braz J. Med. Bio.I Res., v. 30, n. 4, p. 533 - 543, 1997. 
MADDEN, C. J. et al. Lesions of the c1 catecholaminergic neurons of the ventrolateral medulla in rats using anti-DbetaH-saporin. Am. J. Physiol., v. 277, n. 4, pt 2, p. R1063 - 1075, 1999.

MARTELLI, D.; STANIĆ, D.; DUTSCHMANN, M. The emerging role of the parabrachial complex in the generation of wakefulness drive and its implication for respiratory control. Respir. Physiol. Neurobiol., v. 188, n. 3, p. 318 - 323, 2013.

MCCRIMMON, D. R.; MITCHELL, G. S.; ALHEID, G. F. Overview: The neurochemistry of respiratory control. Respir. Physiol. Neurobiol., v. 164, n. 1 - 2, p. 1 - 2, 2008.

MENANI, J. V.; THUNHORST, R. L.; JOHNSON, A. K. Lateral parabrachial nucleus and serotonergic mechanisms in the control of salt appetite in rats. Am. J. Physiol., v. 270, n. 1, pt. 2, p. R162 - 168, 1996.

MENKES, H. A.; DUBOIS, A. B. Subtraction of cardiopneumatic pulsations from body plethysmograph records. J. Appl. Physiol., v. 27, n. 6, p. 910 - 911, 1969.

MERRILL, E. G. Where are the real respiratory neurons? Fed. Proc., v. 40, n. 9, p. 2389 - 2394, 1981.

MILLER, R. L. et al. Fos-activation of foxp2 and Imx1b neurons in the parabrachial nucleus evoked by hypotension and hypertension in conscious rats. Neuroscience, v. 218, p. $110-125,2012$.

MIURA, M.; REIS, D. J. Termination and secondary projections of carotid sinus nerve in the cat brain stem. Am. J. Physiol., v. 217, n. 1, p. 142 - 153, 1969.

MIURA, M.; TAKAYAMA, K.; OKADA, J. Difference in sensitivity of cardiovascular and respiratory control neurons in the subretrofacial nucleus to glutamate receptor subtype agonists in SHR, WKY and cats. J. Auton. Nerv. Syst., v. 36, n. 1, p. 1 - 12, 1991.

MIZUSAWA, A. et al. Role of the parabrachial nucleus in ventilatory responses of awake rats. J. Physiol., v. 489, pt. 3, p. 877 - 884, 1995.

MOREIRA, T. S. et al. Central chemoreceptors and sympathetic vasomotor outflow. J Physiol., v. 577, pt. 1, p. 369 - 386, 2006.

MOREIRA, T. S. et al. Central chemoreceptors and neural mechanisms of cardiorespiratory control. Braz J. Med. Biol. Res., v. 44, n. 9, p. 883 - 889, 2011.

MORSCHEL, M.; DUTSCHMANN, M. Pontine respiratory activity involved in inspiratory/expiratory phase transition. Philos. Trans. R. Soc. Biol. Sci., v. 364, n. 1529, p. 2517 - 2526, 2009.

MULKEY, D. K. et al. Respiratory control by ventral surface chemoreceptor neurons in rats. Nat. Neurosci., v. 7, n. 12, p. 1360 - 1369, 2004. 
NATTIE, E. E.; LI, A. Substance P-saporin lesion of neurons with NK1 receptors in one chemoreceptor site in rats decreases ventilation and chemosensitivity. $\mathbf{J}$. Physiol., v. 544, pt. 2, p. 603 - 616, 2002.

OKAZAKI, M. et al. Synaptic mechanisms of inspiratory off-switching evoked by pontine pneumotaxic stimulation in cats. Neurosci. Res., v. 44, n. 1, p. 101 - 110, 2002.

OKU, Y.; DICK, T. E. Phase resetting of the respiratory cycle before and after unilateral pontine lesion in cat. J. Appl. Physiol., v. 72, n. 2, p. 721 - 730, 1992.

ONIMARU, H.; ARATA, A.; HOMMA, I. Primary respiratory rhythm generator in the medulla of brainstem-spinal cord preparation from newborn rat. Brain Res., v. 445, n. 2, p. 314 - 324, 1988.

ONIMARU, H.; IKEDA, K.; KAWAKAMI, K. Postsynaptic mechanisms of CO(2) responses in parafacial respiratory neurons of newborn rats. J. Physiol., v. 590, pt. 7, p. 1615 - 1624, 2012.

ONIMARU, H.; KUMAGAWA, Y.; HOMMA, I. Respiration-related rhythmic activity in the rostral medulla of newborn rats. J. Neurophysiol., v. 96, n. 1, p. 55 - 61, 2006.

PALKOVITS, M.; ZÁBORSZKY, L. Neuroanatomy of central cardiovascular control. Nucleus tractus solitarii: Afferent and efferent neuronal connections in relation to the baroreceptor reflex arc. Prog. Brain Res., v. 47, p. 9 - 34, 1977.

PAXINOS, G.; WATSON, C. The rat brain in sterotaxic coordinates. San Diego: Academic Press, 1998.

PERRY, T.; HODGES, H.; GRAY, J. A. Behavioural, histological and immunocytochemical consequences following 192 igG-saporin immunolesions of the basal forebrain cholinergic system. Brain Res. Bull, v. 54, n. 1, p. 29 - 48, 2001.

RADULOVACKI, M.; PAVLOVIC, S.; CARLEY, D. W. Pontine intertrigeminal region attenuates sleep apneas in rats. Sleep, v. 27, n. 3, p. 383 - 387, 2004.

RADULOVACKI, M. et al. Intertrigeminal region attenuates reflex apnea and stabilizes respiratory pattern in rats. Brain Res, v. 975, n. 1 - 2, p. 66 - 72, 2003.

REKLING, J. C.; FELDMAN, J. L. PreBötzinger complex and pacemaker neurons: Hypothesized site and kernel for respiratory rhythm generation. Annu. Rev. Physiol., v. 60, p. 385 - 405, 1998.

RICHTER, D. W. Generation and maintenance of the respiratory rhythm. J. Exp. Biol., v. 100, p. 93 - 107, 1982.

ROSIN, D. L.; CHANG, D. A.; GUYENET, P. G. Afferent and efferent connections of the rat retrotrapezoid nucleus. J. Comp. Neurol., v. 499, n. 1, p. 64 - 89, 2006. 
RYBAK, I. A. et al. Spatial organization and state-dependent mechanisms for respiratory rhythm and pattern generation. Prog. Brain Res., v. 165, p. 201 - 220, 2007.

RYBAK, I. A. et al. Modeling the ponto-medullary respiratory network. Respir. Physio. Neurobiol., v. 143, n. 2 - 3, p. 307 - 319, 2004.

SAPER, C. B.; LOEWY, A. D. Efferent connections of the parabrachial nucleus in the rat. Brain Res., v. 197, n. 2, p. 291 - 317, 1980.

SCARPELLINI CDA, S. et al. Role of preoptic opioid receptors in the body temperature reduction during hypoxia. Brain Res., v. 1286, p. 66 - 74, 2009.

SCHREIHOFER, A. M.; GUYENET, P. G. Identification of c1 presympathetic neurons in rat rostral ventrolateral medulla by juxtacellular labeling in vivo. J. Comp. Neurol., v. 387, n. 4, p. 524 - 536, 1997.

SHAFEI, M. N.; NASIMI, A. Effect of glutamate stimulation of the cuneiform nucleus on cardiovascular regulation in anesthetized rats: Role of the pontine kolliker-fuse nucleus. Brain Res., v. 1385, p. 135 - 143, 2011.

SHAPIRO, R. E.; MISELIS, R. R. The central neural connections of the area postrema of the rat. J. Comp. Neurol., v. 234, n. 3, p. 344 - 364, 1985.

SMITH, J. C. et al. Spatial and functional architecture of the mammalian brain stem respiratory network: a hierarchy of three oscillatory mechanisms. J. Neurophysiol, v. 98, n. 6, p. 3370 - 3387, 2007.

SMITH, J. C. et al. Pre-Bötzinger complex: A brainstem region that may generate respiratory rhythm in mammals. Science, v. 254, n. 5032, p. 726 - 729, 1991.

SONG, G.; POON, C. S. Functional and structural models of pontine modulation of mechanoreceptor and chemoreceptor reflexes. Respir. Physiol. Neurobiol., v. 143, n. 2-3, p. 281 - 292, 2004.

SONG, G.; TIN, C.; POON, C. S. Bilateral lesions of pontine kolliker-fuse nuclei provoke apnea instead of apneusis in anesthetized adult rats. Adv. Exp. Med. Biol., v. 669 , p. 185 - 188, 2010.

SONG, G. et al. Kölliker-fuse neurons send collateral projections to multiple hypoxiaactivated and nonactivated structures in rat brainstem and spinal cord. Brain Struct. Funct., v. 217, p. 835 - 858,2012.

SONG, G. et al. Hypoxia-excited neurons in nts send axonal projections to köllikerFuse/parabrachial complex in dorsolateral pons. Neuroscience, v. 175, p. 145 - 153, 2011.

STELLA, G.On the mechanism of production, and the physiological significance of "apneusis". J. Physiol., v. 93, n. 1, p. 10 - 23, 1938. 
ST-JOHN, W. M. Neurogenesis of patterns of automatic ventilatory activity. Prog. Neurobiol., v. 56, n. 1, p. 97 - 117, 1998.

ST JOHN, W. M.; WANG, S. C. Integration of chemoreceptor stimuli by caudal pontile and rostral medullary sites. J. Appl. Physiol., v. 41, n. 5, pt. 1, p. 612 - 622, 1976.

STIRPE, F.; BARBIERI, L. Ribosome-inactivating proteins up to date. FEBS Lett., v. 195, n. 1 - 2, p. 1 - 8, 1986.

STORNETTA, R. L.; GUYENET, P. G. Distribution of glutamic acid decarboxylase mrna-containing neurons in rat medulla projecting to thoracic spinal cord in relation to monoaminergic brainstem neurons. J. Comp. Neurol., v. 407, n. 3, p. 367 - 380, 1999.

STORNETTA, R. L.; SEVIGNY, C. P.; GUYENET, P. G. Inspiratory augmenting bulbospinal neurons express both glutamatergic and enkephalinergic phenotypes. $\mathbf{J}$. Comp. Neurol., v. 455, n. 1, p. 113 - 124, 2003.

STRACK, A. M. et al. CNA cell groups regulating the sympathetic outflow to adrenal gland as revealed by transneuronal cell body labeling with pseudorabies virus. Brain Res., v. 491, n. 2, p. 274 - 296, 1989.

SUBRAMANIAN, H. H.; HOLSTEGE, G. Stimulation of the midbrain periaqueductal gray modulates preinspiratory neurons in the ventrolateral medulla in the rat in vivo. J. Comp. Neurol., v. 521, n. 13, p. 3083 - 3098, 2013.

SWANSON, L. W. Cerebral hemisphere regulation of motivated behavior. Brain Res., v. 886, n. 1 - 2, p. 113 - 164, 2000.

TAKAKURA, A. C. et al. Phox2b-expressing retrotrapezoid neurons and the integration of central and peripheral chemosensory control of breathing in conscious rats. Exp. Physiol., 2013.

TAKAKURA, A. C.; MOREIRA, T. S. Contribution of excitatory amino acid receptors of the retrotrapezoid nucleus to the sympathetic chemoreflex in rats. Exp. Physiol., v. 96, n. 10, p. $989-999,2011$.

TAKAKURA, A. C.; MOREIRA, T. S. Arterial chemoreceptor activation reduces the activity of parapyramidal serotonergic neurons in rats. Neuroscience, v. 237, p. 199207, 2013.

TAKAKURA, A. C. et al. Peripheral chemoreceptor inputs to retrotrapezoid nucleus (RTN) $\mathrm{CO}_{2}$-sensitive neurons in rats. J. Physiol., v. 572, pt. 2, p. 503 - 523, 2006.

TAKAKURA, A. C. et al. Selective lesion of retrotrapezoid phox $2 b$-expressing neurons raises the apnoeic threshold in rats. J. Physiol., v. 586, pt. 12, p. 2975 2991, 2008. 
TAKAKURA, A. C. et al. Gabaergic pump cells of solitary tract nucleus innervate retrotrapezoid nucleus chemoreceptors. J. Neurophysiol., v. 98, n. 1, p. 374 - 381, 2007.

TAN, W. et al. Projections of preBötzinger complex neurons in adult rats. J. Comp. Neurol., v. 518, n. 10, p. 1862 - 1878, 2010.

TAXINI, C. L. et al. Control of the central chemoreflex by A5 noradrenergic neurons in rats. Neuroscience, v. 199, p. 177 - 186, 2011.

TEPPEMA, L. J. et al. Expression of c-fos in the rat brainstem after exposure to hypoxia and to normoxic and hyperoxic hypercapnia. J. Comp. Neurol., v. 388, n. 2, p. 169 - 190, 1997.

TSUKAMOTO, K.; SVED, A. F. Contrasting effects of the gaba transaminase inhibitors gamma-vinylgaba and aminooxyacetic acid on arterial pressure following injection into nucleus tractus solitarius. Neuropharmacology, v. 32, n. 6, p. 575 579, 1993.

WANG, H.; GERMANSON, T. P.; GUYENET, P. G. Depressor and tachypneic responses to chemical stimulation of the ventral respiratory group are reduced by ablation of neurokinin-1 receptor-expressing neurons. J. Neurosci., v. 22, n. 9, p. 3755 - 3764, 2002.

WANG, $H$. et al. Neurokinin-1 receptor-immunoreactive neurons of the ventral respiratory group in the rat. J. Comp. Neurol., v. 434, n. 2, p. 128 - 146, 2001.

WANG, S. et al. Phox2b-expressing retrotrapezoid neurons are intrinsically responsive to $\mathrm{H}^{+}$and $\mathrm{CO}_{2}$. J. Neurosci., v. 33, n. 18, p. 7756 - 7761, 2013.

WANG, W.; FUNG, M. L.; ST JOHN, W. M. Pontile regulation of ventilatory activity in the adult rat. J. Appl. Physiol., v. 74, n. 6, p. 2801 - 2811, 1993.

YOKOTA, S. et al. Glutamatergic pathways from the kölliker-fuse nucleus to the phrenic nucleus in the rat. Brain Res., v. 995, n. 1, p. 118 - 130, 2004.

ZANELLA, S. et al. When norepinephrine becomes a driver of breathing irregularities: How intermittent hypoxia fundamentally alters the modulatory response of the respiratory network. J. Neurosci., v. 34, n. 1, p. 36 - 50, 2014. 